\title{
Local drug administration : an experimental study on its possibilities and limitations
}

Citation for published version (APA):

Daemen, M. J. A. P. (1987). Local drug administration : an experimental study on its possibilities and limitations. [Doctoral Thesis, Maastricht University]. Rijksuniversiteit Limburg. https://doi.org/10.26481/dis.19870320md

Document status and date:

Published: 01/01/1987

DOI:

10.26481/dis.19870320md

Document Version:

Publisher's PDF, also known as Version of record

\section{Please check the document version of this publication:}

- A submitted manuscript is the version of the article upon submission and before peer-review. There can be important differences between the submitted version and the official published version of record.

People interested in the research are advised to contact the author for the final version of the publication, or visit the DOI to the publisher's website.

- The final author version and the galley proof are versions of the publication after peer review.

- The final published version features the final layout of the paper including the volume, issue and page numbers.

Link to publication

\footnotetext{
General rights rights.

- You may freely distribute the URL identifying the publication in the public portal. please follow below link for the End User Agreement:

www.umlib.nl/taverne-license

Take down policy

If you believe that this document breaches copyright please contact us at:

repository@maastrichtuniversity.nl

providing details and we will investigate your claim.
}

Copyright and moral rights for the publications made accessible in the public portal are retained by the authors and/or other copyright owners and it is a condition of accessing publications that users recognise and abide by the legal requirements associated with these

- Users may download and print one copy of any publication from the public portal for the purpose of private study or research.

- You may not further distribute the material or use it for any profit-making activity or commercial gain

If the publication is distributed under the terms of Article $25 \mathrm{fa}$ of the Dutch Copyright Act, indicated by the "Taverne" license above, 
LOCAL DRUG ADMINISTRATION

- AN EXPERIMENTAL STUDY ON ITS POSSIBILITIES AND LIMITATIONS - 
Drukkerij Groenevelt b.v. - Landgraaf 


\title{
Local drug administration - an experimental study on its possibilities and limitations -
}

\author{
Proefschrift
}

ter verkrijging van de graad van doctor in de geneeskunde aan de Rijksuniversiteit Limburg te Maastricht, op gezag van de Rector Magnificus, prof. dr. F.I.M. Bonke, volgens het besluit van het College van Dekanen, in het openbaar te verdedigen op vrijdag 20 maart 1987 des namiddags om vier uur

door

Matthias Joseph Alphons Pieter Daemen

geboren te Heerlen. 
Promotor : Prof. dr. H.A.J. Struyker Boudier

Co-promotor : Dr. H.H.W. Thijssen

Referenten : Prof. dr. J.M. van Rossum

Prof. dr. D.K.F. Meijer

Prof. dr. F.T. Bosman 
Voor Trudie en Rob Voor mijn ouders 

TABLE OF CONTENTS

Chapter 1: Introduction 11

1.1 General introduction 11

1.2 Drug targeting systems 11

1.3 Rationale for local drug delivery 13

1.4 Clinical applications of local drug administration $\quad 14$

1.4.1 Regional cancer chemotherapy

1.4.2 Thrombolytic therapy

1.5 Experimenta1 applications of local drug administration

1.6 Theoretical considerations of local drug administration

1.6.1 The physiological pharmacokinetic approach

1.6.2 Reglona1 and systemic advantages of intra-arterial over systemic drug administration

1.7 Theory and practice - analysis of the applications of local drug administration

1.7.1 The drug is efficiently extracted by the target organ

1.7.2 The blood flow to the target organ

1.7.3 A high systemic clearance in relation to the blood flow of the target organ

1.8 This thesis

Chapter 2: Materials and methods 43

2.1 Introduction 43

2.2 Routes of local drug administration 43

2.2.1 The kidney

2.2.2 The transplanted heart

2.2 .3 The 1 iver

2.2.4 The testis

2.3 Substances used for pharmacokf net fc analysis

2.3.1 Indocyanine green

2.3.2 Propranolo1

2.3.3 Cr EDTA and iodohippurate

2.3.4 Acenocoumaral

2.4 Methods for the measurement of blood flow in large vessels

2.5 Pharmacokinetic analysis 
Chapter 3: Measurement of 11 ver blood flow in the rat: the effect of pentobarbital anesthesila and hypothermia on the hepatic clearance of indocyanine green 57

3.1 Introduction 57

3.2 Experimental section 57

3.2.1 Infuston and sampling protocol

3.2 .2 Statistical analysis

3. 3 Results

58

3.4 D1scussion 60

Chapter 4: Liver blood flow measurement in the rat: the electromagnetic vis. the clearance method 62

4. I Introduction 62

4.2 Experimental section 63

4.2. 1 Surgery

4.2.2 Electromagnetic measurement of hepatic blood flow

4.2.3 Infustion protocol

4.2.4 Statistical analys is

4. 3 Results

4.3.1 Adenosine/phenylephrine infusion

4.3.2 Clearance studies

4.4 Discussion

Chapter 5: Tissue sampling in the rat: the liver biopsy 72

5. 1 Introduction

5.2 Experimental section

5.2.1 Matertals

5.2.2 Animal experiments

5.2.3 Drug administration and sampling

5.2 .4 Liver biopsy

5. 3 Results

5.4 Discussion

Chapter 6: Local drug admintstration: kinetic evaluation of direct infuston of Cr EDTA and Lodohippurate into the left and right kidney 77

$\begin{array}{ll}6.1 \text { Introduction } & 77\end{array}$

6.2 Experimental section $\quad 77$

6.2 .1 Methods

6.2.2 Experimental protocol

6.2.3 Composition of the experimental groups

6.2 .4 Statistical analysis

6.3 Results

6.4 Discussion 
Chapter 7: Local drug administration: kinetic evaluation of long-term intrarenal and systemic infusion of propranolol in consclous Wistar rats

7.1 Introduction

7.2 Experimental section

7.2.1 Animal experiments

7.2.2 Experimental protocol

7.2.3 Statistical analysis

7.3 Results

7.4 Discussion

Chapter 8: Local drug administration: kinetlc evaluation of local and systemic infusion of the high hepatic clearance substance propranolol in rat cardlac grafts

8.1 Introduction

8.2 Experimental section

8.2.1 Materials

8.2.2 Anlmal experiments

8.2.3 Drug administration and sampling.

8.2.4 Pharmacokinetic analysis

8.2 .5 Statistical analysis

8.3 Results

8.4 Discussion

8.5 Appendix

Chapter 9: Lacal drug administration: kinetic evaluation of intrahepatic and intravenous infusion of

$S$-acenocoumarol

9.1 Introduction

9.2 Experimental section

9.2.1 Experimental protocol

9.2.2 Statistical analysis

9.3 Results

9.3.1 Distribution of AC in the 1iver

9.3.2 Influence of the route of admintstration

9.4 Discussion

Chapter 10: Local drug administration: kinetic evaluation of long-term intrarenal and intratesticular infusion of s-acenocoumarol in consclous rats

10.1 Introduction

10.2 Experimental section

10.2.1 Intratesticular administration

10.2.2 Intrarenal administration

10.2.3 Analytical procedures

10.2.4 Statist 1 cal analysis

10. 3 Results

10.3.1 Intratesticular administration

10.3.2 Intrarenal administration

10.4 Discussion 
Chapter 11: Suppression of vitamin $K$ dependent enzyme systems in the testis of the rat does not affect fertility

11. I Introduction

11.2 Experimental section

11.2.1 Intratesticular administration

11.2.2 Fertility experiments

11.2.3 Experimental protocol

11.2.4 Analytical procedures

11.2 .5 Statistical analys 1.5

11.3 Results

11.3.1 Five days experiments

11.3.2 Fertility experiments

11.4 Discussion

Chapter 12: Concluding remarks and outlook

12.1 P1tfalls of local drug admintstration

12.1.1 Saturation

12.1.2 Inhomogeneous drug distribution

12.2 Drug targeting, a problem of selectivity

Appendix I: A phystologlcally based computerlized model to simulate pharmacokinetics - simulations on the pharmacokinetics of s-acenocoumarol in the rat -

I. 1 Introduction

I. 2 Simulations

1.2.1 "Systemic and intrahepatic administration of $\mathrm{AC}^{\prime \prime}$

I.2.2 "Intrarenal and intratesticular administration of $\mathrm{AC}^{\prime \prime}$

I. 3 Conclusions

Summary/gamenvatting

References

1.44

Curriculum vitae

List of publications

Dankwoord 


\section{INTRODUCTION}

\subsection{GENERAL INTRODUCTION}

For a drug to produce a specific pharmacological response it must gain access to its primary site of action. The therapeutic efficacy of drugs is often limited by their inabllity to gain access to the site of action at an appropriate dosage, and/or by their ability to reach non-desired sites of action and producing unwanted side-effects. The use of effective drug delivery systems might enhance the efficacy of drugs by establishing a more selectlve presence of the drug at its primary site of action. To do so, particular attention must be given to (1) the desired site of action, (2) the site of action of the drug that has to be avoided because of toxicity, (3) the route of administration of the drug.

The last decades have seen the emergence of a great number of approaches to the problem of controlled drug delivery. Recent technological developments, such as polymeric sustalned release systems and osmotic pumps (Blackshear et a1, 1972; Urquhart et al, 1984; Struyker Boudier, 1986) have made rate controlled drug delivery possible (Poznansky and Juliano, 1984). These drug delivery systems are used to control drug dellvery in time whlle less attention has been paid to their uses in the spatial control of drug delivery, in which applications they are conventently termed drug targeting systiems.

\subsection{DRUG TARGETING SYSTEMS}

A number of drug targeting systems have been described in the Iiterature with varying degrees of scientiflc testing to validate the promise they seem to offer. A brief overview follows:

1. Liposomal drug delivery systems (revilewed by Jullano and Layton, 1980; Gregorladis et al, 1982a). A great varlety of drugs can easily be incorporated in 1 iposomes or phospholipid vestcles. Liposomes interact with target cells via endocytosis and/or fuston 
(Pagano and Weinstein, 1978). Primary sites of uptake are the reticulo-endothelial cells in the liver and the spleen. A few years ago, 11posomes were seen as a major new approach to cancer chemotherapy, but this is now seen as an unlikely eventuality, although it 1 shown that 11 posomes can to some extent be taken up by solid tumors (Kaye, 1981). A 11posome, 1 injected into the circulation, rast cross several barriers, be effectively taken up by tissues or pathologlcal tumors and meanwhile evade the capture by cells of the reticulo-endothellal system. Use of 1 iposomes as sustained release systems is another promising approach, although alternative technologles are avallable.

2. Cellular drug carriers. For this purpose, erythrocytes (Humpreys and Ihler, 1982), fibroblasts and leucocytes (Dean et a1, 1981; Hobbs, 1983), or encapsulated cells (Chang, 1972) loaded with enzymes or drugs can act as a carrier to target the encapsulated substance. The use of intact cells for drug delivery represents a highly experimental approach.

3. Microspheres and macromolecules as drug carriers. Here, denaturated albumin microspheres, capable of entrapping certain drugs and delivering them in vivo are used (Kato et al, 1980). Additionally they may contain ultraftme $\mathrm{Fe}_{3} \mathrm{O}_{4}$ particles, making them susceptible to the effect of an externally applied magnetic field (Widder and Senyel, 1983). This system allows a high degree of target site speclficlty. Soluble macromolecules, like albumin, fibrinogen and polyethylene glycol (Poznansky et al, 1982; Trouet et a1, 1982) may gain access to reglons not avallable to larger insoluble particles and have the capacity to avold rapld clearance by the reticuloendothelial system, which makes them advantageous over 11 posomes. Although they offer important advantages, the question of drug targeting beyond the vascular space remains open*

4. Antibodies as drug carriers. Antibodies, linked to drugs, can be used as targeting agents to introduce drugs to specific tissues. This technique has been applied espectally in the area of tumor therapy (Levy and Miller, 1983; Towbridge and Domingo, 1983). Toxicity and specificity are limitations of this means of drug de11 very. 
5. Pro-drug delivery systems. A pro-drug is an agent whlch must undergo biotransformation prior to exerting its pharmacological effect (Ste11a et al, 1980; Notar1, 1981; Bodor, 1982). Pro-drugs are used in experimental research (Smits and Struyker Boudier, 1985) on the treatment of hypertension and for a site-specific release of drugs like dopamine to the brain (Bodor and Simpkins, 1983). Taking advantage of the unique characteristics of cells and/or tissues, it has to be possible to design pro-drugs as cell or organ spectfic entities.

6. (Implantable) infusion pumps used for Instance for intra-arterial or intrathecal drug administration (Sandouk et al, 1986). The most elementary drug targeting system is the infusion pump. A number of commercial as well as experimental versions of the lntra-arterial Infusion pump are now avallable. A major advantage of these systems is that they allow not only spatial, but also time-control of drug delivery.

A11 above described targeting systems have not proceeded to the stage of extensive published clinical experience. The infusion pumps have been used in phase III clinical trials; extensive clinical testing is proceeding.

\subsection{RATIONALE FOR LOCAL DRUG DELIVERY}

In clinical practice as well as in experimental research there Is a great need to deliver a drug directly to a speciftc target site. In fact localized drug delivery has acquired a place in daily medical routine in for example the topical treatment of certain dermatological diseases, the use of masal decongestants, the use of aerosols to treat bronchial asthma, and the local application of ear- and eyedrops. An example of the latter is the use of the beta-adrenergic blocking drug timolol in the treatment of glaucoma. In 11terature, effects of systemic spill-over of timolol eye drops, 1.e. bradycardia and hypotension, are reported (Kosman, 1979; Chiou, 1981). In a11 these applica- 
thons, the respective target tissue can be reached easily. When the target tissue is not that easy to reach, other routes for the local administration of drugs have to be used. In the following paragraph examples w11 be given of one approach of local drug deliwery $1 . e$. the delivery of drugs directly into the blood vessel supplying the target organ.

The use of local arug delivery is mainly based on the hope that the drug, when delivered locally, will be confined to the target site, thus avolding any systemic effects, and/or that higher drug concentrations will be reached at the target site. However the lack of a theoretical basis for these interventions is striking. In the present chapter applications of intra-arterial drug administration also called local drug administration, in several areas of clinical practice and experimental research w11 be described. Pharmacokinetic guidelines w11 be provided which clarify the potentials and 1imitations of local drug administration. In the last part of this chapter, the practical applications will be analyzed on the basis of these pharmacokinetic principles.

\subsection{CLINICAL APPLICATIONS OF LOCAL DRUG ADMINISTRATION}

\subsubsection{Reglonal cancer chemotherapy}

\section{The 11ver}

Local drug administration has found wide application in cancer chemotherapy. It is used, for example, to treat hepatic metastases of colon carcinoma. The liver is the most frequent localization of metastases of colon carclnoma. The presence of hepatic metastases has a major influence on the prognosis (Jaffe et al, 1968; Wagner et a1, 1984). The survival of untreated patients with hepatic metastases of colon carcinoma is short and varies from $1-22$ months (Pettavel and Morgenthaler, 1978; Bengtsson et a1, 1981). Control of hepatic metastases could therefore provide a substantial improvement of the therapy. However, the results of traditional therapy of hepatic metastases (systemic chemotherapy, surgery, radiation) are unsatisfac- 
tory (Kemeny, 1983a; Stagg et al, 1984).

Malignant lesions in the liver derive their blood supply predominantly from the hepatic artery (Breedis and Young, 1954; Ackermann et $a 1,1969)$, which favors the hepatic artery as the route of administration for cytotoxic drugs. Since the Infuston of cytotoxic drugs directly into the hepatic artery could expose the tumor to higher drug concentrations and/or reduce the systemic side-effects (Ensminger et al, 1978), the latter often limiting chronic systemic chemotherapy, local i.e. intra-arterial drug delivery was seen to be of $11 \mathrm{kely}$ benefit to treat hepatic metastases.

5-Fluorourac 1 (5-FU) and 5-fluoro-2'-deoxyuridine (5-FUdr) are the drugs mostly used for continuous intrahepatic infusion. In table 1. I, examples of clinical studies applying the intra-arterial infusion of 5-FU and 5-FUdr are given.

Table 1.1: Studies applying the intra-arterial infusion of $5-\mathrm{FU}$ and 5-FUdr.

Author

Drug

dasage
Number of

patlents Response (\%)

\section{5-F1uorouracil}

Grage et al, $1979^{\circ}$

$20 \mathrm{mg} / \mathrm{kg} / \mathrm{d}$ for $14 \mathrm{~d}$ then $10 \mathrm{mg} / \mathrm{kg} / \mathrm{d}$ for $7 \mathrm{~d}$

Berger et a1, 1981 *

$20 \mathrm{mg} / \mathrm{kg} / \mathrm{d}$ for $14 \mathrm{~d}$

30

$30 / 31$

34 then $15 \mathrm{mg} / \mathrm{kg} / \mathrm{d}$ for $7 \mathrm{~d}$

\section{5-Fluoro-2-deoxy uridine}

Sullivan et a1, 1964* $0.1-0.5 \mathrm{mg} / \mathrm{kg} / \mathrm{hr}$ for 


\begin{tabular}{|c|c|c|c|}
\hline Ensminger et a1, 1983* & $\begin{array}{l}0.3 \mathrm{mg} / \mathrm{kg} / \mathrm{d} 14 \mathrm{~d}, \text { alter- } \\
\text { nated wth saline } 14 \mathrm{~d}\end{array}$ & 60 & 83 \\
\hline Kerneny et a1, $1983 b^{*}$ & $\begin{array}{l}0.3 \mathrm{mg} / \mathrm{kg} / \mathrm{d} 14 \mathrm{~d}, \text { alter- } \\
\text { nated with saline } 14 \mathrm{~d}\end{array}$ & 54 & 50 \\
\hline Balch et a $1,1983 *$ & $\begin{array}{l}0.3 \mathrm{mg} / \mathrm{kg} / \mathrm{d} 14 \mathrm{~d}, \text { alter- } \\
\text { nated with saline } 14 \mathrm{~d}\end{array}$ & 81 & 88 \\
\hline Weliss et a1, 1983* & $\begin{array}{l}0.3 \mathrm{mg} / \mathrm{kg} / \mathrm{d} 14 \mathrm{~d}, \text { alter- } \\
\text { nated th saline } 14 \mathrm{~d}\end{array}$ & 21 & 29 \\
\hline $\begin{array}{l}\text { Wederhuber et a } 1 \text {, } \\
1984\end{array}$ & $\begin{array}{l}0.3 \mathrm{mg} / \mathrm{kg} / \mathrm{d} 14 \mathrm{~d}, \text { a } 1 \mathrm{ter}- \\
\text { nated with sal1ne } 14 \mathrm{~d}\end{array}$ & 93 & 79 \\
\hline Schwartz et a1, 1985* & $\begin{array}{l}0.3 \mathrm{mg} / \mathrm{kg} / \mathrm{d} 14 \mathrm{~d} \text { alter- } \\
\text { nated with saline } 1.4 \mathrm{~d}\end{array}$ & 20 & 15 \\
\hline Shepard et a1, 1985* & $\begin{array}{l}0.3 \mathrm{mg} / \mathrm{kg} 14 \mathrm{~d} \text { alter } \\
\text { nated with saline }+ \\
\text { mitomycin } 1 . \mathrm{v} \cdot 15 \mathrm{mg} / \mathrm{m}^{2} \\
\text { in } 1 \mathrm{~d}\end{array}$ & 53 & 32 \\
\hline Cohen et a $1,1986^{*}$ & $\begin{array}{l}0.3 \mathrm{mg} / \mathrm{kg} / \mathrm{d} 14 \mathrm{~d} \text { alter- } \\
\text { nated with saline, mitomy } \\
15 \mathrm{mg} / \mathrm{m}^{2} \text { and } \mathrm{BCNU} 150 \mathrm{mg} / \mathrm{t} \\
\text { in } 1 \mathrm{hr} \text { every } 8 \text { weeks }\end{array}$ & $\begin{array}{r}36 \\
\mathrm{~m}^{2}\end{array}$ & 70 \\
\hline $\begin{array}{l}\text { Kemeny et a1, } \\
1985 a, 1986\end{array}$ & $\begin{array}{l}0.3 \mathrm{mg} / \mathrm{kg} / \mathrm{d} \text { for } 14 \mathrm{~d} \\
\text { alternated with saline } \\
14 \mathrm{~d}\end{array}$ & $12 / 10$ & $\begin{array}{l}\text { A trend to- } \\
\text { ward better } \\
\text { survival }\end{array}$ \\
\hline Hodgson et a $1,1986 *$ & $\begin{array}{l}0.3 \mathrm{mg} / \mathrm{kg} / \mathrm{d} 14 \mathrm{~d} \text { alter- } \\
\text { nated with saline } 14 \mathrm{~d} \\
\text { (A) + resection (B) } \\
+ \text { arterlal embolization } \\
\text { (C) + portal veln } \\
\text { branch } 11 \text { gation }\end{array}$ & $\begin{array}{l}\text { A: } 6 \\
\text { B: } 11 \\
\text { C: } 4 \\
\text { D: } 6\end{array}$ & $\begin{array}{l}\text { The more ra- } \\
\text { dical the } \\
\text { intervention, } \\
\text { the better } \\
\text { the results }\end{array}$ \\
\hline
\end{tabular}

* non comparative

Most studies use historical control as the reference. Response rate is defined differently in almost every study. It may vary from a subjective clinical benefit, improvements of liver-function tests (Sullivan et al, 1964) to response on liver scans (Niederhuber et a1, 1984). Although a comparison between the studies is difficult because of non- 
uniformity in the definitions of response rates and in criteria for patient selection, some conclusions may be drawn: (1) A reduction in systemic concentration can be achieved by the intrahepatic administration of 5-FU as well as 5-FUdr (Ensminger et al, 1978); (2) Systemic side-effects are less than during the classic intravenous drug administration (Ensminger and Gyves, 1983); (3) Although the response rate with local drug administration is enhanced as compared to systemic therapy ( $34-88 \%$ vs. $15-20 \%$, respectively), a prolonged survival of the patients has not yet been reported (Schwartz et a1, 1985; Dy et a1, 1986; Hubernan, 1983); (4) Regional side-effects especially fibrosis of the extrahepatic billary system (17\%; Hohn et al, 1985; Haq et a1, 1986), chemical hepatitis (20-50\%; Cohen et al, 1986) and cholecystitis (13\%; Kemeny et al, 1985b) are relatively frequent; (5) In general, the therapeutic effects of regional chemotherapy for the treatment of hepatic metastases of colorectal carcinoma are not increased as compared to systemic chemotherapy (Foster, 1984; Schwartz et $\mathrm{a} 1,1985$; Dy et al, 1986; Hodgson et a1, 1986); (6) To date, there is no experimental or clinical pharmacokinetic study denonstrating an increase of drug concentration at the tumor slte during local as compared to intravenous drug administration of the same dose.

Recent studies describe the effects of continuous hepatic arterial infusion therapy with 5-FU or 5-FUdr in combination with other cytotoxic drugs (Shepard et a1, 1985; Cohen et a1, 1986), with surglcal resection of hepatic metastases (Kemeny et 1 , 1985, 1986; Hodgson et $a 1,1986)$ and/or with hepatic arterial and portal velin embolization (Hodgson et a1, 1986) to improve the survival rate of patients with hepatic metastases from colorectal origin. Embolization is performed to disrupt tumor cells from any blood supply.

The brain

The brain is another region to which cytotoxic drugs bave been administered directly. Patients with brain tumors have a poor prognosis (W1 1son, 1979). The median survival of patients with brain metastases from extra-cranial primary tumors $1 s$ about 2-3 months; patients with malignant astrocytoma survive about 1 year following radiation therapy and systemic chemotherapy. The regional, i.e. the 
$\underbrace{}_{0}$

9

9

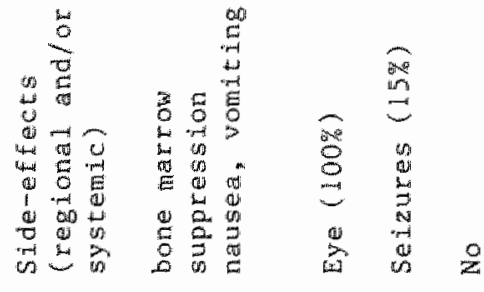

की

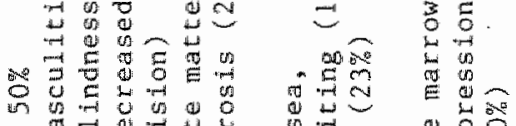

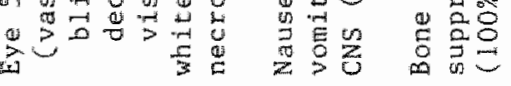

莣

is

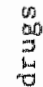

$\operatorname{lsc}_{0} 6$

崖䓪

m $\vec{m}$

$m$

$m a$

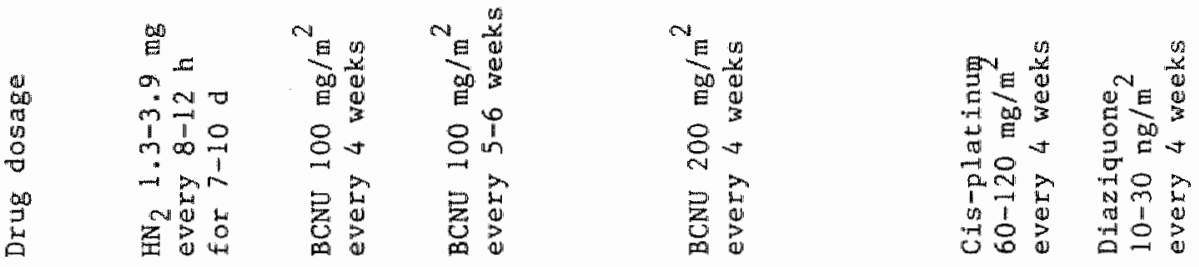

垈

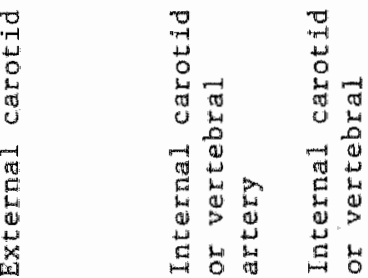

要

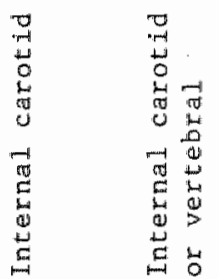

鼻

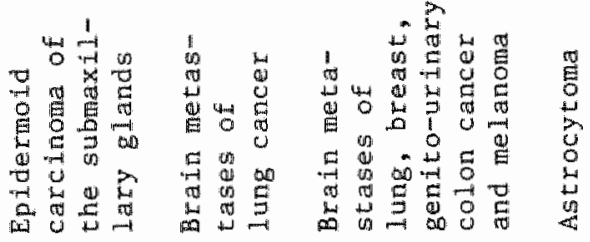

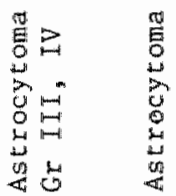

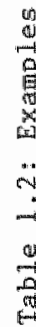

E $\quad$ 시
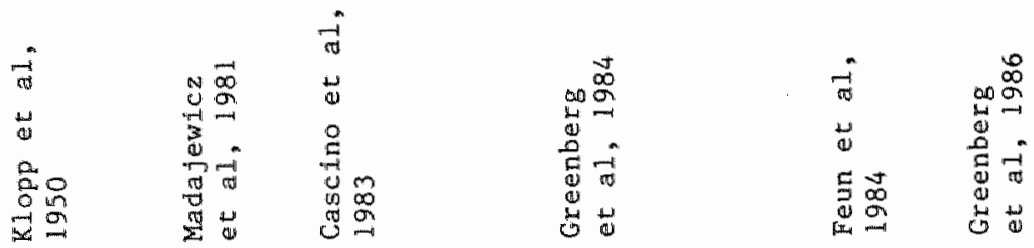
intracarotid or intravertebral arterlal adminlstration of cytotoxic drugs, such as BCNU (1,3-bis-(chloro ethy1)-1-nitrosurea), has been used for the treatment of malignant brain tumors. This application of target organ directed drug delivery is also based on the assumption that the drug avallability to the tumor region is enhanced while the systemic drug avallability is decreased as compared to systemic chemotherapy (Kleinschmidt-DeMasters, 1986). Table 1.2 describes examples of clinical studies in which the delivery of cytotoxic drugs to the braln has been reported. As may be concluded from this table, there is a wide variety of drugs in use and regional (1.e. central nervous system) toxicity is an important limiting factor.

Response rates of $10-50 \%$ during regional cytotoxic drug therapy Indicate that this method might be useful to treat brain tumors. Again however, there is yet no clinical study, indicating a significant increase in survival after the regional drug treatment of bratin tumors, as compared to systemic therapy.

\section{Other regions}

Other regions into which cytotoxic drugs are administered drectly are the bronchus, the maxillofactal region, the pelvis, the bladder and the extremities (table 1.3). Reglonal chemotherapy by perfusion (Muchmore et a1, 1985; Krementz, 1986) is often applied to treat tumors like melanoma and soft-tissue sarcoma of the $11 \mathrm{mb}$. As may be obvious the systemic toxicity is greatly reduced.

As may be clear thus far, almost every part of the body has been catheterized for reglonal chemotherapy of a tumor in that specific area. However, there seems to be no conslstency in the use of the drugs at the different regions. The actual therapeutic benefits of equi-dose regional over systemic chemotherapy have not been clarified yet.

\subsubsection{Thrombolytic therapy}

The intra-arterial administration of thrombolytic drugs, like streptokinase, into occluded vessels is a second important area of localized drug administration. Streptoklnase was discovered in 1933 when Tillet and Gauner observed that a flltrate of group C beta hemo- 


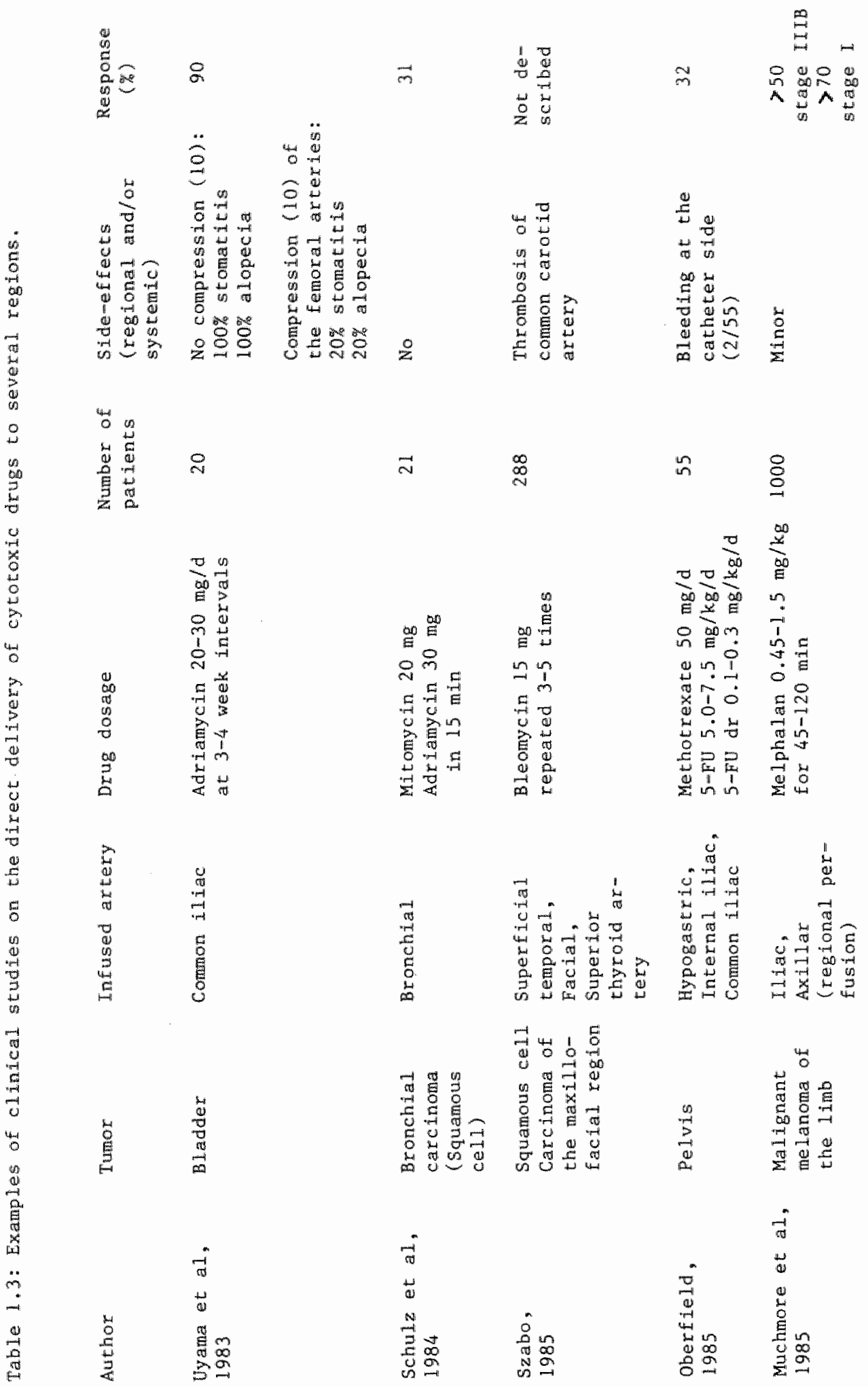


lytic streptococci lysed a human plasma clot (Tillet and Gauner, 1933). Streptokinase produces fibrinolysis by activating the body's natural fibrinolytic system by converting the inactive pro-enzyme plasminogen to the active enzyme plasmin, which lyses fibrin clots (Sharma et $a 1,1982$ ). In table 1.4, examples of studies applying the intra-arterial administration of streptokinase are described.

Table 1.4: Studies applying the intra-arterial infusion of streptokinase

Author

$$
\text { Infusion rate }
$$

Num- Reperfusion* ber of Systemilc sidepatients effects

Intrarenal administration of streptokinase

\begin{tabular}{|c|c|c|c|c|}
\hline $\begin{array}{l}\text { Fisher et a1, } \\
1981\end{array}$ & $\begin{array}{l}25.000 \mathrm{U} / \mathrm{hr} \\
\text { for } 25 \mathrm{~h}\end{array}$ & $\mathbb{1}$ & $100 \%$ & No \\
\hline $\begin{array}{l}\text { Cronan and } \\
\text { Dorfman, } 1983\end{array}$ & $\begin{array}{l}5000 \text { U/hr } \\
\text { for } 24-36 \text { hr }\end{array}$ & 3 & $100 \%$ & No \\
\hline $\begin{array}{l}\text { Brandjes et } \\
\text { a1, } 1985\end{array}$ & $\begin{array}{l}5000 \mathrm{U} / \mathrm{hr} \\
\text { for } 19 \mathrm{hr}\end{array}$ & 1 & $100 \%$ & No \\
\hline Intracoronary & administration of & \multicolumn{2}{|c|}{ streptokinase } & \\
\hline $\begin{array}{l}\text { Anderson et } \\
\text { a1, } 1983\end{array}$ & $\begin{array}{l}5000 \mathrm{U} / \mathrm{min} \\
\text { until reperfusion } \\
3000 \mathrm{u} / \mathrm{min} \\
\text { for } 30-60 \mathrm{~min}\end{array}$ & 24 & $78 \%$ & Minor \\
\hline $\begin{array}{l}\text { Khaja et a1, } \\
1983\end{array}$ & $\begin{array}{l}15.000 \mathrm{~J} / \mathrm{min} \\
\text { for } 2 \mathrm{~min} \\
5000 \mathrm{u} / \mathrm{min} \\
\text { to a tata } 1 \text { of } \\
250.000\end{array}$ & 20 & $60 \%$ & No \\
\hline $\begin{array}{l}\text { Kennedy et } \\
\text { a1, } 1983\end{array}$ & $\begin{array}{l}4000 \mathrm{U} / \mathrm{min} \\
\text { for } 60 \mathrm{~min}\end{array}$ & 134 & $68 \%$ & $5.2 \%$ \\
\hline $\begin{array}{l}\text { Rogers et } \\
\text { a1, } 1983\end{array}$ & $240.000 \mathrm{v}$ & 25 & $80 \%$ & $4 \%$ \\
\hline
\end{tabular}




$\begin{array}{lllll}\text { Siruonset } & 250.000 \mathrm{U} & 264 / 269 & 85 \% & 16 \% \text { (Ver- } \\ \text { a1. } 1985 & \text { (preceded by } & & \text { heugt et al, } \\ & 500.00 \mathrm{UH.v.} & & 1985 \text { ) } \\ & \text { in } 117 & & \\ & \text { patients) } & & \end{array}$

Intravenous administration of streptokinase (myacardia1 infarction)

\begin{tabular}{|c|c|c|c|}
\hline $\begin{array}{l}\operatorname{ECSQ} \\
1979\end{array}$ & $\begin{array}{l}250.000 \mathrm{~J} \mathrm{In} \\
20 \mathrm{~min} \\
100.000 \mathrm{~J} / \mathrm{hr} \\
\text { for } 12 \mathrm{hr}\end{array}$ & 155 & not determined \\
\hline $\begin{array}{l}\text { Schröder, } \\
1983 \\
\text { (review) }\end{array}$ & $\begin{array}{l}250.000 \mathrm{U} \\
\text { loading dase } \\
100.000 / \mathrm{h} \text { for } \\
12-24 \mathrm{hr}\end{array}$ & 2467 & $78 \%$ \\
\hline $\begin{array}{l}\text { GISS I } \\
1986\end{array}$ & $\begin{array}{l}500.000 \mathrm{U} / \mathrm{hr} \\
\text { (1n total } \\
1.500 .000 \mathrm{U}) \\
\text { vs no therapy }\end{array}$ & $\begin{array}{l}5905 / \\
5901\end{array}$ & $\begin{array}{l}18 \% \text { de- } \\
\text { crease in } \\
3 \text { weeks hospital } \\
\text { mortality (time- } \\
\text { dependent) }\end{array}$ \\
\hline
\end{tabular}

* Reperfuston is defined as the re-establishment of flow in the occluded vesse 1

Streptokinase has been administered also to occluded vessels other than renal and coronary arterles. Examples are the administration of streptokinase to the supertor mesenteric artery, the abdominal aorta, the superficlal femoral artery (Hess et a1, 1982), a distal calf artery and a palmar artery (Marder and Francis, 1984). In 11terature, however, only case reports are avallable.

In general, it can be sald that the dose of intracoronary administered streptokinase is reduced more than 5-fold as compared to systemic admintstration $( \pm 250.000 \mathrm{U}$ vs. $\pm 1.500 .000 \mathrm{U}$ at $10 \mathrm{cal}$ and systemic therapy). Reperfusion is reached in about $80 \%$ at local vs. $70 \%$ at intravenous therapy and seems strongly dependent on the time at which thrombolytic therapy is started. Systemic bleeding effects during local therapy are observed in approximately $5 \%$ of the patients and in $25 \%$ during systemic therapy (a minority of which is fatal). Thrombolytic therapy at myocardial infarction seems to be especially 
advantageous when admitted within the first hours of symptoms to patients with large Infarction. (Vermeer et al, 1986; Serruys et a1, 1986; Simoons et al, 1986)

A major drawback of intracoronary thrombolytic therapy, however, is the necessity to intraduce the catheter. Since the facllitles (equipment and trained people) are not uniformly avallable, only a minority of all patients recelve the local therapy. Another disadvantage is that the introduction of an intra-arterial catheter prolongs the time before the treatment can be started (Dewood, 1985).

\subsection{EXPERIMENTAL APPLICATIONS OF LOCAL DRUG ADMINISTRATION}

In comparison with the above described clinical applications, local drug administration is used in a wide variety in experimental research. The kidney may serve as an example: to study the renal effects of drugs or to elucidate the role of the kidney in the pathogenesis of hypertension. Examples of the former are the intrarenal vs. the systemlc administration of atriopeptin II to investigate the renal vasodilatory effects of this substance (Smits et al, 1986) and the beneficial effects of intrarenal over systemic administration of prednisolome to prolong the survival time of rat renal transplants (Ruers et a1, 1986). Circumenting the brisk first-pass effect of the lung, bradykinin was given intrarenally instead of intravenously, to study the effects on rat renal nerves (Smits and Brody, 1984). Local (intrarenal) administration of noradrenalin has been used to invest gate the role of renal neurogenic activity in the development and maintenance of hypertension (Kleinjans et a1, 1983).

The brain is another target for local drug admintstration in experimental research. Injections of drugs into the vertrebral artery to achieve higher drug concentrations in the brain as compared to systemic delivery were performed by Bock and Van Zwieten (1971) in experiments on the central mechanism of drugs like clontdine and alphamethyldopa (Henning and Van Zwieten, 1968; cf review Van Zwleten, 1975). However, there are great species differences in the brain regions that are supplied by the vertebral arterles (Reneman et al, 
1974; Wellens et a 1 1975), Indicating the need for caution in distingulshing local vs. systemlc effect when drugs are infused intravertebra11y.

In experimental cancer research the technique of local drug administration 18 also applied (Verbeek, 1983). Hepatic tumors in rats were treated elther by intrahepatic arterial, intravenous or oral administration of the cytotoxlC agent 5-FU by Cotino and Zwaveling (1976): Intra-arterially administered $5-F U$ was found to be more effectlve than intravenously or orally administered 5-FU. Intrarenally admintstered vincristine resulted in 2.8 times higher drug concentrations in sarcoma transplants situated in the kidney as compared to systemic delivery of the same drug (Tvete et al, 1984). This beneFlcial effect could even be enhanced by clamping the renal artery. A tumor transplanted lnto the hind limb of a rabbit was successfully treated by the intra-arterial administration of adriamycin. Intravenous infusion was not effective (Swistel et al, 1984).

The above-described examples of applications of local arug administration in clinical practice and experimental research may present a rather confusing picture: on the one hand, it seems as if any drug is thought to be suitable for intra-arterial drug administrathon. On the other hand most properly controlled clinlical studies suggest that systemic side-effects of intra-arterial drug administration are not avolded and that the therapeutic effect is 1ittle increased, if at al1. The use of target organ directed drug administration whout any considerations of 1 ts theoretical base wight explain the disctepancy between the enthusiastic use and the poor results* Therefore, this theoretical basis will be described below. Since the administration of a drug directly into the supplying artery of the target organ is the most often used varlant, the theoretical considerations will be restricted to the admintstration of drugs into the supplying artery of the target organ. Other forms of target organ directed drug delivery such as the use of pro-drugs (Smits and Struyker Boudier, 1985) or the intracerebroventricular administration (Levin and Landah1, 1985) will not be discussed. Also drug targeting 
by 1iposomes (Gregoriadis and Allison, 1982, Jori et al, 1986; Ranney, 1986), lactosaminated albumin (Fiume et a1, 1986), or by monoclonal antibodies (Zalcberg, 1985) will not be further discussed here.

\subsection{THEORETICAL CONSIDERATIONS OF LOCAL DRUG ADMINISTRATIOM}

\subsubsection{The physiological pharmacokinetic approach}

In general, three mathematical approaches have been taken to describe and interpret pharmacokinetic data. The first and most widely used approach is to describe the fate of drugs in the body by the so called open compartment models. In this approach the mathematical analysis is abstracted from a physiological description of the body as a set of tissues and argans. Instead, the body is described as a set of compartments, each based upon a number of unique kinetic parameters for each given drug. An example of this approach $1 \mathrm{~s}$ the so-called two-compartment model with a central and peripheral distribution compartment. The mathematical descriptions of the kinetic pattern of the drug in the compartments are based on the concentration time relation of the drug in the plasma. Analyzing the time course of the drug concentrations in plasma, values of an imaginary distribution volume, half-life time of elimination and total body clearance can be calculated (Cibaldi et a1, 1969; Greenblatt and Koch-Weser, 1975).

An Implication of dynamical systems theory offers a phystological approach to the subject (Cutler, 1979; Van Rossum et a1, 1986). In this approach the body is considered as a dynamical system, not only reacting to the input from outside but also self-organizing and controlling to some extent its input. The pharmacokinetlc behavior of tissues and organs is characterlzed by parameters as transit and residence times, blood flow, clearance and distribution vollume. The body transport function, fixed for a given individual and drug, is found from measurement of the output concentrations, applying a known input function. Statistical moments are used to describe the proflle of these functions (Van Rossum, 1985).

A third approach to describe and interpret pharmacokinetlc data is phystological modelifing, emphasizing on physlologleal and anato- 
mical parameters (Rowland, 1984a, 1985). Measurements of the concentration of the drug in tissues are used to analyze and describe pharmacokinetics mathematically. It has its orlgins in 1937, when Teorell Eormulated a general model with circulating blood and tissue compartments, some of whlch are sites of adminlstration and others are sites of elimination, to describe drug kinetics (Rowland, 1985). Ever since, the physlological approach has been developed by many authors (BIsschoff and Dedrlck, 1968; Welss and Forster, 1979; Gerlowski and Jain, 1983; Tsujl et a1, 1985; KIng et al, 1986).

F1g. 1.1 shows a physiologlcally based perfusion model. In this model, the pharmacokinetic processes in each organ, tissue or group of kinetically related tissues are described in terms of parameters relatling to physiology, anatomy and biochemistry (Rowland, 1985). Examples

\section{PHYSIOLOGICAL PHARMACOKINETIC MODEL}

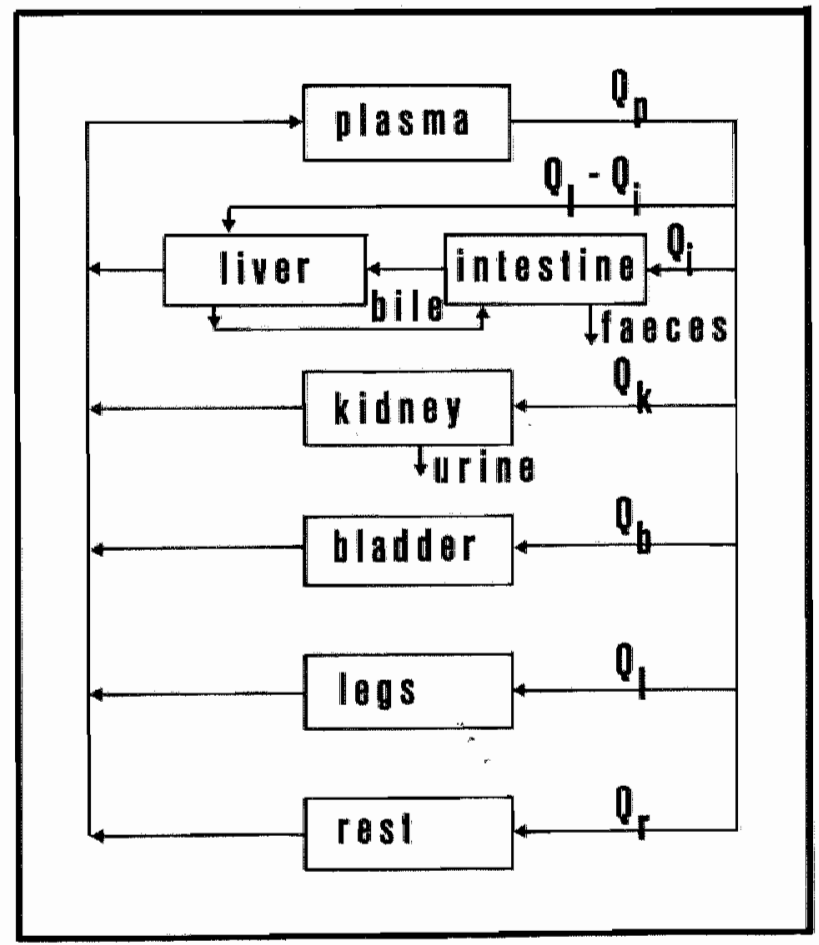

Fig. 1.1: Scheme of a flow-dependent physiological pharmacokinetic model. $Q$ is the flow to the respective organs. 
of these parameters are tissue size, vascular perfusion, permeabllity of the tissue membrane to a drug, binding and/or partition of the drug between blood and tissue compartments, and elimination processes.

With this physiological approach it is possible to describe and even predict the pharmacokinetic behavior of a given drug in a given tissue, provided that physiological parameters as tissue blood flow and volume, drug distribution coefficient between organ tissue and plasma, protein binding, and tissue clearance are known.

The rate of presentation of a drug to a tissue is the product of blood flow, $Q$, and the arterial blood concentration of the drug, $C_{A}$ (Eig. 1.2)

Rate of presentation $=Q \cdot C_{A}$

The rate at which the drug leaves on the venous side is $Q_{*} C_{V}$, where $C_{V}$ is the blood concentration in the returning venous blood. The difference between these rates is the rate of drug extraction by the organ.

Rate of extraction $=Q \cdot\left(C_{A}-C_{V}\right)$

By dividing (2) Into (1), a useful parameter, the extraction ratio, $E$, is found

$E=\frac{\text { Rate of extraction }}{\text { Rate of presentation }}=\frac{C_{A}-C_{V}}{C_{A}}=1-\frac{C_{V}}{C_{A}}$

The value of the extraction ratio is anywhere between zero and one. Relating the rate of drug extraction to the lncoming concentration another useful parameter clearance, $\mathrm{Cl}$, is found: 
MASS BALAHCE

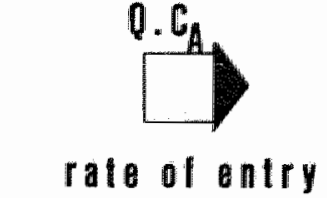

A

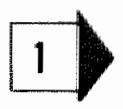

B

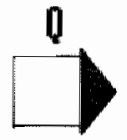

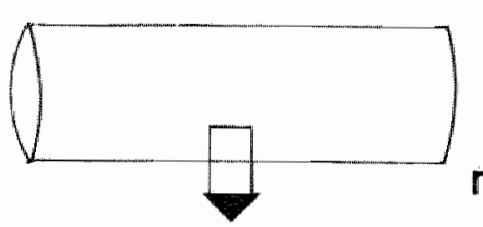

Q. $C$

rate of leaving $\left.0 . \mid c_{A}-\tilde{c}_{\boldsymbol{V}}\right]$

rate of extraction

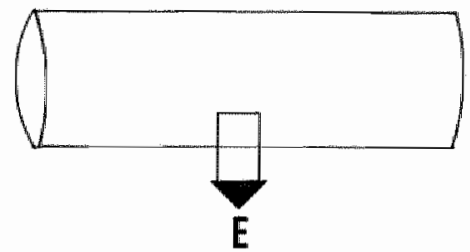

1-E

extraction ratio

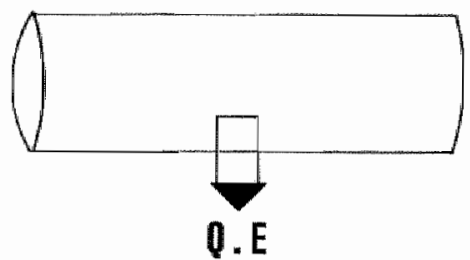

Q. $\mid 1-E]$

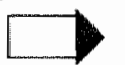

\section{cisarance}

Fig. 1.2: The extraction of a drug by an eliminating organ in relathon to the mass balance: the extraction accounted for its rates of entry and leaving: A. normallzed to the rate of eatry, whlch provides the fraction extracted: the extraction ratio. B. normalized to the entering concentration allowing to account for the drug in terms of clearance and flow.

$\mathrm{Cl}=\frac{\text { Rate of extraction }}{\text { Arterial blood concentration }}=Q \cdot \frac{\left(\mathrm{C}_{\mathrm{A}}-\mathrm{C}_{\mathrm{V}}\right)}{\mathrm{C}_{\mathrm{A}}}$ 
The dependency of $\mathrm{E}$ on the intrinsic capability of an organ to eliminate (i.e. Its intrinsic clearance) a drug was analyzed by wilkinson and Shand (1975):

$E=\frac{C 1_{\text {intr }}}{Q+C I_{\text {intr }}}=\frac{1}{\frac{Q}{C I_{\text {intr }}}+1}$

hence

$C 1=Q \cdot \frac{C 1_{\text {intr }}}{Q+C 1_{\text {intr }}}$

This approach shows that for a drug with a high extraction ratio $(>0.7)$ changes in blood flow produce corresponding changes in clearance but not in extraction ratio (table 1.5). In other words, the clearance of a high extraction drug is flow dependent. On the other hand for a drug with a low extraction ratio $(<0.3)$ changes in blood flow produce inversely related changes in extraction ratio but not in clearance: the clearance of low extraction drugs is flow Independent.

Table 1.5: Changes in clearance and extraction ratio with changes in blood flow.

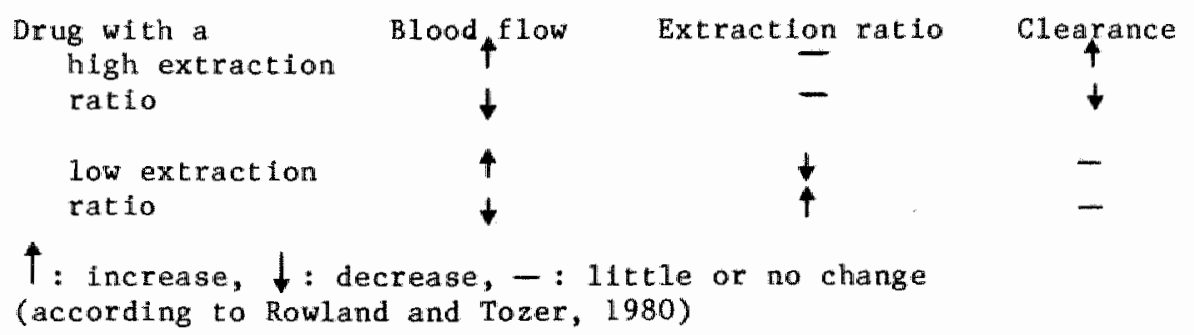


Taking the drug's plasma protein binding in the blood into account (equation 8) it is indicated that

$E=\frac{f u \cdot C I_{\text {inte }}}{\text { O+tu.CI' } \text { intr }}$

where $\mathrm{Cl}^{\prime}$ is the intrinsic clearance of unbound drug and $f_{u}$ the fraction of drug, unbound in the plasma. From equation 8 it can be derived that the higher a drug's intrinsic free clearance the less sensitive is 1 ts extraction and clearance to changes in binding (Jansen, 1981). On the other hand, for drugs with a low intrinstc free clearance, and extraction ratio, an almost linear relationship exists between clearance and binding:

$\mathrm{Cl} \approx \mathrm{fu} \cdot \mathrm{Cl}$ intr

The physlological pharmacokinetic approach also forms the basis of theoretical considerations of the advantages of local over systemic drug delivery. In the following section mathematical expressions wil be derived for the advantages of local over systemic drug delivery using the above described physiological model.

In general, the rate equation for a given drug in a given tissue I. given by:

Rate of change of mass of the drug in the tissue Rate of entry - Rate of exit - Rate of elimination +

Rate of synthesis

A simplifled physlologlcal pharmacokinetic model in which a drug can be given directly to a tissue or systemlcally, is depleted in fig. 1.3. In thls figure, a target organ with a given volume $V_{T}$, a blood flow $\mathrm{Q}_{\mathrm{T}}$ and an extraction ratio $\mathrm{E}_{\mathrm{T}}$ is described. All remaining organs are lumped into one compartment with a flow $\left(Q_{S}\right)$ and a clearance for the drug $\left(\mathrm{Cl}_{\mathrm{S}}\right) \cdot \mathrm{Cl}_{\mathrm{S}}$ is defined by the total body clearance of the drug minus the clearance of the drug by the target organ. 


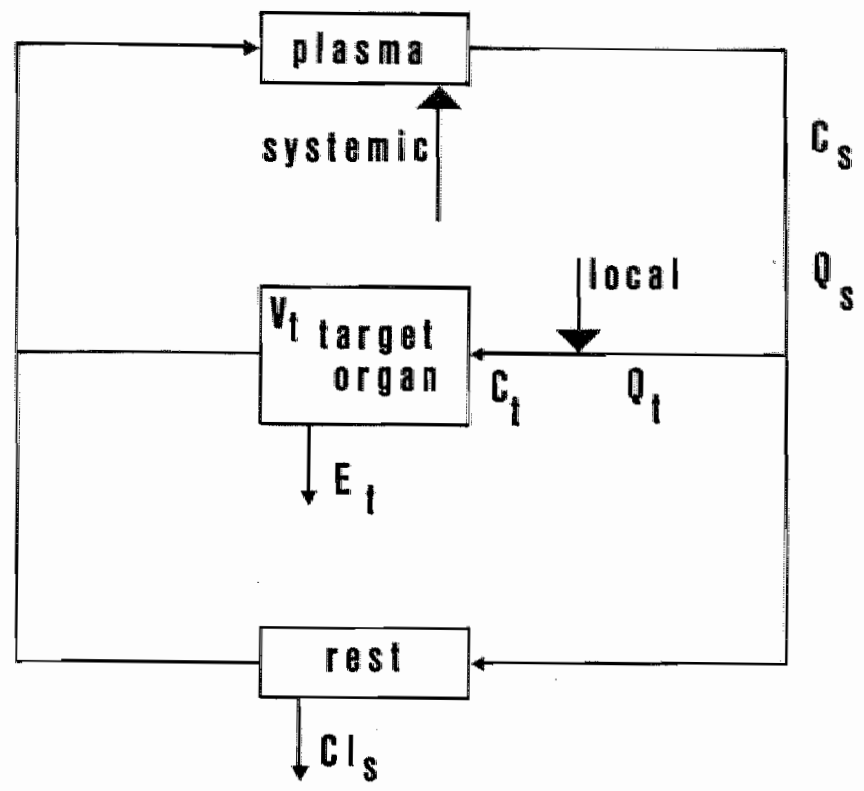

F1g. 1.3: Scheme of a two-compartment physiologlcal pharmacokinetic model, suited for local drug administration. $\mathrm{C}_{S}$ is the systemic plasma concentration, $Q_{S}$ the systemic plasma flow. $C_{r}$ and $Q_{\mathrm{T}}$ the concentration and the plasma flow, respectively, in the artery supplying the target organ. $V_{T}$ is the volume of the target organ. $E_{\mathrm{T}}$ the extraction ratio of a drug in the target organ. Other organs are lumped together (rest). $\mathrm{Cl}_{\mathrm{S}}$ is the systemic (i.e. non-target organ) clearance.

More or less non-physiological assumptions of the model are that the drug in an organ is well-mixed and that the drug concentration In an organ is proportional to the drug concentration in the venous blood (Wagner, 1985; Roberts and Rowland, 1985; Terasaki et a1, 1985).

The mass balance of a drug in organ $T$ is:

$v_{T} \frac{d C_{T}}{d t}=Q_{T} \cdot\left(C_{p}-\frac{C_{T}}{R_{T}}\right)-C 1_{T} \cdot \frac{C_{T}}{R_{T}}$

where $V_{T}$ is the volume of the organ, $c_{T}$ and $c_{P}$ the organ and afferent blood (plasma) concentration, respectively; $Q_{T}$ the blood flow, $R_{T}$ the distribution coefficient of the drug between argan tissue and plasma at equilibrium; $\mathrm{CI}_{\mathrm{T}}$ is the clearance constant in the organ.

For the drug in the blood (plasma) compartment the mass balance is

$V_{p} \cdot \frac{d C_{P}}{d t}=Q_{T} \cdot \frac{C_{T}}{R_{T}}-Q \cdot C_{p}-C I_{P} \cdot C_{P}$ 
were $Q$ represents the total blood flow 1 .e. cardiac output. For steady state, expressions of $C_{T}$ and $C_{p}$ for intra-arterlal (1.a.) and intravenous (1.v.) infusion can be derived from equations (11) and (12).

1.v. Infusion:

$\mathrm{C}_{\mathrm{T}}$

$Q_{T} \cdot C_{P}-\frac{C_{T}}{R_{T}}-C 1_{T} \cdot \frac{C_{T}}{R_{T}}=0$

$C_{T}=\frac{Q_{T} \cdot R_{T}}{Q_{T}+C 1_{T}} \cdot C_{P}=C_{P} \cdot R_{T} \cdot \frac{1}{1+E_{T}}$

$\mathrm{C}_{\mathrm{p}}$

$Q_{T} \cdot \frac{{ }^{C}}{R_{T}}-Q_{T} \cdot C_{p}-C_{S} \cdot C_{p}+k_{o}=0$

where $\mathrm{Cl}_{\mathrm{s}}$ represents the total body clearance of the drug outside the target organ and $k_{0}$ the constant rate infusion input.

$C_{P}\left(Q_{T}+C 1_{S}\right)=Q_{T} \cdot \frac{C_{T}}{R_{T}}+k_{o}$

Substitution of (14) Into (16) leads to

$C_{P}\left(Q_{T}+C_{S}\right)=Q_{T} \cdot \frac{Q_{T} \cdot R_{T} \cdot C_{p}}{\left(Q_{T}+R_{T}\right) \cdot R_{T}}+k_{o}$

By rearrangement, this leads to

$C_{p}=k_{0} / C 1_{S}+\frac{Q_{T} \cdot C 1_{T}}{Q_{T}+C l_{T}}=k_{o} / C l_{s}+\frac{C l_{T}}{1+E_{T}}$ 


\section{I.a. Infusion}

$\mathrm{C}_{\mathrm{T}}$

$\mathrm{Q}_{\mathrm{T}} \cdot\left(\mathrm{C}_{\mathrm{P}}-\frac{\mathrm{C}_{\mathrm{T}}}{\mathrm{R}_{\mathrm{T}}}\right)-\mathrm{Cl}_{\mathrm{T}} \cdot \frac{\mathrm{C}_{\mathrm{T}}}{\mathrm{R}_{\mathrm{T}}}+k_{\mathrm{O}}=0$

$\left(k_{\mathrm{O}}+\mathrm{Q}_{\mathrm{T}} \cdot \mathrm{C}_{\mathrm{p}}\right) \cdot \mathrm{R}_{\mathrm{T}} / \mathrm{Q}_{\mathrm{T}}+\mathrm{Cl}_{\mathrm{T}}=0$

$\mathrm{C}_{\mathrm{p}}$

$Q_{T} \cdot \frac{C_{T}}{R_{T}}-Q_{T} \cdot C_{P}-C \mathbb{I}_{S} \cdot C_{P}=0$

Substitution of equation (20) into (21) leads to

$Q_{T} \cdot \frac{\left({ }_{0}+Q_{T} \cdot C_{P}\right.}{Q_{T}+C I_{T}}-Q_{T} \cdot C_{p}-C 1_{S} \cdot C_{p}=0$

Rearrangement of equation (22) leads to

$C_{P}=\frac{Q_{T} \cdot k_{O}}{Q_{T}+C 1_{T}} / C 1_{S}+\frac{Q_{T} \cdot C 1_{T}}{Q_{T}+C 1_{T}}$

$C_{\mathrm{T}}=\frac{k_{0}}{Q_{T}}+c_{p}$

1.6.2 Regional and systemic advantages of intra-arterlal over systemic drug admilnistration

Assuming that local and systemic drug effects are concentration related, the ratio of the concentrations (local or systemlc) at local and systemic drug administration are used as parameters of advantage (regional or systemic respectively) of local over systemic drug administration. Hence at steady state the regional advantage, $\mathbb{R}_{D}$, defined 
as the galn in drug concentration in the artery supplying the target organ $\left(\mathrm{C}_{\mathrm{TA}}\right)$ following local over systemlc drug administration, is glven by

$R_{D}=C_{\text {TALa }} / C_{\text {TALV }}$

Substitution of equation (23) into (24) and division by (18) leads to

$\mathrm{R}_{\mathrm{D}}=1+\mathrm{C} 1_{\mathrm{S}} / \mathrm{Q}_{\mathbb{D}}$

The reduction $\mathbb{1 n}$ the systemic concentration following local over systemic drug administration, the so-called systemic advantage, is given by:

$\mathrm{C}_{\text {pial }} / \mathrm{C}$ piv

$\mathrm{C}_{\text {pla' }}$, the systemlc plasma concentration at intra-arterial drug administration, equals

$\left(1-\mathrm{E}_{\mathrm{T}}\right) \cdot \mathrm{k}_{\mathrm{o}} / \mathrm{Cl} \mathrm{S}$

where $E_{\mathrm{T}}$ represents the extraction ratio of the drug by the target organ. $\mathrm{C}_{\mathrm{piv}}$ is defined by:

$\mathrm{k}_{\mathrm{o}} / \mathrm{Cl} \mathrm{S}$

Division of (28) by (29) leads to

$\mathrm{C}_{\text {pia }} / \mathrm{C}_{\mathrm{piv}}=\mathbb{1 - \mathrm { E } _ { \mathrm { T } }}$ 
The above-described relationships are valid at steady-state conditions following constant rate infusion, but represent also the total amounts of drug delivered to the target organ following bolus injections (Eckman et a1, 1974; Chen and Gross, 1979; Weiss, 1985).

Any advantage of local over systemic drug administration can only be achieved under special conditions: 1) the infused drug is extracted efficiently by the target organ or 2) the drug has a high systemic (i.e. non-target organ) clearance $\left(\mathrm{Cl}_{s}\right)$ in relation to the blood flow of the target organ $\left(q_{n}\right)$. The local infusion of a drug with a high extraction ratio leads to a reduced systemic concentration as compared to systemic administration of the same drug at the same constant rate of infusion. Hence, systemic side-effects are reduced, assuming these to be dose dependent (Collins, 1984). On the other hand local infusion of a drug with a low extraction ratio does not reduce the systemic concentration significantly as compared to systemic administration. In relation to the second option 1 t can be seen that equation (25) and (26) approach one, indicating no advantage, when the drug clearance outside the target organ is small with respect to the blood flow through the target organ. A regional advantage achleved by local drug administration can be applied to lower the dose and thus the systemic side-effects, during local as compared to systemic drug administration, assuming a defined therapeutic steady state drug concentration in the arterial bed supplying the target organ.

1.7 THEORY AND PRACTICE : ANALYSIS OF THE APPLICATIONS OF LOCAL DRUG ADMINISTRATION

From the above, $f t$ is clear that advantages of intra-arterial over systemic drug administration are determined by three parameters: (1) the extraction ratio of the drug by the target organ; (2) the bload flow of the target organ; (3) related to two, the systemlc clearance of the drug.

To reduce the systemic drug avallability, the drug has to be cleared efficiently before it reaches the systemic circulation. Is such a drug not found or not effective then a drug that is not cleared by the target organ, but that has a high non-target organ clearance, 
has to be infuged into a target organ with a relatively low blood flow.

In the following paragraph, the applications of local drug administration described earlier in this chapter wil be analyzed according to the above theoretical requisites for advantageous local drug administration.

\subsubsection{The drug is efflctenty extracted by the target organ}

The cytotoxic agents 5-FU and 5-FUdr are used to treat hepatic metastases of colorectal carcinoma by infusing them into the hepatic artery. The hepatic extraction ratio of 5-FU 1 s 0.4 and of 5 -Fudr 0.9 (Ensmlnger and Gyves, 1984). Some authors have suggested that 5-Fudr is a pro-drug from which 5-FU is generated, which would make predictions of advantages based on the extraction ratio of 5-Fudr questionable (Armstrong and Dlasio, 1980; Ishitsuka et a1, 1980). When infused locally, both drugs should be expected to result in lowered systemic concentrations as compared to their systemic delivery. However, no one has yet done controlled clinical comparative pharmacokinettic studies on the actual concentrations of these drugs in the venous blood and in the tumor and normal liver tissue during local and systemic administration. Therefore the advantage of hepatic arterial over systemic chemotherapy with $5-F U$ and $5-F U d r$ remains unverified. In this respect a disturbing observation was made by Boubli1 et al (1985) measuring systemtc plasma concentrations of 5-FU during a continuous 5-day reglonal chemotherapy of $500-1650 \mathrm{mg} / \mathrm{m}^{2} / \mathrm{d}$ in patients with hepatic metastases from colorectal origin. They showed increased plasma concentrations and a decline in the hepatic extraction ratio in the last 2 days of a 5-day infusion perfod. These data suggest saturation of hepatic elintnation mechanisms and/or hepatic coxicity during longterm continuous infusion. This may lead to a reduction in the systemic advantage of intrahepatic arterial drug administration and to increased systemic toxic effects of the drug.

As described in paragraph 1.4 .1 , the long-term intra-arterial infusion of cytotoxic drugs for the treatment of cancer of the head is another important area of regional cancer therapy. BCNU (1.3-bis-(2chloroethy 1 )-1-nitrosurea) is the most effective single agent in brain 
chemotherapy (Walker et al, 1980). A reduction in the systemilc concentration is not to be expected since the brain and/or the brain tumor have no extraction capacity for the drug (Russo et al, 1981). For achieving an advantage of local over systemic drug administration in such a non-clearance-organ, the ratlo of the systemic clearance of the infused drug and the blood flow through the target argan has to be considered.

\subsubsection{The blood flow to the target organ}

Low flow organs: A low blood flow of a target organ facilltates a high regional advantage by local adninistration of the proper drug. One approach therefore has been to reduce flow by embolizing the local vascular bed before infusing the active agent. Another case to consider is local vs systemic thrombolysis. As may be obvious, only small amounts of blood, if any, pass through embolized vessels. The local administration of thrombolytic agents to embolized vessels therefore yields high regional drug concentrations as compared to systemic thrombolytlc therapy. According to the theory, the locally infused dose is reduced (in fact about one fifth) as compared to systemic thrombolytic therapy, thereby reducing the systemic side-effects $(<25 \%$, Sharma et a1, 1982). However, there are competitors in the field: the fibrin-selective agent, Tissue-Type Plasminogen Activator ( $t-P A)$ which has a clot spectifle thrombolytic action (Co11en, 1986), can be given intravenously and may in future end the necessity of the application of intra-arterial drug admintstration in thrombolytic therapy.

High flow organs: The kidney and the liver are of ten used target organs. If the drug of cholce 1 s not extracted by elther target organ, then a regional advantage of local drug administration can only be achieved if the blood flow is reduced. A low flow does not hold for the kidney nor for the 1iver, which recelve about 10 and $25 \%$ of the cardiac output respectively. They are classical examples of high flow organs, and in theory unsulted for achieving a reglonal advantage by local drug administration.

However, under special circumstances a reglonal advantage in these both organs can still be achleved. An example is the intrarenal 
Infuston of a vasoconstrictor agent like noradrenalin (Kleinjans et a1, 1983) which 111 enhance the regional drug concentration as courpared to systemic administration since the blood flow to the kidney is reduced.

Another example of an approach to reduce the blood flow to the target organ can be found in regional chemotherapy especially in the regional therapy of hepatic metastases. Since the degree of regional advantage of local over systemic drug administration is inversely related to the flow through the target organ a decrease in the flow of the hepatic artery should enhance the drug concentration in the hepatic tumor: decreasing the blood flow by $90 \%$ should increase the drug concentration $\mathbb{H}$ the hepatic artery about 10-fold. Therefore, in clinical practice several methods have been applied to decrease hepatic arterial blood flow (Ensminger and Gyves, 1984) such as:

1. Lifgation of the hepatic artery (Car1sson et a1, 1981; A1-Jurf et a1, 1984; Petre111 et al, 1984). Important drawbacks of this method are rapid collateralization as well as thrombosis in and around the catheter and the irreversibility of the manoeuvre (Civalleri et al, 1985).

2. The use of a balloon catheter (Watkins et a1, 1960).

3. The simultaneous infusion of vasoconstrictor agents as epinephrine, vasopressin and anglotensin (Iwaki et a1, 1978; Hafström et a1, 1980 ).

4. The use of microparticles or microspheres. Biodegradable starch mictospheres injected concurrently with the cytotoxilc agent block the hepatic arterlal flow for about $30 \mathrm{~min}$, thus allowing more time for the tumor to be exposed to high drug concentrations (Erichsen et 1,1985$)$. It is shown that a delayed systemlc drug distribution (Lindell et $a 1,1978$ ) and a high reglonal advantage (Dakhill et al, 1982; Gyves et a1, 1983) can be achieved by injectting starch microspheres into the hepatic artery. Conclusive reports indicating an enhanced survival rate as compared to "normal" intra-arterial chemotherapy are lacking (Ensminger et al, 1985; Fujimoto et al, 1985).

Arterial chemo-embolization with ethylcellulose microcapsules containing the cytotoxic agent is another method for enhancing the drug 
concentration to the tumor (Kato et al, 1978; Okamoto et al, 1986).

1.7.3 high systemic clearance in relation to the blood flow of the target organ

$B C N U$ is the drug of choice in brain chemotherapy. In humans, the plasma clearance of BCNU is about $1200 \mathrm{ml} / \mathrm{m} 1 \mathrm{n}$ (Russo et al, 1981). A reduction in the systemic concentration is not to be expected since the brain and the brain tumor have no extraction capacity for the drug. The regional drug concentrations should be about 5-6 times those after intravenous drug administration (Greenberg et al, 1984), assuming a carotid blood flow of $250 \mathrm{ml} / \mathrm{min}$. In experiments in monkeys, Levin et al (1978) showed that the brain tissue levels at intracarotid Infusion were twice those at intravenous administration of ${ }^{14} \mathrm{C}-\mathrm{BCNO}$, while 0ldendorf (1975) described a reglonal advantage of 4.6 in rats. Since encephalopathy is a major complication of intravenous therapy with high doses (1500-2000 mg; Burger et a1, 1981), the dose during local therapy has to be reduced at least 5-6 times, to reach equivalent concentrations and toxicity in the target region during local therapy. Indeed, in a study on the regional toxiclty of BCNU during its intracarotid infusion a dose of $400 \mathrm{mg}$ was used, while the regtonal (i.e. central nervous system) toxiclty was comparable to that seen during systemic therapy with high dosages. In summary, pharmacokinetically $\mathrm{BCNU}$ does seem to be a drug of cholce for regional therapy (high systemic clearance and low blood flow to the target organ). However, because of its important reglonal toxiclty, which cannot be reduced by applying the technique of $10 \mathrm{ca} 1$ drug administration, local adminlstration does not serve to reduce its limiting toxictiy.

Diaziquone (aziridinyl benzoquinone or $A Z Q$ ), a drug with a plasma clearance of about $460 \mathrm{ml} / \mathrm{min}$, is active agalnst human brain tumors when given intravenously. Its most important side-effect is myelosuppression. In theory, intracarotid delivery might triple the concentration to the target tissue or might enable to reduce the infused dose to about one third. Therefore, this drug seems to be an alternative for $\mathrm{BCNU}$, because the reduced dose at local drug administration should result in decreased systemlc slde-effects. However, Egorin et al (1984) were unable to detect any slgniflcant rëglonal advantage to intracarotid infusion of $\mathrm{AZQ}$ in tumor bearing puppies. As may be 
obvlows, reduction of the carotid blood flow might enhance the concentration in the target tissue and the reglonal advantage.

The total body clearances of 5-Fu and 5-Fudr are 2-5 and 5-1.5 $1 / \mathrm{min}$, respectively (Ensminger and Gyves, 1984). Since hepatic metastases of $3-5$ cul recelve $95 \%$ of thell blood supply vila the hepatic artery (Ackermann et a1, 1969) the hepatic arterial blood flow and not the total hepatic blood flow is used for calculating the regional advantage. For 5-FU, this advantage would be about 6-13, for 5-FUdr 13-38, assuming a hepatic arterial flow of $0.41 / \mathrm{min}$. The reduction $1 \mathrm{n}$ systemic concentration should in theory be about $50 \%$ for $5-$ FU and $80 \%$ for 5-FUdr, assuming steady-state conditions and linear kinetics, and could be even enhanced by reducing the dose. As before, the suggested generation of 5-FU from 5-FUdr is a complicating factor, which may decrease the advantage of local administration of 5-Fudr.

In conclusion, (1) examples can be found of the correct application of the theoretical guidelines; (2) as many examples can be found in which theory is neglected; (3) a kinetic evaluation of the actual advantages of local over systemic drug administration is rare.

\section{8. THIS THESIS}

The introduction of intra-arterlal infusions of cytotoxic drugs in cancer chemotherapy by Klopp et al (1950) excited interest in this means of drug delivery. Clinical studies were performed to prove its superiority over systemic drug administration, but they lacked theoretlcal and/or experimental justification.

The theoretical basis for Intra-arterial drug administration was provided for in the $70 \mathrm{~s}$ and $80 \mathrm{~s}$ (Eckman, 1974; Chen and Gross, 1979, 1980; Welss, 1985; Smits and Thijssen, 1986). It was found that only under special circumstances, wh the right combination of drug and target organ, could the method be expected to have advantage over systemic administration.

To date, experimental verification of this theoretical basis is still rare. Evaluation of the advantages of intra-arterial over systemic drug administration has to be performed under controlled experi- 
mental conditions in which important physiologleal and pharmacologlical parameters such as the blood flow to the target organ, the extraction ratio of the drug by the target organ, the concentration of the drug in the target artery and/or the target organ, the systemic concentration, and the systemic clearance of the drug are known or can be calculated.

In this thesis, techniques are described that enable the measurement of these parameters in a small experimental animal, the rat, providing a means for the experimental evaluation of the advantages of regional over systemic drug administration. These techniques include the evaluation of indocyanine green as an indicator of rat liver blood flow (chapter 3), the introduction of the electromagnetic flow method to assess rat hepatic arterial and portal venous blood flow (chapter 4), and the liver blopsy technique for repeated liver tissue sampling in one animal (chapter 5).

Drug administration directed to the kidney, heart, liver and testis was compared to the systemic administration of the same drug at the same rate at steady-state conditions (table 1.6). To evaluate the often used method of intrarenal drug administration in the rat, a low renal clearance substance, Chromium-51 Ethylenediaminetetracetate ( ${ }^{51} \mathrm{Cr}$ EDTA), and a high renal clearance substance, ${ }^{125}$ Iodo hippuric acid $\left({ }^{1.25} \mathrm{IHA}\right.$ ), were given directly to the left and right kidney (chapter 6). Propranolol, a high hepatic clearance substance, was given into the coconary system of rat cardlac grafts (chapter 8) and intrarenally (chapter 7) to Investigate the sultablifty of the rat cardiac transplant for local drug administration and to investigate the reglonal advantage during local administration. Acenocoumarol, an oral anticoagulant, was infused intrahepatically (vla the hepatic artery) and intravenously to study the effect of the route of administration on the hepatic drug concentration (chapter 9). Acenocoumarol was a so given intrarenally and intratestlcularly to study the effect of flow on the regional and systemfc advantage. Phenobarbital co-treatment was used to study the effect of an enhanced systemic clearance on the regional advantage (chapter 10; table 1.6). The effects of chronlc local acenocoumarol administration in the testis on testicular vitamin $K$ dependent enzyme systems and an fertility were studied in chapter 
11. In the last chapter, concluding remarks and future lines are presented. In Appendix I the results of a simulation study are presented. The effects of saturable tissue binding sites on the reglonal and systemic advantages of a locally administered drug were studied. This simulation study 1 s based on data described in chapter 2 and chapter 9.

Table 1.6: An outline of the experiments described in chapter $6-11$ of this thesis.

The infused drug is cleared by the "target organ"

High extraction ratio 125 IHA in the kidney (ch. 6)

Propranolol in the transplanted heart (ch. 8)

Low extraction ratio $\quad{ }^{51} \mathrm{Cr}$ EDTA in the kidney (ch. 6)

Acenocoumarol in the liver (ch.9)

The infused drug is not cleared by the "target organ"

$\begin{array}{ll}\text { High systemic } & \text { Low systemic } \\ \text { clearance } & \text { clearance }\end{array}$

High blood flow Propranolol in Acenocoumarol in

the kidney (ch. 7) the kidney (ch. 10)

Low blood flow

Acenocoumarol

in the testis

(phenobarbital co-

Acenocoumarol in

the testis (ch. 10,

treatment; ch. 10)

11) 


\section{MATERIALS AND METHODS}

\section{1 INTRODUCTION}

From the previous chapter, it may be obvious that several conditlons have to be fulfilled before the actual benefits of local over systemic drug administration can be evaluated experimentally. Some of these conditions are described below.

1. Access for drug administration directly to the target organ has to be possible;

2. Determination of the drug concentration has to be performed in systemic blood (plasma) and in the target organ;

3. The blood flow to the target organ has to be measured in absolute terms.

In this chapter, routes for local drug administration to the kidney, the transplanted heart, the liver and the testis of the rat will be described. The drugs used in our experiments will be presented in paragraph 2.3. Special attention will be given to pharmacokinetic aspects of the drugs in relation to the respective target organ. Analytical procedures for the determination of the concentration of the drugs in blood or plasma and target tissue w111 be described. Methods for Elow measurements wil1 be given in paragraph 2.4. Mathe-m matical descriptions for pharmacokinetic analysis of experimental data will be described in the last paragraph of this chapter.

\section{2 ROUTES OF LOCAL DRUG ADMINISTRATION}

For the direct administration of a drug inta the blood stream of a target organ, techniques that allow long-tern access to the supplying artery, but do not disturb the organ blood flow, are preferred. In this thesls, target organ directed drug administration is described for several organs: the kidney, the heart, the liver, and the testis. The techniques used to gain access to the respective target organs are described here. 


\subsubsection{The kldney}

Intrarenal infusion in the left or the right kidney (chapter $6,7,10)$ was performed following the method of Smits et al (1983). Brief1y, a stretched poly-ethylene (PE-10) catheter was introduced in a retrograde fashion in the suprarenal artery, which originates from the renal artery. The tip was placed just proximal to the renal artery to prevent flow changes in that artery (fig. 2.1). With this method of renal drug administration, renal function 1 s not affected (Smits et a. 1,1983$)$.

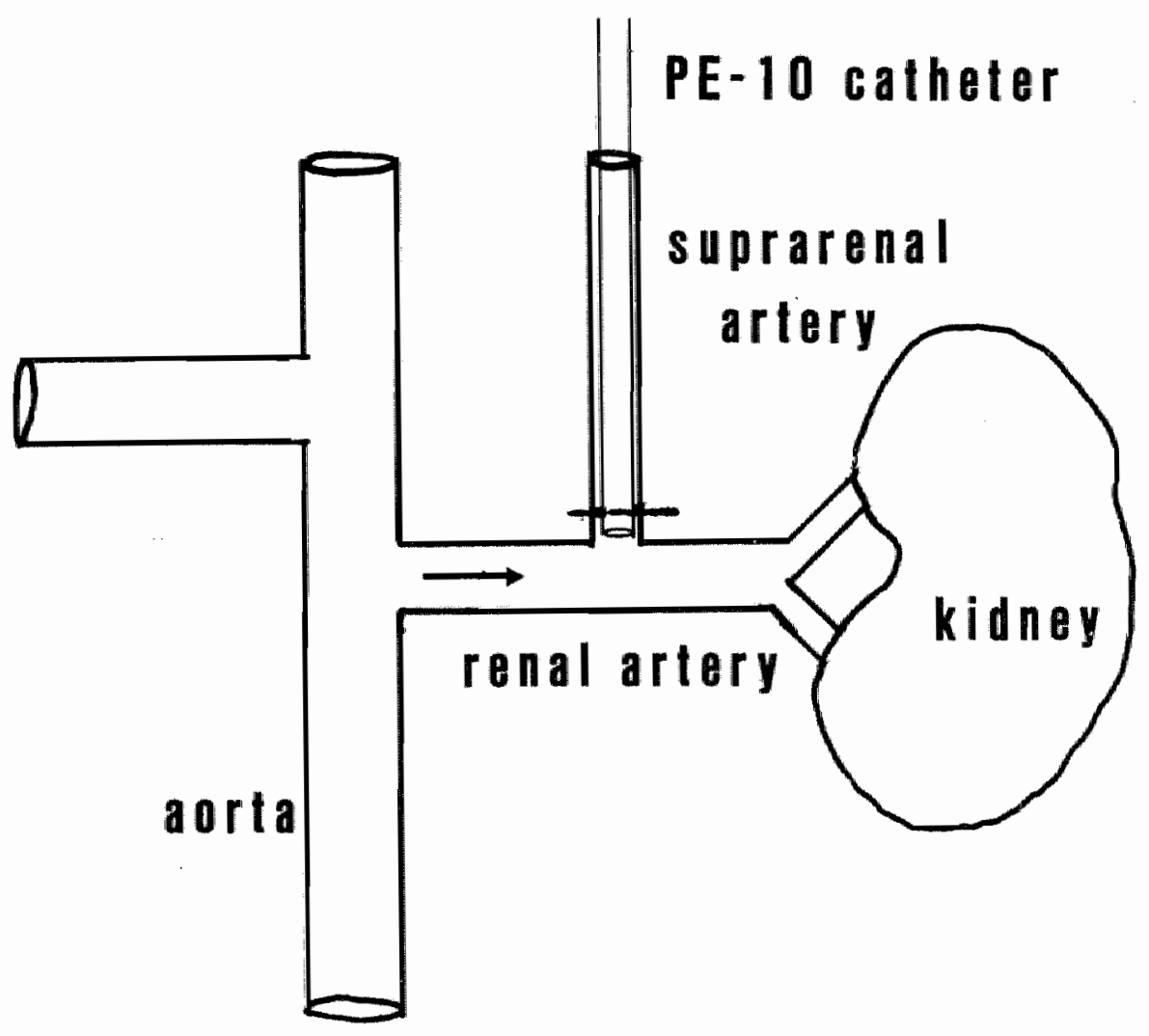

Fig. 2.1: Schematic drawing of a catheter, placed in the suprarenal artery of the rat, used for intrarenal infusion. 


\subsubsection{The transplanted heart}

Based on the same principle as above, a PE-10 catheter was introduced in a retrograde fashion in the carotid artery for local infusion into the coronary circulation of rat cardiac grafts (chapter 8). Since in this model the arch of the transplanted aorta is situated at a very close distance to the liver of the acceptor animal, the cannulation of the caratid artery was performed before the transplantation (Ruers et $a 1,1987$ ). As will be described in more detail in chapter 8, the blood flows in a retrograde fashion through the transplanted aorta. A drug infused via the carotid artery reaches the transplanted heart almost immediately (fig. 2.2). The aortic valves are closed. Hence, blood reaching the transplanted heart flows retrom gradely through the coronary arteries only.

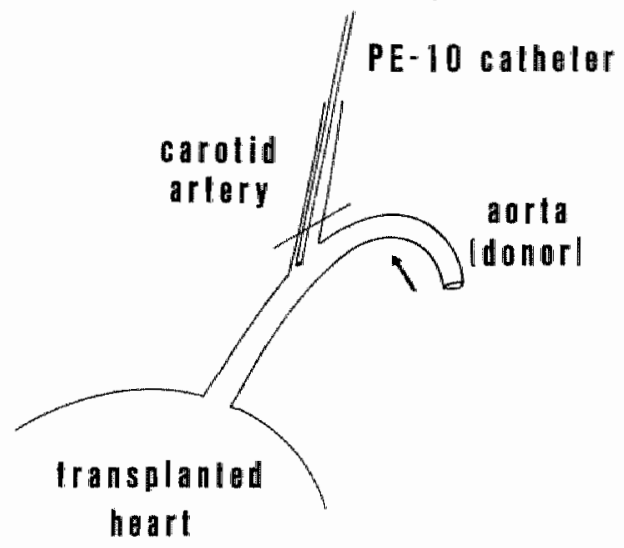

Fig. 2.2: Schematic drawng of a catheter, placed $\mathbb{1}$. the carotid artery, used for local infusion in the rat cardiac graft.

\section{2 .3 The 11ver}

For intrahepatic arterial drug administration, the th of a catheter was introduced into the gastroduodenal artery (f L . 2.3) according to Cotino and Zwaveling (1976).

As illustrated in fig. 2.3, the proper hepatic artery and the gastroduodenal artery orlginate from the comon hepatic artery. To gain access to the proper hepatic artery a stretched PE-10 catheter was introduced in a retrograde fashion into the gastroduodenal artery. The tip of the catheter was fust proximal to the common hepatic artery to prevent flow changes in the hepatic artery. 


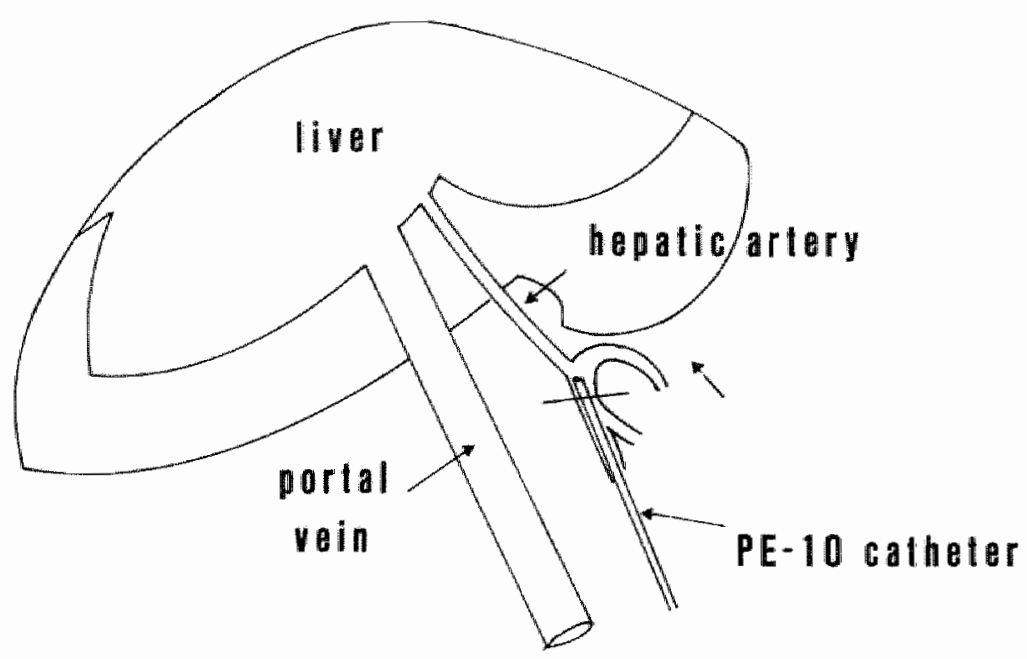

Fig. 2.3: Schematic drawing of catheter, placed in the gastroduodenal artery, used for intrahepatic infusion.

\subsubsection{The test1s}

The method of cannulation of a side-branch of the target artery to gain access to the target artery itself could not be applifed in experiments on the effects of local infusion of acenocoumarol in the rat testis (chapter 10,11 ). The spermatic arteries of the rat originated, in most of the animals Investlgated for this purpose, directly from the arta and had no branches to be cannulated. Investigation of several stralns of rats (Sprague-Dawley, Wistar, Wistar-Kyoto and Brown-Norway) indicated that this phenomenon should be regarded as the normal rat anatomy.

The following procedure was developed for intratesticular drug administration. Under light ether anesthesia, the lower part of the abdomen was opened by a midline inciston of about $2 \mathrm{~cm}$ and the left thests retracted into the abdomen. A sllastic tube (internal diameter $0.6 \mathrm{~mm})$, filled with the infusion solution, was placed directly into the cestis and flxed with a suture. The testis including the catheter was pushed back gently into the scrotum and the abdomen was closed. 


\subsection{SUBSTANCES USED FOR PHARMACOKINETIC ANALYSIS}

In all studies but one, the infused substances were chosen not because of their specific effects but because of their pharmacokinetic behavior in a given mode1. The pharmacokinetics of these substances: indocyanine green, propranolol, ${ }^{25}$ Iodine labeled hippuric acid $\left({ }^{125}\right.$ IHA) and ${ }^{51}$ Chromium labeled EDTA $\left({ }^{51} \mathrm{Cr}\right.$ EDTA), will be described briefly below. The fifth, S-acenocoumarol, will be described in more detail, because local administration of $\mathrm{s}$-acenocoumarol in the test was used to evaluate not only the kinetic advantages but also to study the effects of intratesticular administration of this drug.

\subsubsection{Indocyanine green}

Indocyanine green (ICG, cardiogreen, Fox Green) is a synthetic dye developed for use in color emulsion. Later, it has been used as an indicator in dye dilution techniques for the measurement of cardiac output (Fox et a1, 1957).

It is excreted unchanged and almost completely in blle although recent 1iterature reports suggest the formation of a metabolite without any sign of enterohepatic circulation. ICG is also used to evaluate hepatic function and hepatic blood flow in man and experimental animals (Cherrick et a1, 1960; Wiegand et al, 1960; Caesar et a1, 1961 ; Leevy et a1, 1962).

\section{Assay}

ICG is analyzed in plasma by spectrophotonetry at 800 nm using pool plasma as reference. In recent studies (Rappaport and Thlessen, 1982; Thiessen et a1, 1984), a more speciflc HPLC method was reported, yielding different ICG plasma concentrations in a rabbit following an intravenous dose of about $100 \mathrm{mg}$, pointing to an unidentifled ICG metabolite or an Impurity of the commercially avallable product (Heintz et a1, 1986). The suggested metabolite has not been found in humans (Svensson et a.1, 1982).

\subsubsection{Propranolo1}

Propranolol was used in 3 studles (chapter 4,7 , and 8 ). It was 
chosen because of lts high hepatic clearance $(14-28 \mathrm{ml} / \mathrm{min})$ in the rat. According to the physiologic pharmacoklnetic approach, the clearance of propranolol should be flow-dependent (chapter 1). Assuming a linear kinetic pattern local administration of such a high hepatic clearance drug should result in a relatively high systemic advantage In the rat cardlac graft (chapter 8 ), while the regional and systemic advantages of intrarenal over systemic administration of propranolol should be minimal (chapter 7 ).

\section{Analytical procedure}

Following the addition of metoprolol for internal standardization, samples (plasma or heart homogenates) were prepared for analysis by HPLC. For measurement of propranolol in cardiac tissue, the wet heart tissue was homogentzed in 4 times $1 t s$ volume $(w / v)$ saline. Propranolol was extracted by $1.5 \%$ pentanol in hexane, after alkalization with NaOH (10 N). Propranolol was re-extracted from the organic phase by 150 ul of $0.01 \mathrm{~N} \mathrm{H}_{2} \mathrm{SO}_{4}$. An aliquot of the acld phase was analyzed by HPLC.

For ${ }^{3} \mathrm{H}$ labeled propranolol, the radloactivity in the acid phase of the organic solvent extract was measured. HPLC analysis established that all of that radioactivity could be attributed to propranolol. Propranolol was measured in a scintillation counter after the addition of a commercial scintiliation solution, correcting for quenching by internal standardization with ${ }^{3} \mathrm{H}$ toluene.

\subsubsection{Cr EDTA and lodohtppurate}

Both substances are often used to evaluate renal hemodynamics (Smart et a1, 1981; Wanner et a1, 1981). ${ }^{51} \mathrm{Cr}$ EDTA is elliminated by the kidney vila glomerular filtration and ${ }^{125}$ IHA via glomerular f11tration and active tubular secretion (Cho and Cafreeny, 1970; Brenner et $a 1,1972$ ).

Assay and urine concentrations of both substances (chapter 6) were determined in a LKB Wallace Universal gamma-counter with overlap correction. 


\section{ACENOCOUMAROL}

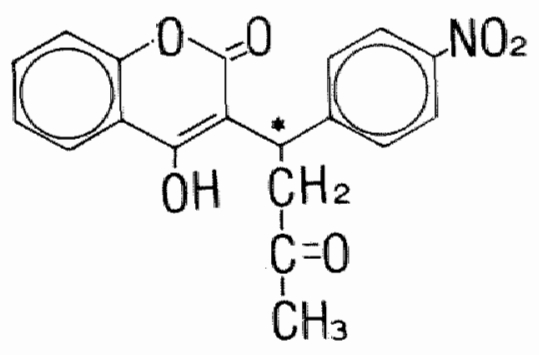

\section{* centre of asymmetry}

Fig. 2.4: Structure formula of acenocoumarol.

\subsubsection{Acenocoumarol}

Acenocoumarol is a 4-hydoxycoumarin derivative, which, 1ike warfarfn and phenprocoumon, is clinically in use as an oral anticoagulant. The compound is in use as a racemate (fig. 2.4). The pharmacokinetics of racemic acenocoumarol in the rat were recently investigated by Th1jssen et al (1983a). The drug has a short duration of action. Following a single dose of $2 \mathrm{mg} / \mathrm{kg}$ subcutaneously in consclous male Wistar rats, prothrombin time, an indicator of plasma coagulation activity, returns to normal within $24 \mathrm{hr}$. Its apparent half-1ife time of elimination $\mathrm{In}$ the rat is about 3-4 hr. Elimination $1 \mathrm{~s}$ malnly via hepatic metabolism, i.e. hydroxylation of the coumarin part of the molecule with subsequent conjugation. There tis stereoselectivity of the pharmacokinetics and pharmacodynamics of acenocoumarol in the rat (Thifssen et al, 1985) as well as in man (Godbillon et a1, 1981).

Following the subcutaneous infusion of $1 \mathrm{mg} / \mathrm{kg}$ of $\mathrm{s}(-)$-acenocoumarol (AC) in conscious male Wistar rats, the elimination rate of AC was found to be $740 \mathrm{ml} / \mathrm{hr} / \mathrm{kg}$ (Thijssen et a1, 1985). The blologlcal half-1ife time was about half an hour. $R(+)$-acenocounarol was found to have an elimination rate of $183 \mathrm{ml} / \mathrm{hr} / \mathrm{kg}$ and a half-life time of 
elimination of about $90 \mathrm{~min}$. Plasma proteln binding of $\mathrm{s}(-)$-acenocoumarol was high: $98.5 \%$, which differed only slightly from the plasma protein bladlag of the $R(+)$-enantiomer.

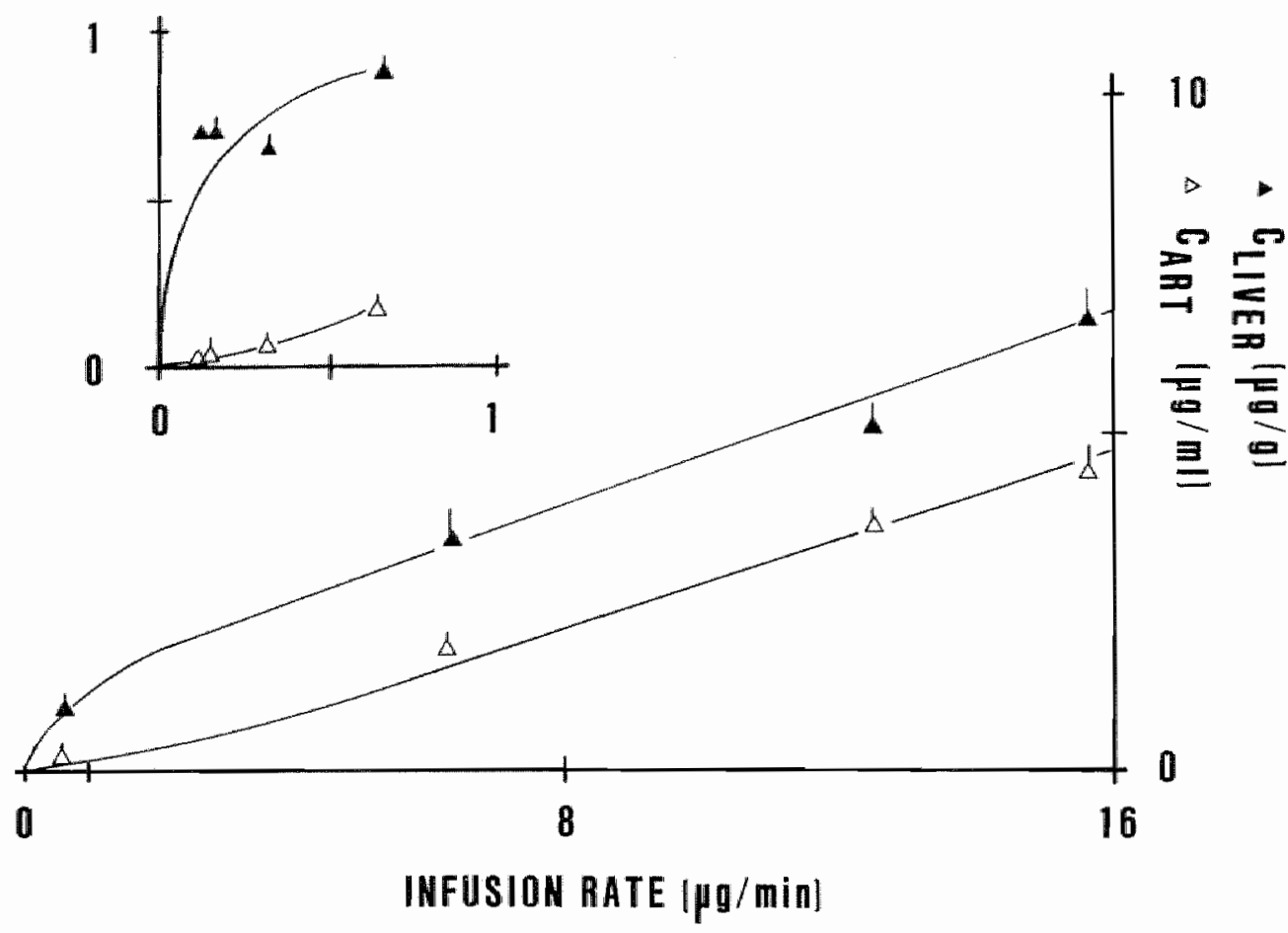

Flg. 2.5: The S-acenocoumarol concentration In blood and 11 ver as a function of the infusion rate $(0-15 \mathrm{ug} / \mathrm{m} i \mathrm{n})$

There is an extensive liver uptake of acenocoumarol and an apparent dose-dependent hepatic clearance (Thifssen et a1, 1983a, 1985; Daemen et al, 1986a) (fig. 2.5; table 2.1). The elimination from the 1iver is slower than from the circulation (fig. 2.6). From experiments invest1gatilag $S(-)$-acenocounarol 11 ver distribution in pentobarbital-anesthetized rats during constant rate infusion, we found a saturable hepatic binding site $\left(K_{D}=6.7 \mathrm{nM} ; B_{\max }=3\right.$ nmole/g. 11ver tissue) for $s(-)$-acenocoumarol which might account for its apparent dose-dependent clearance (fig. 2.7 and Daemen et al, 1986a; see also Appendix I). 


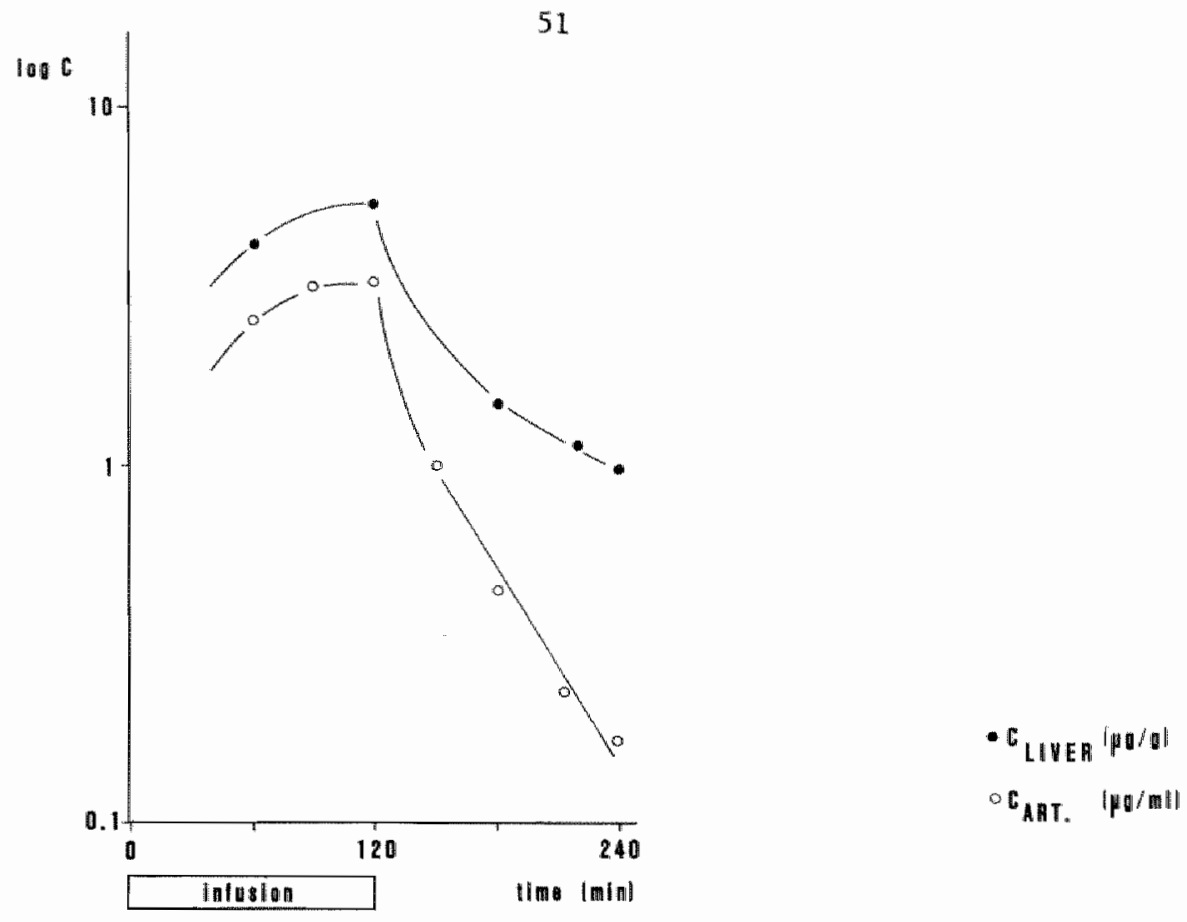

Fig. 2.6: The S-acenocoumarol concentration in the arterial blood flow (o) and liver (•) of an individual rat as a function of time. S-acenocoumarol was administered by constant rate infusion $(12.5 \mathrm{ug} / \mathrm{min})$ over $120 \mathrm{~min}$.

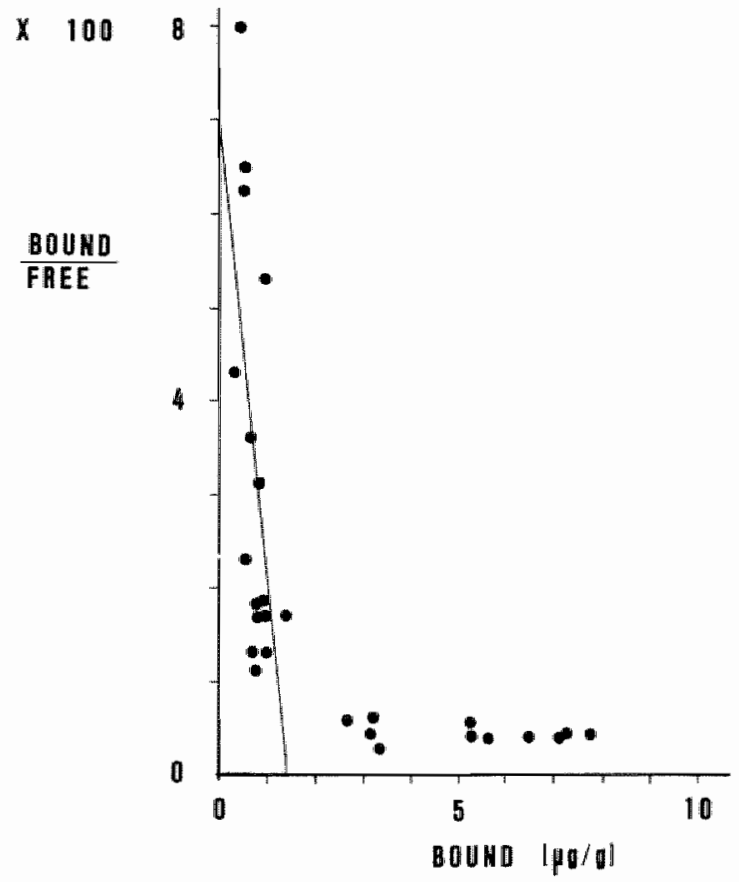

Fig. 2.7: Scatchard analysis of S-acenocoumarol binding in the 11ver tissue. The liver concentration was assumed to be equal to the plasma concentration. The line is derlved from a leastsquares fit of the data below $1.5 \mathrm{ug} / \mathrm{g}$ liver. 


\section{Mechanism of action}

Oral anticoagulants of the coumarin type interrupt the cellular vitamin $k$ cycle by blocking the witamin $k$ epoxide reductase (Suttie et a1, 1974; Vermeer et a1, $1984 \mathrm{a} ; \mathrm{fig.} 2.8$ ). In the 11 wer cell, the hydroquinone of vitamin $K$ is a necessary cofactor for a carboxylase which converts clotting factor protelns to their calcium binding form and leaves the cofactor as witamin $K$ epoxide. Vitamin $K$ epoxide is then reduced by vitamin $K$ epoxide reductase to vitamin $K$ and vitamin $K$ 1 further reduced to 1 ts hydroquinone by other reductases. In the $11-$ ver, vitamin $K$ dependent carboxylase are involved $\mathbb{i n}$ the synthesis of

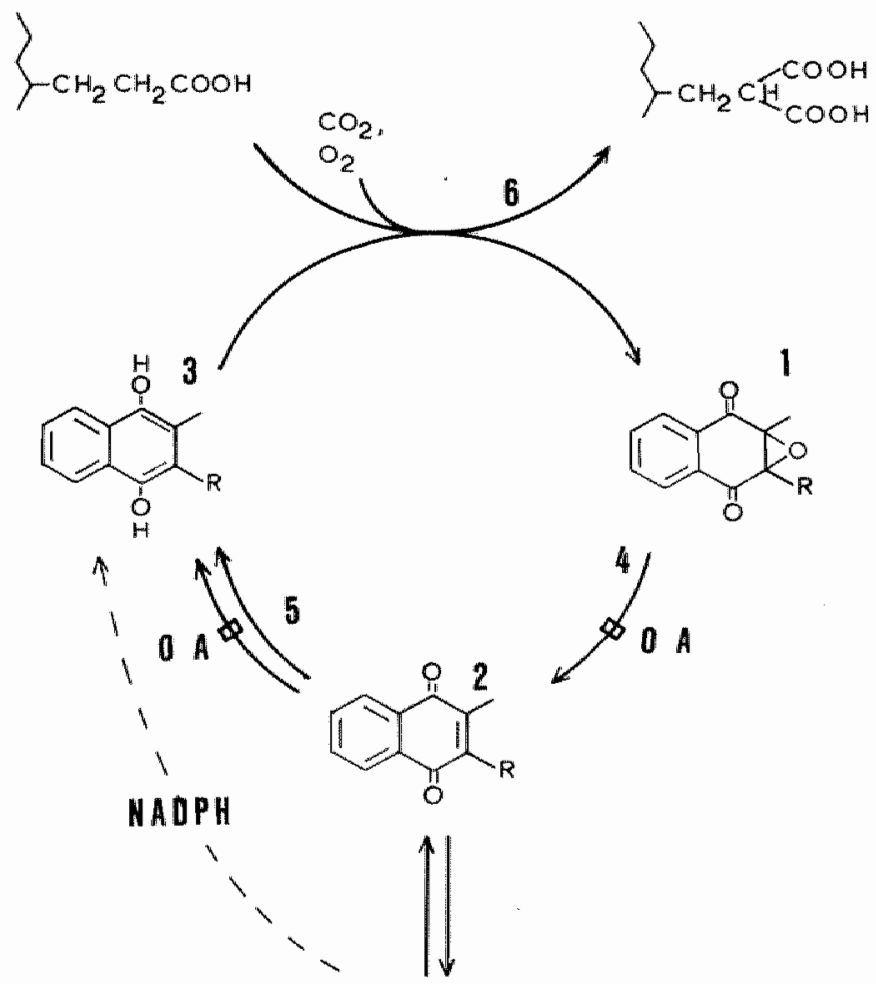

\section{ax日ongous}

\section{VITAMIN K CYCLE}

Fig. 2.8: Vitamin $K$ cycle. $O A=$ oral anticoagulants.

l:vitamin $\mathrm{K}$ epoxide; 2 : vitamin $\mathrm{K}$; 3 : vitamin $\mathrm{K}$ hydroquinon; 4: vitamin $K$ epoxide reductase; 5 : vitamin $K$ reductase(s); 6: carboxylase 
Table 2.1: The steady-state blood and liver $5(-)$-acenocoumarol concentration and the estimated blood clearance in relation to the infuston rate (mean $\pm S E M$ ).

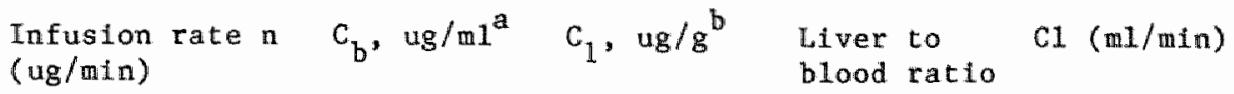

$\begin{array}{llllll}0.12 & 2 & 0.019 & 0.70 & 36.8 & 6.3 \\ 0.15 & 3 & 0.023 \pm 0.002 & 0.70 \pm 0.06 & 30.4 \pm 3.0 & 6.5 \pm 0.6 \\ 0.31 & 4 & 0.068+0.07 & 0.64 \pm 0.06 & 9.4 \pm 1,1 & 4.5+0.4 \\ 0.625 & 8 & 0.161+0.01 & 0.87 \pm 0.09 & 5.4 \pm 0.6 & 3.9 \pm 0.3 \\ 6.25 & 3 & 1.8 \pm 0.44 & 3.63 \pm 0.7 & 2.0 \pm 0.4 & 3.5+0.9 \\ 12.5 & 3 & 3.5 \pm 0.12 & 4.9 \pm 0.6 & 1.4 \pm 0.6 & 3.6+0.12 \\ 15.0 & 3 & 4.7 \pm 0.13 & 6.6 \pm 0.3 & 1.4 \pm 0.1 & 3.2+0.1\end{array}$

${ }^{a} C_{b}$ is the blood concentration

${ }^{b} c_{j}^{b}$ is the liver concentration

${ }^{c} \mathrm{Cl}$ is the blood clearance

Source: Daemen et al, J Pharm Sci 75: 238-240, 1986.

the coagulation factors II, VII, IX and X (Stenflo et a1, 1974). Vitamin $K$ dependent carboxylase activity is also shown to be present in several non-hepatic tissues, such as the spleen, arterlal vessel. wa11, osteoblast cells, kidney and testid (Vermeer et a1, 1982). Vitamin $K$ epoxide reductase is shown to be present in non-hepatic tissues as kidney and testis (Thijssen et al, 1986), whlle gamma carboxy glutamic acid residues containing protelns are found in bone (asteocalcine) and human spern (Vermeer, 1984b). The functions of these proteins and/or the extrahepatic physlological vitamin $K$ dependent systems are not clear yet.

\section{Analytical procedures}

Acenocoumarol concentrations in biological tissues were analyzed by HPLC as described by Thifssen et al (1983b). 


\subsection{METHODS FOR THE MEASUREMENT OF BLOOD FLOW IN LARGE VESSELS}

As stated before, knowledge of the mount of blood flow to the target organ is essential in order to evaluate the potentlal benefits of target organ directed drug administration.

There are several methods for the measurement of the blood flow to an organ. These can be divided into two groups: direct and indirect methods (table 2.2; Ohnhaus, 1979).

In our experiments target organ blood flow was measured by electromagnetic flowneters because this method enables continuous measurement of blood flow. The method has long-term stability and does not require frequent calibration. Blood flow of one or more vessels can be measured selectively (Charbon and Wan der Mark, 1981).

In chapter 3 and 4 , the sultability of the ICG clearance method to determine liver blood flow in the anesthetized rat is evaluated and compared with the electronagnetic assessment of liver blood flow.

Table 2.2: Flow measurements in large blood vessels

A. Direct methods

- Doppler technique

- Electromagnetlc technique

- Heat exchange method

- Drop counts

B. Indrect methods

- clearance/dilution method (e.g. Indocyanine green, bromosulphthaletin blue)

- Inert gas washout technique $\left(\mathrm{H}_{2}, \mathrm{~N}_{2}\right)$

- Eractional distribution method (microspheres) 


\subsection{PHARMACOKIMETIC ANALYSIS}

A11 phamacokinetic studies were performed at steady-state conditions, using constant rate infusions over prolonged time. Under those conditions, the following equations hold.

Systemic plasma clearance at steady state $\left(\mathrm{Cl}_{S} ; \mathrm{mL} / \mathrm{min}\right)$ was calculated by

$$
\ln \mathbb{f} / \mathrm{C}_{\mathrm{S}}
$$

where inf represents the infusion rate (ug/min) and $C_{S}$ the systemic arterial plasma or blood concentration at steady state (ug/mi). The concentration in the artery supplying the target organ at intravenous drug administration $\left(\mathrm{C}_{\mathrm{Tiv}}\right)$ equalled the systeric concentration $\left(\mathrm{C}_{\mathrm{S} \perp \mathrm{v}}\right)$. The concentration in the artery supplying the target organ, at target organ directed drug administration $\left(\mathrm{C}_{\mathrm{Tla}} ; \mathrm{ug} / \mathrm{ml}\right)$ was calculated by

$$
\mathrm{C}_{\mathrm{Tia}}=\mathrm{C}_{\mathrm{Sia}}+\inf / \mathrm{Q}_{\mathrm{T}}
$$

where $\mathrm{C}_{\mathrm{Sia}}$ (ug/ml) represents the steady-state systemic blood (plasma) concentration at intra-arterial drug administration and $Q_{T}$ the blood flow through the target organ $(\mathrm{ml} / \mathrm{m} / \mathrm{n})$. The clearance of the target organ during target directed drug administration $\left(\mathrm{Cl}_{\mathrm{T}} ; \mathrm{ml} / \mathrm{min}\right)$ was defined by

$$
\mathrm{C} 1_{\mathrm{T}}=\inf / \mathrm{C}_{\mathrm{pla}}
$$

During the intrarenal administration of substances, the remal clearance $\left(\mathrm{Cl}^{\prime} \mathrm{ml} / \mathrm{min}\right)$ was defined by

$$
C \mathbb{1}=\mathbb{U} / \mathrm{C}_{\mathrm{T}}
$$

where $U$ equals the amount of $d r u g$ excreted in the urine (counts/min). C1 during systemic drug adrinistration was defined by

$$
\mathrm{c} 1=\mathrm{U} / \mathrm{C}_{\mathrm{S}}
$$


The extraction ratio of the kidney (E) was calculated by

$$
\mathrm{E}=\mathrm{Cl} / \mathrm{Q} \text {. }
$$

As before (chapter 1 and Appendix I), the systemic advantage of local drug administration was defined by the formula

$$
\mathrm{C}_{\mathrm{Sia}} / \mathrm{C}_{\mathrm{SIV}}=1-\mathrm{E}_{\mathrm{T}}
$$

and the reglonal advantage by the formula

$$
C_{\mathrm{THa}} / \mathrm{C}_{\mathrm{TIV}}=1+C 1_{\mathrm{S}} / \mathrm{Q}_{\mathrm{T}}
$$


3. MEASUREMENT OF LIVER BLOOD FLOW IN THE RAT: THE EFFECT OF PENTOBARBITAL ANESTHESIA AND HYPOTHERMIA ON THE HEPATIC CLEARANCE OF INDOCYANINE GREEN

\subsection{INTRODUCTION}

For evaluation of the advantages of intrahepatic over systemlc drug admintstration in the rat, the total liver blood flow has to be determined. The Indocyanine green clearance method is often used for this purpose (Ohnhaus, 1979; Yates et al, 1983). In pharmacokinet1c experiments the use of anesthesta is frequently necessary. This study was performed to investigate the effects of anesthesia on the ICG clearance in the rat.

Anesthesla can influence organ flow as well as intrinsic clearance. It is known to depress the autonomic nerwous reflex system involved in blood pressure regulation (Cox and Bagshaw, 1979) and It may cause hypothermia (Birnie and Grayson, 1952), which might decrease processes (metabolism, active transport) of drug distribution and of drug elimination (McAllister et al, 1978, 1979; Spurr and Dwyer, 1972). Also a direct inhibitory interaction of the anesthetic with the drug metabolizing system might occur (Vermeulen et al, 1983). An indication of the pitfalls of estimating physlological parameters during anesthesla may be found in the deviating data on hepatic blood flow in rats as estimated by the indocyanine green (ICG) clearance method. Values between $0.9-1.5 \mathrm{ml} / \mathrm{min} / \mathrm{g}$ liver are reported for anesthetized as well as for consclous rats (Yokota et a1, 1976). To evaluate the influence of anesthesia in the rat, we have invest 1 gated the effect of pentobarbital anesthesia alone and together with the changes in body temperature, on the hepatic clearance of ICG.

\subsection{EXPERIMENTAL SECTION}

In this study, male inbred Wistar Kyoto rats, 280-330 g, were used. Two days before the experfment, under light ether anesthesla, rats were cannulated $(\mathrm{PE}-10)$ in the left femoral artery for blood 
sampling, in the left femoral vein for drug infusion, and in the right femoral veln for the intravenous administration of pentobarbital. The catheters were exteriorlzed in the neck and were flushed with heparin In $\mathbb{1}$ sotonic saline $(5 \mathrm{v} / \mathrm{ml})$.

\subsubsection{Infuston and sampling protocol}

ICG infusion was started in the conscious anlmal at a constant rate of $25 \mathrm{ug} / \mathrm{min}$. Two blood samples (100 u1) were obtalned at 60 and $75 \mathrm{~min}$. Pilot experiments showed these times sufficient to reach steady-state conditions. While maintaining infusion of ICG, pentobarbital anesthesia was induced by a bolus injection of $0.2 \mathrm{ml}$ pentobarbital solution ( $60 \mathrm{mg} / \mathrm{ml}$ ) intravenously and malntalned by administration of $0.1 \mathrm{ml}$ every $60 \mathrm{~m} / \mathrm{n}$. After animals had lost consclousness, their body temperature (measured rectally) was maintalned at $37.5^{\circ} \mathrm{C}$ by a heat lamp and a regulator. Two blood samples were obtained following the time schedule as before.

A separate group of rats was anesthetized with pentobarbital and the body temperature maintafned at $37.5^{\circ} \mathrm{C}$ (as above). Infuston of ICG was started and arterial blood was sampled twilce at steady state (see time schedule above). During infusion, the body temperature was either increased to $39.5^{\circ} \mathrm{C}$ by additional heat or cooled to $32.5^{\circ} \mathrm{C}$ by stopping the heat and when steady state had been attained, blood samples were obtalned according to the prevlous time schedule. ICG plasta concentrations were determined as described in chapter 2.3 .

\subsubsection{Statistical analysis}

All data are presented as mean $\pm S E M$. DIfferences between the groups were determined by Student's t-tests. Differences were considered to be statistically signiflcant if $p<0.05$.

3.3. RESULTS

Plasma concentrations of ICG in the conscious state and under pentobarbital anesthesia were $5.2 \pm 0.7$ and $9.6 \pm 0.8 \mathrm{ug} / \mathrm{m} 1$ (mean $\pm \mathrm{SEM}$, $\mathrm{n}=8$ ). The estimated blood clearances are in table 3.1. 
Table 3.1: The effect of pentobarbital anesthesia and temperature on the blood clearance of indocyanine green (mean $\pm S E M, n=8$ ).

Experimental condtion

Blood clearance $(\mathrm{ml} / \mathrm{min})$

Consclous

$8.0+1.7$

Anes thesia

$4.9+0.6^{\mathrm{a}}$

Body temperature

$$
37.5^{\circ} \mathrm{C}
$$

Anesthesia $39.5^{\circ} \mathrm{C}$

$32.5^{\circ} \mathrm{C}$

$5.7+0.8$

$5.6 \overline{+0.7}$

$0.9+0.16$

a $p<0.01$ vs conscious
b $<0.001$ vs. $37.5^{\circ} \mathrm{C}$

Anesthesia decreased the mean ICG clearance to about $45 \%$. No difference in ICG clearance was observed during hyperthermia as compared to normothermia $(5.6+0.7$ vs. $5.7+0.8 \mathrm{~m} 1 / \mathrm{min})$. In hypothermia, the clearance of ICG dropped dramatically to $0.9 \mathrm{ml} / \mathrm{min}$ which was only $16 \%$ of the normothermic value. The time effect of anesthesia on the clearance of ICG was investigated with rats in the normothermic state $\left(37.5^{\circ} \mathrm{C}\right)$. No changes in clearances over the infusion period were observed (fig. $3 \cdot 1)$.

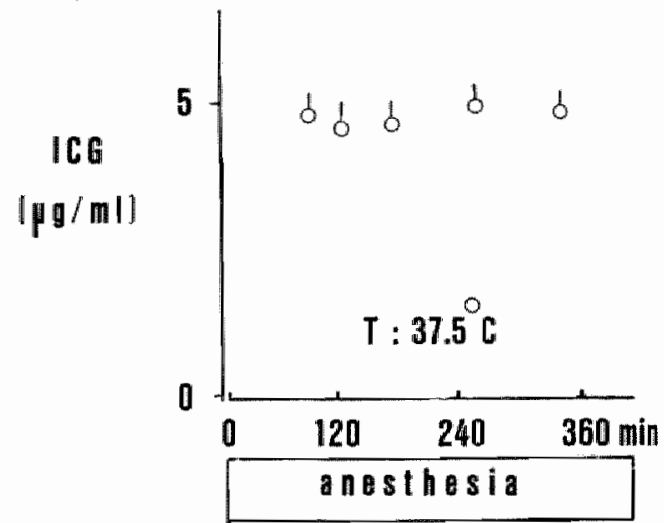

Fig. 3.1: Arterial blood concentration (ug/ml) of findocyanine green (ICG; mean + SEM; $n=4$ ) following continuous systemic infusion of $25 \overline{\mathrm{ug}} / \mathrm{min}$ for $360 \mathrm{~min}$ during anesthesta, while body temperature was kept at $37.5^{\circ} \mathrm{C}$. 


\subsection{DISCUSSION}

The primary purpose of these experiments was to investigate the effect of anesthesta and the effect of hypothermil induced by it on the hepatic clearance of ICG. In the 11terature, few authors discuss the effect of anesthesia on drug disposition explicitly. Recentiy. vermeulen et al (1983) showed that ather anesthesla almost halved hexobarbital clearance in rats. Yokota et al (1976) observed the depressant effect of pentobarbital on ICG clearance in rats and considered hypothermia as a possible cause.

We found that pentobarbital anesthesla depressed the clearance of ICG despite that the body temperature was maintalned at $37.5^{\circ} \mathrm{C}$. The hypothermla related to anesthesia further reduced the body clearance to one tenth of the conscious values.

Though it is generally assumed that the ICG clearance is Itver flow dependent (Caesar et al, 1961; Leevy et a1, 1962), our results clearly indicate that the effect of anesthesia and hypothermia on ICG clearance do not reflect changes in litver blood flow. The observed clearance $t \mathrm{n}$ the consclous rat (about $24 \mathrm{ml} / \mathrm{min} / \mathrm{kg}$ ) is low compared wh 11ver blood flow (about $80 \mathrm{ml} / \mathrm{min} / \mathrm{kg}$; Ohnhaus, 1979). This 1 ndicates that the extraction ratio for ICG is only 0.3 which suggests a low rather than a high clearance drug. Hence the effect of pentobarbital anesthesla $1 \mathrm{~s}$ to depress the intrinsic capacity of the 11ver to extract ICG from it.

Saturation of ICG elimination during the experimental condition. could be a reason for the low hepatilc clearance of the substance. It Is wel1 known that ICG elimination 1 is dose-dependent and it has been shown that ICG plasma concentrations above $10 \mathrm{ug} / \mathrm{ml}$ progressively tend to decrease Its clearance (McDevitt et al, 1977; Stoeckel et al, 1980). However, in our experiments steady-state ICG plasma concentratlons consclous rats were about $5 \mathrm{ug} / \mathrm{ml}$ and in the anesthetized rats 8 ug/ml, thus maktng saturation klnetics a less likely explanation. Yokota et al (1976), using the continuous infusion technique, reported a value of $18 \mathrm{ml} / \mathrm{m} 1 \mathrm{n} / \mathrm{kg}$ for the ICG clearance in the conscious rat and this is comparable with our results. Because of the low extraction (about 0.3) of ICG and its low clearance it is not justified to inter- 
pret ICG clearance in the anesthetized rat using the continous infusion technique in terms of liver flow.

In summary, our data demonstrate clearly that anesthesla and in association with it hypothermia strongly depresses the intrinsic capacity of the liver to extract ICG from the circulation. To estimate pharmacokinetic constants, the use of consclous animals is to be preferred. If the use of anesthesta is necessary, a precise control of the body temperature during anesthesla is essential. 
4. LIVER BLOOD FLOW MEASUREMENT IN THE RAT: THE ELECTROMAGNETIC VS. THE CLEARANCE METHOD

\subsection{INTRODUCTION}

Knowledge of the absolute liver blood flow is important in the expertmental evaluation of the effects of drugs and hormones on the hepatic arterlal and portal venous inflow (Schenk et a1, 1962) as well as in a physlological pharmacokinetic approach to hepatic drug clearance (W11k1nson and Shand, 1975 and chapter 1). Several methods are avallable to determine liver blood flow in small experimental animals like rats (Ohnhaus, 1979).

The clearance of ICG is widely applled to estimate hepatic blood flow in man and experimental animals (Bradley et al, 1945; Rowell et al, 1964; Yates et a1, 1983; Shepherd et a1, 1985; Arends et a1, 1986). The use of the ICG clearance technique is based on the assumption that the substance has a high hepatic extraction ratio and that, according to the physiological pharmacokinetic approach (wilkinson and Shand, 1975), the clearance of high hepatic clearance substances (extraction ratio $>0.7$ ) reflects liver flow. Therefore, measurement of the ICG clearance should give insight into the amount of hepatic blood flow, while clearance changes should reflect hepatic blood flow rather than changes in hepatic extraction.

However, conflicting data on the ICG extraction ratlo are given in literature. In man, an extraction ratlo of $0.6-0.8$ is described (Wiegand et al, 1960; Leevy et al, 1962), while it is suggested to be even lower in rats (Daemen et a1, 1986b), and cats (Krarup and Larson, 1976): 0.30 and 0.25 , respectively. In rabbits and rats, a dose-dependent hepatic clearance has been reported (Stoeckel et a1, 1980). Therefore, 1 t is questionable whether changes $\mathbb{i n}$ ICG clearance really reflect changes in liver blood flow rather than changes in hepatic extraction (Groszmann, 1983 ).

The purpose of this study was to evaluate the value of the ICG clearance method as an indicator of rat hepatic blood flow by comparing the clearance of ICG and of another high hepatic clearance substance, d-propranolol, with the electromagnetic measurement of the 
total hepatic blood flow. For this latter purpose, electronagnetic flowmeters were placed on the portal vein, a technique described previously by Jenkins et al (1984, 1985) and on the hepatic artery of the same animal. To verify the electromagnetic method, the effects of adenosine, a vasodilator, phenylephrine, a vasoconstrictor, and a volume loading on hepatic blood flow were determined.

\subsection{EXPERIMENTAL SECTION}

Male Wistar rats, weighing $300-350 \mathrm{~g}$, were obtained from Winke1man, Borchen, West-Germany. Before the experiment, the animals were on standard lab food and tap water.

\subsubsection{Surgery}

Anesthesla was introduced by a bolus injection of pentobarbltal intraperitoneally $(60 \mathrm{mg} / \mathrm{kg})$. To maintain the anesthetic state, a poly-ethylene $(\mathrm{PE}-10)$ catheter was placed in the right femoral vein for constant rate infusion of pentobarbital in isotonic saline (150 $\mathrm{ug} / \mathrm{min})$. The infusion volume was set at $50 \mathrm{ul} / \mathrm{min}$ to prevent dehydration (Maddox et a1, 1977). Two PE-10 catheters were introduced in the left femoral vein for drug infusion and one in the right femoral artery for blood pressure/heart rate recording and blood sampling. The trachea was cannulated to provide a patent airway. Temperature was measured rectally and maintained at $37.5^{\circ} \mathrm{C}$ by a thermostatically controlled heat lamp.

\subsubsection{Electromagnetic measurement of hepatic blood flow}

After opening the abdominal cavity via a mid-abdominal incision, the intestines were kept in gauzes wetted with isotonic saline. The bursa omentalis was opened and the hepatic artery localized (f1g. 4.1A). The gastroduodenal artery was 11 gated with a sllk tie (6-0). The comon hepatic artery was freed from connective tissue and two silk ties $(6-0)$ were passed under the vessel. An electromagnetlc flow probe (internal diameter $0.5 \mathrm{~mm}$, Skalar, Delft, The Netherlands) was placed around the common hepatic artery. Zero balancting was performed 


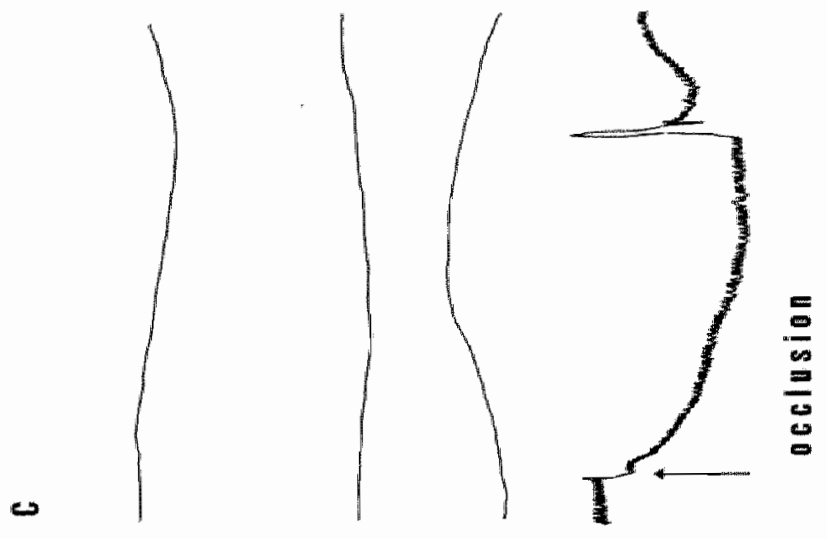

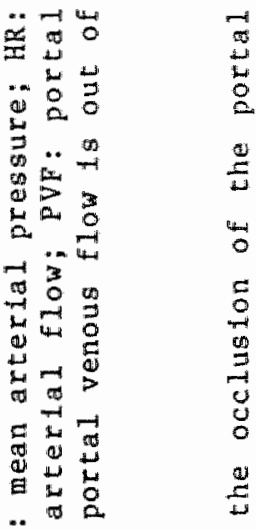

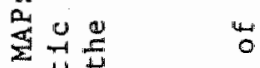

*

II

स...

$\begin{array}{lll}0 & 0\end{array}$

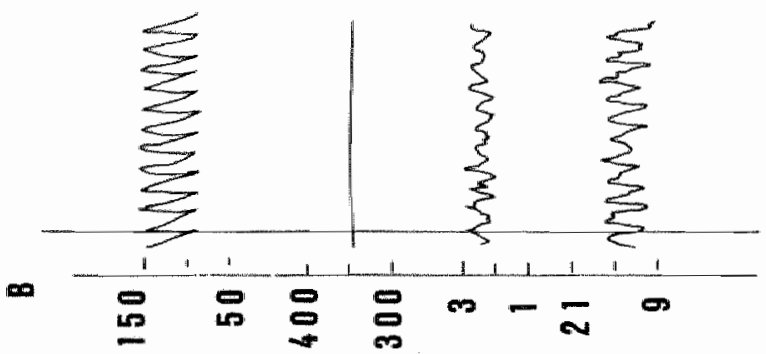

is

का 3 का का

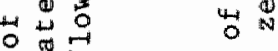

0 is

to

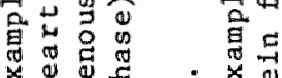

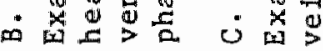
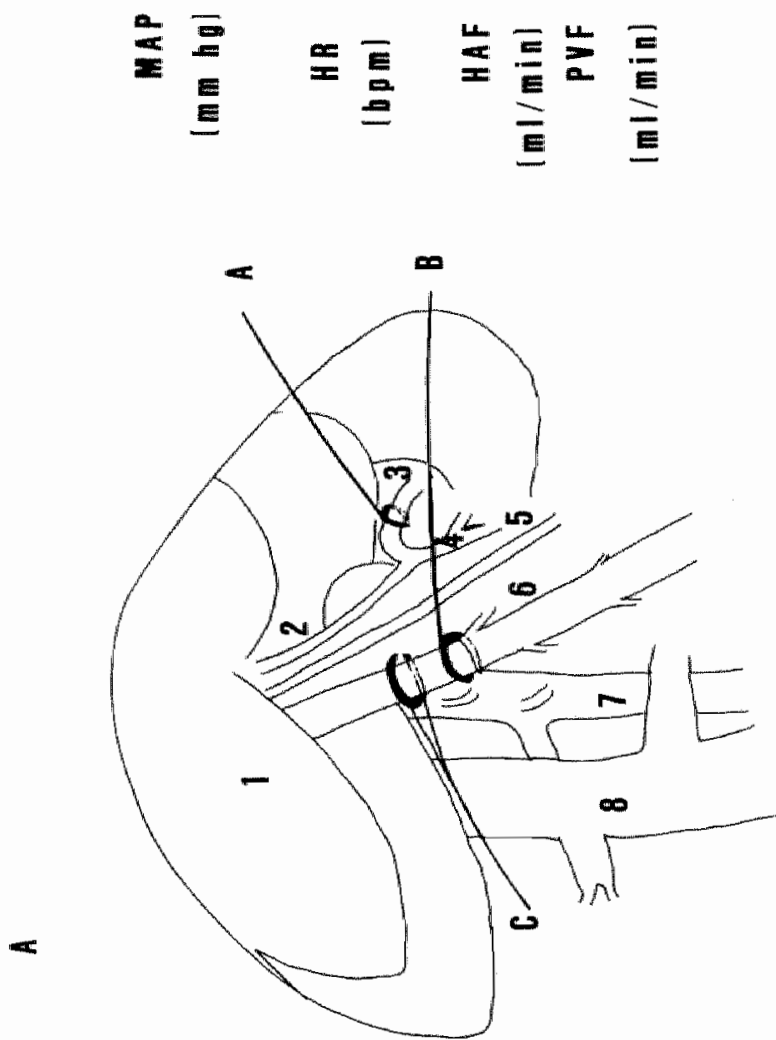

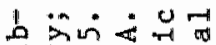
स 4 i 4 出的芒范

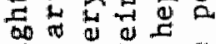
$\rightarrow 0$ 出 $>$

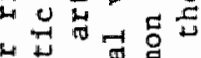
a $\rightarrow 3$ 貝 윽외 웡 웡 ( \& 90

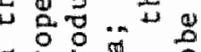
E 的出点 E⿰冫 L... 告

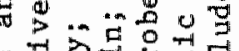
(1) त्म क्ष

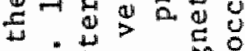
$4-1$ m

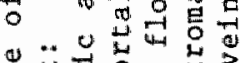

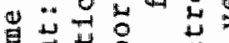

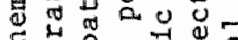
I 40.

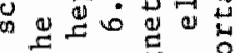

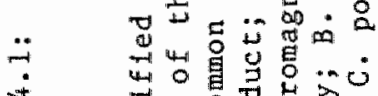

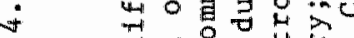

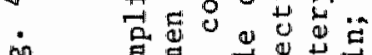
品 
by accluding the vessel via the distally placed tie.

The proximal part of the portal vein was also freed from surrounding tissue. A special mechanic vessel occluder (Skalar, Delft, The Netherlands), which could be remotely controlled, was placed around the portal vein. A second EM flow probe (1nternal diameter 1. 8 $\mathrm{mm}$ ) was placed around the portal vein proximally from the occluder. Zero balancing was here performed by closing the occluder. During the whole procedure care was taken to avold any damage to the bile duct. The intestines were then replaced in the abdomen.

The flow signals (fig. 4.1B) were measured with a sine-wave flowneter (type MDL 400, Skalar, Delft, The Netherlands). Flow as well as blood pressure and heart rate signals were recorded on a schwarzer polygraph.

\subsubsection{Infusion protocol}

After the hepatic blood flow had equilibrated, phenylephrine or adenosine was given intravenously. Adenosine (Sigma, St. Louis, Mo, USA) in isotonic saline $(4.0 \mathrm{mg} / \mathrm{ml})$ was given by a constant rate infustion of 20, 40, and $100 \mathrm{ug} / \mathrm{min}$. Phenylephrine (Sigma, St. luouis, Mo, USA) in isotonic saline $(0.4 \mathrm{mg} / \mathrm{m} 1)$ was given by a constant rate infusion of 2, 4, and $10 \mathrm{ug} / \mathrm{min}$. Both drugs were delivered at random in the same animals. The infusion rates for each drug were increased stepwise and lasted 5 min per infusion rate. Steady-state changes in the measured parameters were used for calculation.

Fifteen ml isotonlc saline $\left(37.5^{\circ} \mathrm{C}\right)$ was infused intravenously in 3 min to study the effect of a rapid volume loading on hepatic blood flow in a second group of animals. Changes in blood pressure and heart rate were measured durlng the maxtmal changes in portal venous and hepatic arterial blood flow.

In another series of animals, Indocyanine green (Brocacef, Heerlen, The Netherlands, $5 \mathrm{mg} / \mathrm{ml}$ ) and d-propranolol in isotonfc saline $(0.2 \mathrm{mg} / \mathrm{ml})$ were given simultaneously at a constant rate of 25 and 1 ug/min, respectively. A bolus of 100 ug (50 ul) of d-propranolol was given at the start of the infusion. The d-enantiomer of propranolol does not affect hepatic blood flow (Branch et al, 1973; Rahn et al, 1974). The infusion was maintalned for 180 min. Arterlal blood samples 
(0.3 1 ) were taken at 120, 150, and $180 \mathrm{~min}$ and transferred into 30 u1 $0.1 \mathrm{M}$ citrate containing glass vessels. Preliminary experiments applying this Infusion scheme had shown that steady-state conditions were achieved after $120 \mathrm{~min}$. The mean of the values of blood pressure, heart rate, portal venous and hepatic arterial flow at the sample times were taken for calculation. Hematocrit was determined before and after each infusion period.

Analysis of ICG and propranolol was performed as described in chapter 2.3 .1 and 2.3 .2 .

\subsubsection{Statistical Analysis}

A11 data are presented as mean \pm SEM. Groups were compared using student's t-test. The 0.05 level of probabllity was used as the level of $s \operatorname{lgnificance.}$
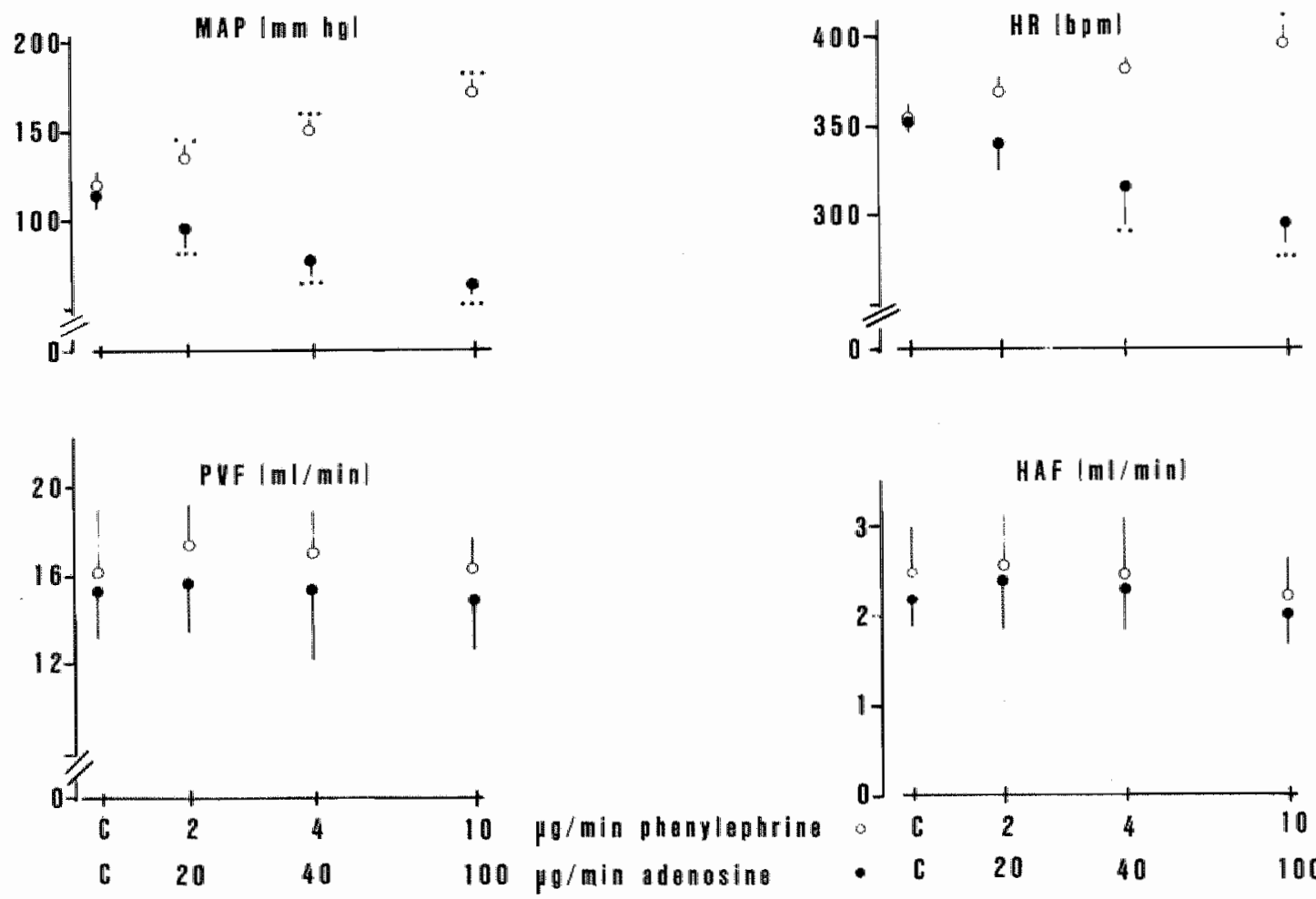

Fig. 4.2: Effects of intravenous phenylephrlne and adenasine infusion on mean arterial pressure (MAP), heart rate (HR), electromagnetically measured portal venous flow (PVF) and hepatic arterial flow (HAF). Data are presented as mean $+\mathrm{SEM} ;$ $\mathrm{n}=7-9 .{ }^{*} \mathrm{p}<0.05 ; * * \mathrm{p}<0.01 ; * * * \mathrm{p}<0.001$. 


\subsection{RESULTS}

The observed values for portal venous and hepatic arterial blood flow were very well comparable in the 3 experiments (adenosine/ phenylephrine infusion, clearance studies and volume loading). Values for portal venous flow varied from $13.5+1.3$ to $16.1+2.1 \mathrm{~m} 1 / \mathrm{min}$ and for mean hepatic arterial flow from $2.2+0.3$ to $2.5+0.6 \mathrm{ml} / \mathrm{mll},(\mathrm{n}=9)$. Hepatic arterial and portal venous flow, measured simultaneously, was found to be very stable over a period of $3 \mathrm{hr}$. An interaction between the hepatic artery and portal vein was observed in our experiments. A reduction of portal venous flow, performed by clamping this vessel for zero balancing, was compensated for by an increase of the hepatic arterial flow (fig. 4.1C). A volume loading of $15 \mathrm{ml}$ isotontc saline Increased the portal venous flow from $13.5+1.3$ to $20.8+1.9 \mathrm{ml} / \mathrm{m} 1 \mathrm{n}$ and the hepatic arterial flow from $2.5+0.2$ to $2.9+0.3 \mathrm{ml} / \mathrm{min}$ (table 4.1 ).

\subsubsection{Adenosine/phenylephrine Infustion}

The effects of intravenous adenosine and phenylephrine on mean arterial blood pressure (MAP), heart rate (HR), portal venous and hepatic arterial blood flow are depicted in flig. 4.2. Adenosine decreased blood pressure and heart rate dose-dependently: mean arterial

Table 4.1: Mean $+\operatorname{SEM}(n=7)$ of the values of all measured parametera during a volume loading of $15 \mathrm{ml}$ saline intravenously.

Control

Volume loading

$\begin{array}{llcc}\text { Blood pressure } & (\mathrm{mmHg}) & 125+6 & 124+9 \\ \text { Heart rate } & (\text { beats/min) } & 384+6 & 384+6 \\ \begin{array}{l}\text { Portal venous } \\ \text { blood flow }\end{array} & (\mathrm{ml} / \mathrm{min}) & 13.5+1.3 & 20.8+1.9 * * * \\ \begin{array}{l}\text { Hepatic arterial } \\ \text { blood flow }\end{array} & (\mathrm{ml} / \mathrm{min}) & 2.5+0.2 & 2.9 \pm 0.3 * *\end{array}$


blood pressure decreased to about $60 \mathrm{~mm} \mathrm{Hg}$ and heart rate to approximately 300 beats/ min during the infusion of $100 \mathrm{ug} / \mathrm{min}$ of adenosine. Control values of MAP and HR were $115 \mathrm{~mm} \mathrm{Hg}$ and 356 beats/min. Neither porta 1 venous nor hepatic arterial flow changed: portal venous flow was $15.4+2.7 \mathrm{~m} 1 / \mathrm{min}$ during the control perlod and remained unchanged durlig infusion of adenosine. Mean hepatic arterial flow values were $2.2+0.3 \mathrm{ml} / \mathrm{min}$ in the control period and $2.0+0.3 \mathrm{ml} / \mathrm{min}$ at the highest infusion rate of adenosine. A dose-dependent increase in MAP and heart rate was observed during the infusion of phenylephrine (fig 4.2). Portal and hepatic arterial flows remalned unchanged.

\subsubsection{Clearance studies}

Mean arterial pressure and heart rate of the animals in this group $(\mathrm{n}=7)$ were $132+4 \mathrm{~mm} \mathrm{Hg}$ and $375+7$ beats/min. Portal venous flow was $15.0+1.4 \mathrm{ml} / \mathrm{mln}$ and mean hepatic arcerial flow $2.2+0.3 \mathrm{ml} / \mathrm{min}$. Steady-state plasma concentrations of ICG and d-propranolol were 8.0 to.7 ug/ml and $82+19 \mathrm{ng} / \mathrm{ml}$ plasma. Calculated plasma clearances were $3.3+0.4$ and $14+2 \mathrm{ml} / \mathrm{mLn}$ for ICG and d-propranolol, respectively (table 4.2). Hematocrt changes during the experiments were not observed: $0.48 \pm 0.005$ at the start and $0.49 \pm 0.006$ at the end of the experiment.

Table 4.2: Mean \pm SEM ( $n=7$ ) of the values of the measured parameters. during continuous intravenous infusion of ICG and d-propranolo1.

Blood pressure

( $\mathrm{mm} \mathrm{Hg}$ )

$1.32+4$

Heart rate

(beats/min) $\quad 375+7$

Portal venous blood flow

$(\mathrm{m} 1 / \mathrm{min})$

$15 \cdot 0+1 \cdot 4$

Hepatic arterial blood flow

$(\mathrm{m} 1 / \mathrm{min})$

$2.2+0.3$

ICG plasma concentration

$(\mathrm{ug} / \mathrm{m} 1)$

$8.0+0.7$

d-propranolol plasma concentration $(\mathrm{ng} / \mathrm{m} 1)$ $82+19$

ICG plasma clearance

(m1/min)

$3.2+0.3$

d-propranolol plasma

clearance

$(\mathrm{ml} / \mathrm{min}) \quad 14.1+2.0$




\subsection{DISCUSSION}

Direct assessment of the total hepatic blood flow has been achieved in several species, like man (Schenk et a1, 1962), dog (Nxumalo et al, 1978), cat (Greenway and Stark, 1967), and rabbit (Takeuch i et al, 1986). To date, it has not been described in the rat. In this study, simultaneous electromagnetic measurements of hepatic arterial and portal venous blood flow in the rat are reported. The measured values are very well comparable with literature data on rat liver flow measurements on the basis of indirect techniques, such as microspheres. Stkuler and Grosmann (1986) reported a value of 20 $\mathrm{ml} / \mathrm{min}$ with the microsphere method whlle a value of $15.9 \mathrm{ml} / \mathrm{min}$ for portal venous flow was found by Jenkins et a1 (1984).

A restriction of the present method is the necessity of anesthesia. The effects of anesthetic agents on the hepatic vascular bed are not well established. After pentobarbital anesthesia, hepatic blood flow was essentially the same as in unanesthetized dogs (Greenway and Stark, 1971). In the rat, pentobarbital anesthesia is known to reduce the clearance of ICG (Daemen et a1, 1986b and chapter 3). Seyde et al (1985) using the microsphere technique reported that pentobarbital anesthesia did not affect total hepatic blood flow. Simflar results were found by Lee et al (1986).

The effects of vasoactive agents, adenosine and phenylephrine, on the hepatic vascular beds were studied. The alpha-adrenoceptor agonist phenylephrine had no effect on portal venous and on hepatic arterial flow. Although hepatic and portal venous pressures were not measured, the rise in systemic mean arterial pressure without changes in flow suggests increases in the resistances of both vascular beds which is consistent with data in literature. Phenylephrine infused intravenously in dogs had similar effects: an increase in reststance but no changes in flow (Greenway and Stark, 1971). On the other hand, direct intrahepatic arterial or intraportal infusion caused a dosedependent reduction in hepatic arterlal and portal venous flow, respectively (Richardson et a1, $1977 \mathrm{a}, \mathrm{b}$ ). Intravenous administration of adenosine did not affect hepatic blood flow efther. Few investiga- 
tors report the effects of adenosine on hepatic hemodynamics. Scholtholt et a1 (1967) observed an increase in portal flow and pressure by intestinal vasodilatation in the dog, while no effects on hepatic arterlal blood flow was found. Our data indicate strong autoregulatory responses in the rat since blood pressure changes of approximately $45 \%$ had no effect on elther hepatic arterlal or portal venous flow. The signiflcance of local vasoregulation in the rat liver is not established yet. It is known to exist in the portal venous and even more in the hepatlc arterial vascular bed, but the phenomenon has not shown to be consistent in literature reports (review: cf. Richardson and Withrington, 1981). A form of intrinsic regulation of the 1iver, the so-called hydrodynamic interaction (Richardson and Withrington, 1981) between hepatic artery and portal veln, was also observed in our experiments during clamplng of the portal vein (fig. 4.1C).

The clearance of ICG was compared here with the clearance of a known high hepatic clearance drug d-propranolol and with the electromagnetic flow method to clarify the sultability of the often used Indocyanine green clearance method as an Indfcator of hepatic blood flow in the anesthetized rat. The plasma clearance of ICG was $3.3+0.4$ $\mathrm{ml} / \mathrm{min}$, which is comparable with a previous study from our laboratory. Liver plasma flow in this group, calculated by (1iver blood flow X (l-Hct)) was $9.0 \mathrm{ml} / \mathrm{min}$. The plasma extraction ratio of ICG, the quotient of plasma clearance and flow, was 0.36 . According to the physiological pharmacokinetlc approach, ICG would be a low rather than a high hepatic cleared drug in pentobarbital-anesthetized rats using the continuous infusion technique. It would therefore be unsuited to estimate liver flow in anesthetized rats since changes in ICG clearance might reflect changes in hepatic flow and extraction capability (Wilkinson and Shand, 1975 ).

Even more evidence of the unsultability of ICG as an indicator of liver blood flow in the anesthetized rat 1 s provided by the data in table 4.3. In this table the values of electromagnetically measured. portal venous and hepatic arterial blood flow in pentobarbital anesthetized rats at normo- and hypothermia are presented. As can be seen the decrease in temperature did not change 11 ver blood flow significantly. 
Table 4.3: The effect of temperature on the portal venous and hepatic arterial blood flow in pentobarbital anesthetized rats (mean $\pm S E M, n=5)$.

Body temperature

$37.5^{\circ} \mathrm{C}$

$32.5^{\circ} \mathrm{C}$
Portal venous flow Hepatic arterial flow $(\mathrm{ml} / \mathrm{min})$

$16.6+1 \cdot 3$

$16.0+1.6$
$(\mathrm{mL} / \mathrm{min})$

$2.0+0.2$

$1.9+0.2$

The extraction ratio of propranolol th the rat is known to be high, i.e. 0.97 (Shand et al, 1972). In the rat, clearances of 12.6 (Twamoto et al, 1985), 14 (Smits and Struyker Boudier, 1979), 19 (Schneck et a1, 1977) up to $28 \mathrm{ml} / \mathrm{min}$ (Evans et a1, 1973) have been reported. Because of this high clearance, the drug should be a rellable indicator of liver blood flow. In our study, a blood (plasma) clearance of 14.1 $+2.0 \mathrm{ml} / \mathrm{min}$ was found. Simultaneous direct measurement of the hepatic blood flow ylelded values of $17 \mathrm{ml} / \mathrm{min}$, which indicates an extraction ratio higher than 0.8 . As the plasma clearance of propranolol equals its blood clearance (Bianchetti et al, 1980) and the extrahepattc (1.e. renal) clearance of propranolol in rats (Iwamoto et a1, 1985) is insignificant, the blood clearance values of d-propranolol correlate more to the values obtained by the electromagnetlc flow measurement than those of indocyanine green.

Summarizing, the electromagnetic measurement of total liver blood flow in the rat is lntroduced in this study and found to be a reproductble and stable method. The obtained values were consistent with data in literature reports. The value of rCG, admintstered by constant rate infusion, to indicate hepatic blood flow $\mathbb{i n}^{\mathrm{n}}$ the rat is seriously questioned. 
5. TISSUE SAMPLING IN THE RAT: THE LIVER BIOPSY

\subsection{TNTRODUCTION}

Not only the deternination of the blood flow to the target organ but also the determination of the systemic drug concentration and the drug concentration in the target organ are essential in the experimental evaluation of the phystologic pharmacokinetic approach in general and of the benefits of local over systemic drug administration in particular. In the mathematical description of the regional advantages of local over systemic drug administration the concentrations in the artery supplying the target organ and not in the target tissue were compared (chapter 1). However, drug concentrations in the artery supplying the target organ and in the target organ may change independently from each other. This was shown in a simulation study by Smits and Thijssen (1986) in which they observed dramatic changes in tissue concentrations, as a result of saturation of intracellular elimination mechanlsms, with only small reflections in the concentrations in the artery supplying the target organ.

In clinical practice, the liver is often the target organ for drug delivery (see chapter 1) and the organ may play a dominant role in the extraction of xenoblotics from the circulation. For determination of the drug concentration in a target organ, as for example the liver, extrpation of the total organ is often necessary. The use of liver btopstes for this purpose seems loglcal. It has, however, rarely been used in pharmacologlcal studies in small animals (Boelsterli and zbinden, 1980), while the use of this technique in humans is common practice (Hegarti and WL1Llams, 1984).

In the present study, we investigate the open-liver biopsy technique and its validity to estimate liver drug concentrations of acenocotumarol in time. 


\subsection{EXPERIMENTAL SECTION}

\subsection{Materials}

The S-enantiomer of acenocoumarol (AC) was used in these experiments. For a description of the pharracokinetics of $A C$ and the analysis of AC see chapter 2.3.

\subsection{Antmal experiments}

Male inbred Wistar-Kyoto rats, welghing $270-330 \mathrm{~g}$, were used. A11 experiments were performed on unconsclous animals. For anesthesta, $60 \mathrm{mg} / \mathrm{kg}$ pentobarbital was given intraperitoneally. The anesthet state was maintained by repeated injections of $6 \mathrm{mg}$ of pentobarbital sodium every $60 \mathrm{~min}$.

A catheter ( $\mathrm{PE}-10$ ) was introduced in the femoral vein and in the femoral artery. A small midabdominal 1 ncision $(2.5-3 \mathrm{~cm})$ was made to give free access to the liver. The incision was held closed with a clamp. The body temperature was controlled rectally and maintained at $37.5^{\circ} \mathrm{C}$ by a heat lamp.

\subsubsection{Drug administration and sampling}

$\mathrm{AC}$, in potassium phosphate buffer $(0.1 \mathrm{M}, \mathrm{pH} 8.0)$ was administered by constant rate infusion via the venous catheter. Arterial blood samples (100 ul) were obtalned via the artertal catheter. The samples were heparinized and stored at $-20^{\circ} \mathrm{C}$ unt11 assayed. To study AC distribution $1 \mathrm{n}$ the 1 fver and between the 1.tver and blood, blood samples and liver biopsies were taken at $120,150,180$ and $210 \mathrm{~min}$. The mean of the 4 samples was taken as the respective steady-state leve1. Control experiments showed that steady state was reached within 100 min of infusion ( $f i g \cdot 5.1$ ).

\section{2 .4 Liver biopsy}

After presenting the 1 iver vila an abdominal inctsion, small pieces of liver tissue $(20 \mathrm{mg})$ were cut out of the edge of a liver lobe with a sharp scissors. The abdomen was cloged agaln with the clamp. The whole procedure lasted less then one minute.

The liver biopsies were rinsed immediately with lce-cold lso- 
tonlc sallne, blotted genty on a soft paper tissue, and transferred to a pre-weighed centrifuge tube. After welghing, 300 ul of acetonitrile and 200 ul of lisotonic saline were added. After an overnight store at $4^{\circ} \mathrm{C}$, the samples were stored at $-20^{\circ} \mathrm{C}$ until assayed. Prior to assay, the frozen biopsles were grained in the centrifuge tube with a glass rod.

After the experiment $(1 . e .210 \mathrm{~min})$, the rat was euthanized by an overdose of pentobarbital $1 . v$. The 11 ver was then removed, rinsed with 1 sotonic saline, and homogenized in isotonic saline $(25 \%, w / v)$.

Table 5.1: Comparison between the concentration of (S)-acenocoumarol $(\mathrm{ug} / \mathrm{g})$ in a blopsy and the total $11 \mathrm{ver}$ homogenate.

$$
\text { Infusion rate (ug/min) }
$$

Place of
biopsy
$0.156 \quad 0.31$
0.625
0.625
0.625
0.625
6.25
$\begin{array}{lll}6.25 & 12.5 & 12.5\end{array}$

Left lateral lobe

0.50

0.72

0.99

1.02

1.10

0.87

3.09

2.62

$7.20 \quad 5.09$

Right lateral lobe

$$
\begin{array}{llllll}
0.52 & 0.78 & 1.02 & 1.07 & 1.28
\end{array}
$$

0.93

3. 09

$2.78 \quad 7.49 \quad 5.00$

Median labe,

left central

part

$\begin{array}{lll}0.72 & 0.79 & 0.99\end{array}$

1.18

0.98

3. 33

2.37

6.91

4.75

Caudate lobe 0.5

$$
0.74
$$

0.91

$0.73 \quad 1.98$

0.87

3. 3

$\begin{array}{lll}2.52 & 7.37 \quad 5.30\end{array}$

Blopsy, mean 0.58

$$
0.75
$$

0.98

$0.94 \quad 1.18$

0.91

3.21

$2 \cdot 5$

$7.25 \quad 5.04$

Total 1iver 0.58

0.79

$0.99 \quad 1.05 \quad 1.31$

0.90

3.15

$2.70 \quad 7.37 \quad 5.38$

The correlation between the concentration in the blopsy and the total liver at different infusion rates is as follows:

- left lateral lobe: $y=0.97 x-0.02, \quad r=0.9931 \quad(n=10)$

- median lobe (right side): $y=0.98 x-0.02, \quad r=0.9982 \quad(n=10)$

- median lobe (left slde): $y=0.91 x-0.07, r=0.9965 \quad(n=9)$

- caudate lobe:

- bilopsy (mean):

$y=1.02 x-0.14, \quad r=0.9984 \quad(n=10)$

$y=0.97 x-0.02, \quad r=0.9990 \quad(n=9)$ 


\subsection{RESULTS}

There was an excellent correlation between drug concentrations in liver blopsies and in total liver tissue (table 5.1). The drug was evenly distributed over the liver lobes. Liver bilopsies could be taken frequently without deteriorating drug pharmacokinetics. In fig. 5.1 , a typlcal control experiment is presented which shows that liver content and blood concentrations of $s$-acenocoumarol remained stable at steady state, although several biopsies were taken.

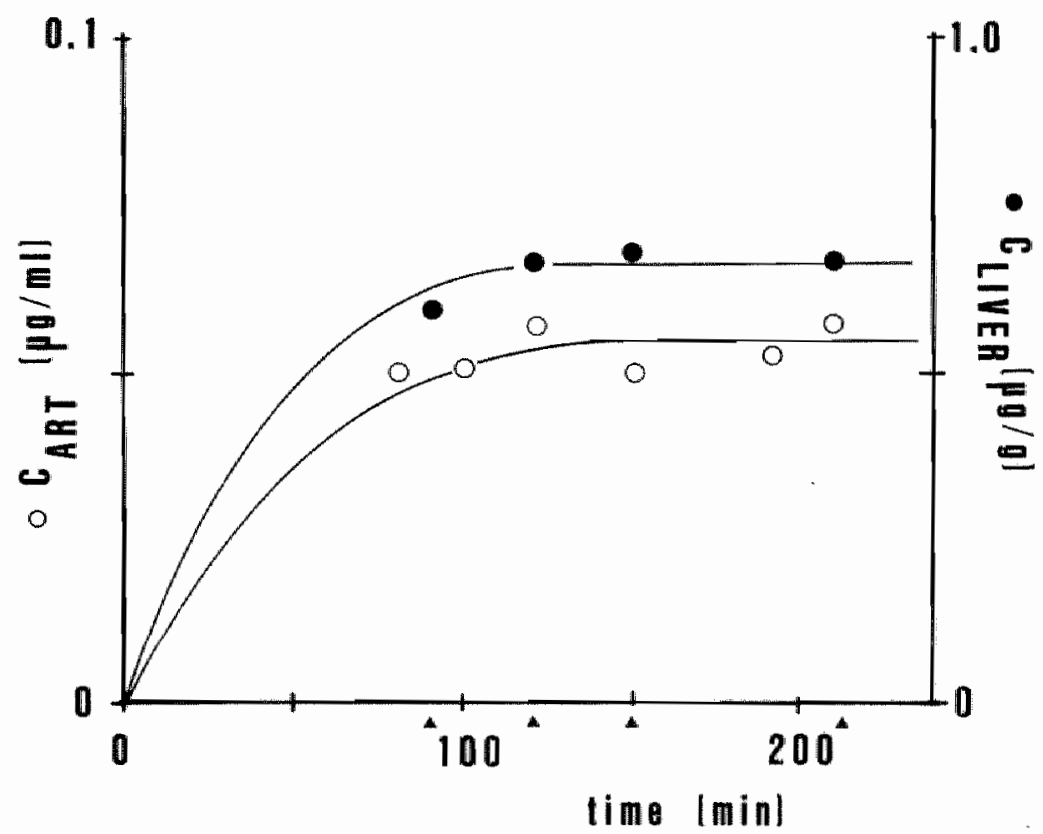

F1g. 5.1: The S-acenocoumarol concentration in the arterial blood (o) and liver (o) of an individual rat as a function of time after a constant rate of infusion of $0.31 \mathrm{ug} / \mathrm{min}$. Arrows indicate the time of biopsies.

\subsection{DISCUSSION}

In studying drug tissue distribution, it would be of value to have a technique to obtain tissue samples at different time polnts from one individual animal. Whereas in human medicine the technique to obtain liver or kidney blopsies is common practice, in small labora- 
tory animals thls technique is hardly developed. Boelsterli and Zbinden (1980) used a liver needle biopsy in the rat for enzyme studies and Anderson et al (1978) the technique of wedge liver biopsies in the isolated liver perfusion system to study propranolol distribution. Our results show that liver blopsies can be taken from different lobes at different times whout disturbing the hepatic clearance function slgniflcantly.

Liver blopsies of approximately $20 \mathrm{mg}$ sufficed for s-acenocoumarol assay in the concentration range studied (1.e. 0.7-6.6 ug/g). The fact that this method constralns the use of anesthetics may be of some disadvantage because anesthesla negatively $\mathbb{1 n f l u e n c e s}$ hepatic clearance. However, provided that body temperature of the rat is kept normal, pentobarbital anesthesia only moderately reduced the clearance of S-acenocoumarol (table 5.2).

Table 5.2.: The effect of pentobarbital anesthesia and temperature on the blood clearance of $S$-acenocoumarol (mean $\pm S E M, n=8$ ).

Experimental condition

Blood clearance ( $\mathrm{ml} / \mathrm{min}$ )

Conscious

Anesthesia

Anesthesia

Body temperature $37.5^{\circ} \mathrm{C}$

Body temperature $32.5^{\circ} \mathrm{C}$

Body temperature $39.5^{\circ} \mathrm{C}$
$4.9+0.4$

$3.4 \pm 0 \cdot 3^{a}$

$3.8+0.4$

$2.5+0.2^{b}$

$4.4 \mp 0.4$

a $p<0.001$ vs. consclous
$p<0.01$ vs. $37.5^{\circ} \mathrm{C}$

Source: J Pharm Pharmacol 38, 122-125, 1986

In summary, the technique of the open-liver biopsy in the rat has been proven rellable for estimating the liver drug distribution in time for one rat. With this technique, the number of laboratory animals (rats) in pharmacokinetic experiments, including hepatic studies, can be reduced. 
6. LOCAL DRUG ADMINISTRATION: KINETIC EVALUATION OF DIRECT INFUSION OF CR EDTA AND IODOHIPPURATE INTO THE LEFT AND RIGHT RIDNEY

\subsection{INTRODUCTION}

Although the local administration of drugs directly into the kidney is often applied in experimental research (Klelnjans et, al, 1983, Smits et a1, 1986) experimental support of the pharmacokinetic considerations of the advantages of intrarenal over systemic drug administration has, to our knowledge, not been presented yet. We investigated the disposition of ${ }^{51} \mathrm{Cr}$ EDTA (Cr EDTA) and ${ }^{125}$ Iodohippurate (IHA) following thelr constant rate of infusion elther intravenously ( $\left.1 . v_{.}\right)$or intra-arterially $\left(1 . a^{\circ}\right)$ into the right or left kidney of the Wistar Kyoto rat. Both compounds are eliminated by the kidney predominantly, the former by glomerular fitration, the latter by f11tration and tubular excretion (Brenner et al, 1972). The study agreed with the theoretical considerations about local drug admintstration, but also revealed pitfalls, i.e. non-linearity in pharmacokinetics.

\subsection{EXPERIMENTAL SECTION}

\subsubsection{Methods}

Male inbred Wistar kyoto rats, weighing $300-350 \mathrm{~g}$, were uged. A11 experiments were performed under anesthesia (Inactin ${ }^{R}$ [5-ethyl5-1"-methyl-propy 1-2-thio-barbituric acid), $100 \mathrm{mg} / \mathrm{kg}$ intraperttonea11y (1.p). A PE-10 catheter was placed in the right femoral artery, for arterial blood sampling, and the jugular veln, for $1 . v$. Infuston. After removal of one kidney, a stretched elongated PE-10 catheter was placed in a retrograde fashion in the suprarenal artery of the other kidney for intra-arterial infusion, as described $\mathbb{1 n}$ chapter 2. Because of marked anatomilcal differences between the blood supply of the right vs. the left kidney (see later), infusion studles were done in the left as we 11 as in the right kidney.

To provide a patent afrway the trachea was cannulated. The body 
temperature was measured rectally and maintalned at $37.5^{\circ} \mathrm{C}$ with a thermostatlcally controlled heat lamp. A PE-10 catheter was placed in the bladder for urfne sampling. An electromagnetic flow probe (internal dlameter $0.7 \mathrm{~mm}$, Skalar, The Netherlands) was placed around the renal artery of the cannulated kidney (fig. 6.1) for renal blood flow measurements. The flow signals were measured with a sine-wave flowmeter (MDL 400, Skalar, The Netherlands) and recorded on a Grass Polygraph.
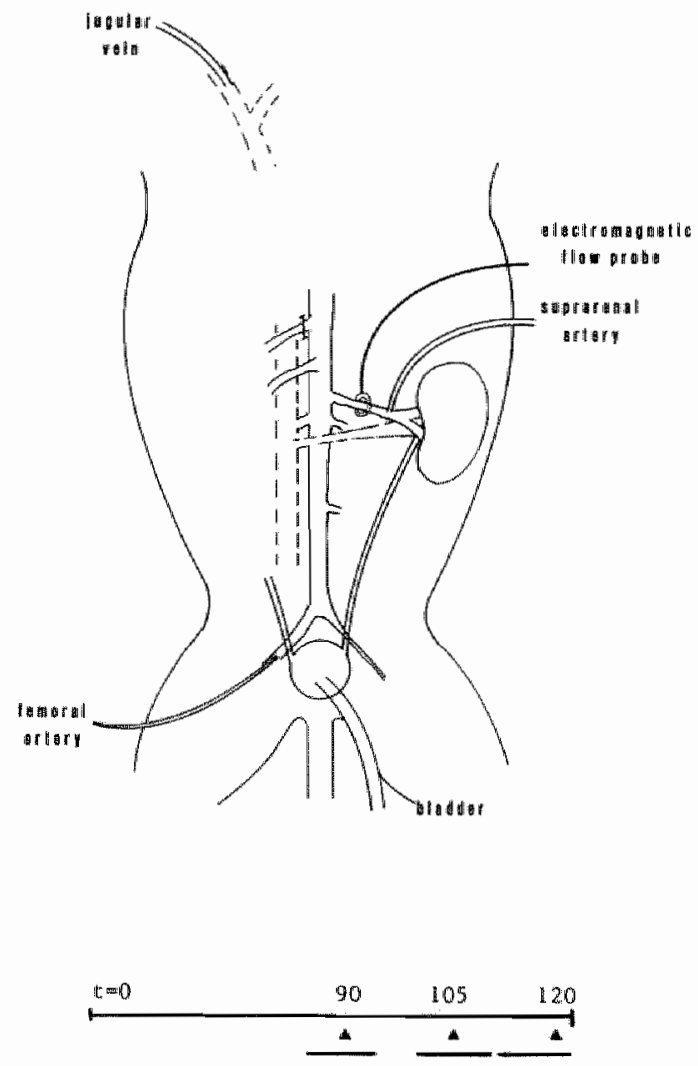

start infusion

La (Left or right kidney; $N=7-8$ ) or iv

- systemic arterial blood sample

- $10 \mathrm{~min}$. urine sample

F1g. 6.1 Scheme of the experimental set-up, Infusion and sampling protocol. Arrows indicate the time of blood sampling. 


\subsubsection{Experimental protocol}

Cr EDTA and IHA CRadlochemical Centre, Amersham, England; product code $\mathrm{Cr}$ EDTA: CJ $13 \mathrm{P}$, speciflc activity $1-2 \mathrm{mCl} / \mathrm{mg} \mathrm{Cr}$, and product code IHA: IM.315P, specific activity $10-50 \mathrm{mCl} / \mathrm{mg} \mathrm{I}$ ), dissolved in isotonlc saline, were infused sinultaneously at a constant rate (50 $u 1 / \mathrm{min}$ ) during 120 minutes either into the jugular vein or into the suprarenal artery of the left or right kidney. In preliminary experiments it was found that steady state was achieved within 90 minutes of infusion. Renal blood flow was recorded durlng the entire experiment. Systemic arterial blood samples (100 ul) were taken at $t=90,105,120$ min (steady state). Urine was collected over 10 minutes periods at $t=$ 85-95, 100-110 and 110-120 minutes. Blood and urine samples were collected 1 in preweighed vessels. The concentrations of Cr EDTA and IHA in the blood and urine samples were determined in a LKB Wallace UnIversa1 Gamma Counter with overlap correction.

\subsubsection{Composition of the experimental groups}

The pharmacokinetics of both substances were studied during $1 . v$. Infusion of Cr EDTA $(2.5 \mathrm{nCl} / \mathrm{min})$ and IHA $(10 \mathrm{nCi} / \mathrm{min})$ in a left nephrectomized group. In a right nephrectomized group, $2.5 \mathrm{nCl} / \mathrm{mln}$ of $\mathrm{Cr}$ EDTA and $40 \mathrm{nCi} / \mathrm{min}$ of IHA were infused intravenously.

Intra-arterial infusions of $\mathrm{Cr}$ EDTA $(2.5 \mathrm{nCl} / \mathrm{min})$ and IHA (10 $\mathrm{nCl} / \mathrm{min}$ ) were performed $\mathrm{in}^{\mathrm{a}} \mathrm{a}$ left and right nephrectomized group (right kidney and left kidney experiments, respectively). As hippurtc acid is eliminated via an active tubular process subject to saturation, this substance was also infused at a rate of $40 \mathrm{nCl} / \mathrm{min} \mathbb{1 n t o}$ both kidneys, to study a posslble dose-dependency of the IHA clearance.

The mean of the three arterlal blood and urine samples of each rat were taken for calculation. Total renal blood flow of each individual rat was calculated as the mean of the flow values measured in each perlod of urine sampling.

\subsubsection{Statistical analysis}

Al1 groups were composed of $7-8$ animals. Data are presented as mean \pm SEM. Data were evaluated by analysis of variance. Significant 
differences beween the varlous groups were determined by a modified $t$-test. Significance was defined at the $p<0.05$ level.

\subsection{RESULTS}

A sumary of the measured parameters is given in table 6.1. As may be geen there, the mean renal blood flows in all experimental groups were between 7.8 and $9.8 \mathrm{ml} / \mathrm{min}$ for the left and between 9.9 and $10.7 \mathrm{mI} / \mathrm{min}$ for the right kidney. Due to the first pass effect of renal extraction, local infusion reduced the systemic avallability of the compounds. The ratio of the systemic $\mathrm{Cr}$ EDTA concentrations $\left(\mathrm{C}_{\mathrm{Sia}} /\right.$ $\mathrm{C}_{\mathrm{Sty}}$ ) was 0.74 for the right kidney and 0.62 for the left kidney. For IHA, this ratio was 0.15 during its administration via the right kidney (infusion rate $10 \mathrm{nCi} / \mathrm{min}$ ). For the left kidney, this amounted to 0.26 , infusing $40 \mathrm{nCi} / \mathrm{min}$. The urinary excretions of the compounds were comparable to the actual infusion rates, confirming a steadystate situation.

There were no differences between the Cr EDTA steady-state concentrations perfusing the kidney ( 1 .e. $C_{T}$ ) whether the compound was Infused systemically or locally. For IHA, a significant $(\mathrm{p}=0.03)$ difference was observed between the arterial concentrations entering the left kidney for the systemic and local administrations at the highest infusion rate (table 6.1 ).

Pharmacokinetic constants estimated from the experiments are presented in table 6.2. For the right kidney, the route of administration ( $1 . \mathrm{a}$. or $1 . \mathrm{v}$. ) did not influence the systemic clearance of $\mathrm{Cr}$ EDTA $(3.2+0.1$ vs. $3.5+0.2 \mathrm{ml} / \mathrm{min}$ for $1 . \mathrm{a}$. and $1 . \mathrm{v}$. Infusion respectively) nor of IHA $(8.3+0.3$ and $7.9+0.3 \mathrm{ml} / \mathrm{mln}$ following the infusion of $10 \mathrm{nCi} / \mathrm{min} 1 . \mathrm{a}$. and $1 . \mathrm{v}$, respectively; $8.7+0.3 \mathrm{ml} / \mathrm{min}$ for the $1 . a$. Infuston of $40 \mathrm{nCi} / \mathrm{min}$ ). Also for the left $\mathrm{kldney}$, systemic clearance of $\mathrm{Cr}$ EDTA was independent of the route of administration: $3.4+0.3$ and $3.5+0.2 \mathrm{ml} / \mathrm{min}$ for $1 . \mathrm{v}$. and $1 . a$. Infusion, respectively. The administration of IHA $i . a$. at a rate of $40 \mathrm{nCi} / \mathrm{min}$ showed a lower blood clearance in comparison to the clearance found for systemic infusion; $6.0 \pm 1.0$ vs. $9.0+0.3 \mathrm{ml} / \mathrm{min}(p<0.01)$. The clearance observed for IHA 


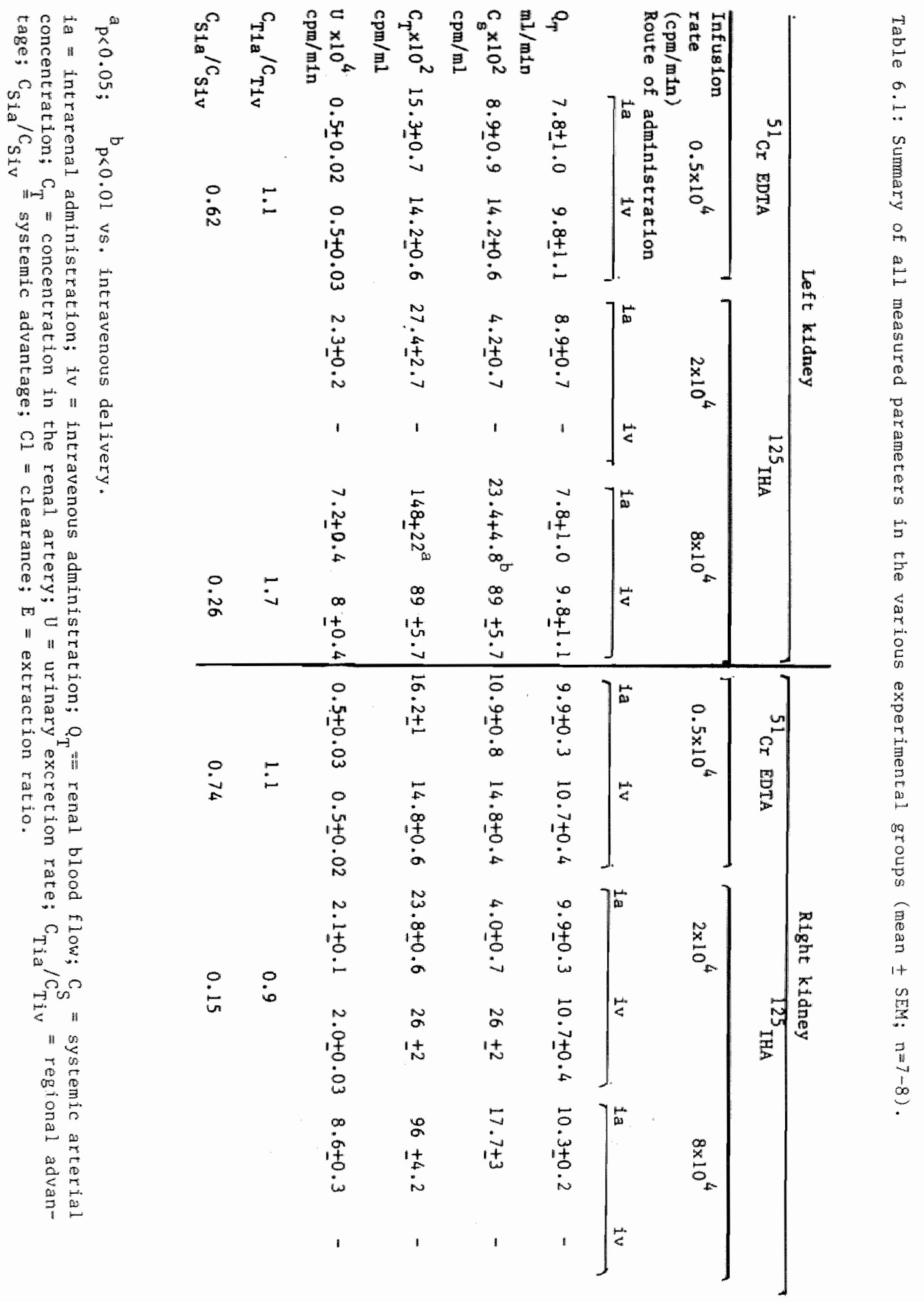


Infused $\mathbb{1}$.a. at a rate of $10 \mathrm{nCi} / \mathrm{min}$ was not different from the clearance found for the systemic admintstration.

The clearances calculated from the urinary excretion rate $(\mathrm{c} 1=$ $\mathrm{U} / \mathrm{C}_{\mathrm{if}}$ ) showed the same pattern as described above for the clearances calcullated by $\mathrm{Cl}=1 \mathrm{nf} / \mathrm{C}_{\mathrm{T}}$ (table 6.2).

The renal extraction ratios of both substances $\left(E_{\mathrm{T}}=U / \mathrm{C}_{\mathrm{T}} \cdot \mathrm{Q}_{\mathrm{T}}\right)$ are also deplcted in table 6.2. For Cr EDTA, this parameter was almost equa 1 , $1 . e .0 .3(0.28-0.35)$ in a11 experimental groups. For the right kidney, the extraction ratio of 1 HA ( $10 \mathrm{nCI} /$ min) was slightly higher during local infusion than during $1 . v$ infusion: 0.9 vs. 0.75. However, upon infusion of $40 \mathrm{nCi} / \mathrm{min}$ of IHA directly into the left $\mathrm{kid}-$ ney, the extraction ratio fell to $0.64+0.03$ which differed significantly from the extraction ratio during the systemic infusion of the same dose $(0.89+0.04 ; p<0.01)$ and from that during intrarenal infusion of the lower dose $(0.92+0.04 ; \mathrm{p}<0.01)$.

\subsection{DISCUSSION}

We compared the pharmacoknetics of intrarenal administration of a hlgh (IHA) and a low ( $\mathrm{Cr}$ EDTA) renal clearance substance with those of their systemic administration. In accordance to what should be expected, intrarenal adminlstration, in the right as well as in the left kidney, reduced the systemic avallability of the compounds due to the first pass effect of elimination of the kidney. The extent of the reduction was in close agreement to $1-E_{T}$, where the extraction ratio $\mathrm{E}_{\mathrm{T}}$ was obtained from the urinary excretion rate (table 6.2). Differences were observed between the left and right kidney for the extraction of IHA. The right kidney showed an equal extraction for IHA independent of the route of infusion and the infusion rate. The left kidney showed a reduced extraction $(-30 \%)$ following intrarenal administration of the highest IHA amount compared to its systemic administration or to its intrarenal administration at a 4-fold lower IHA infusion rate. Concomitant with the reduced IHA extraction, the IHA clearance decreased from 9 to $6 \mathrm{~m} 1 / \mathrm{min}$. The reduced clearance can partly be explained by the lower remal blood flow $(-20 \%)$ observed in 

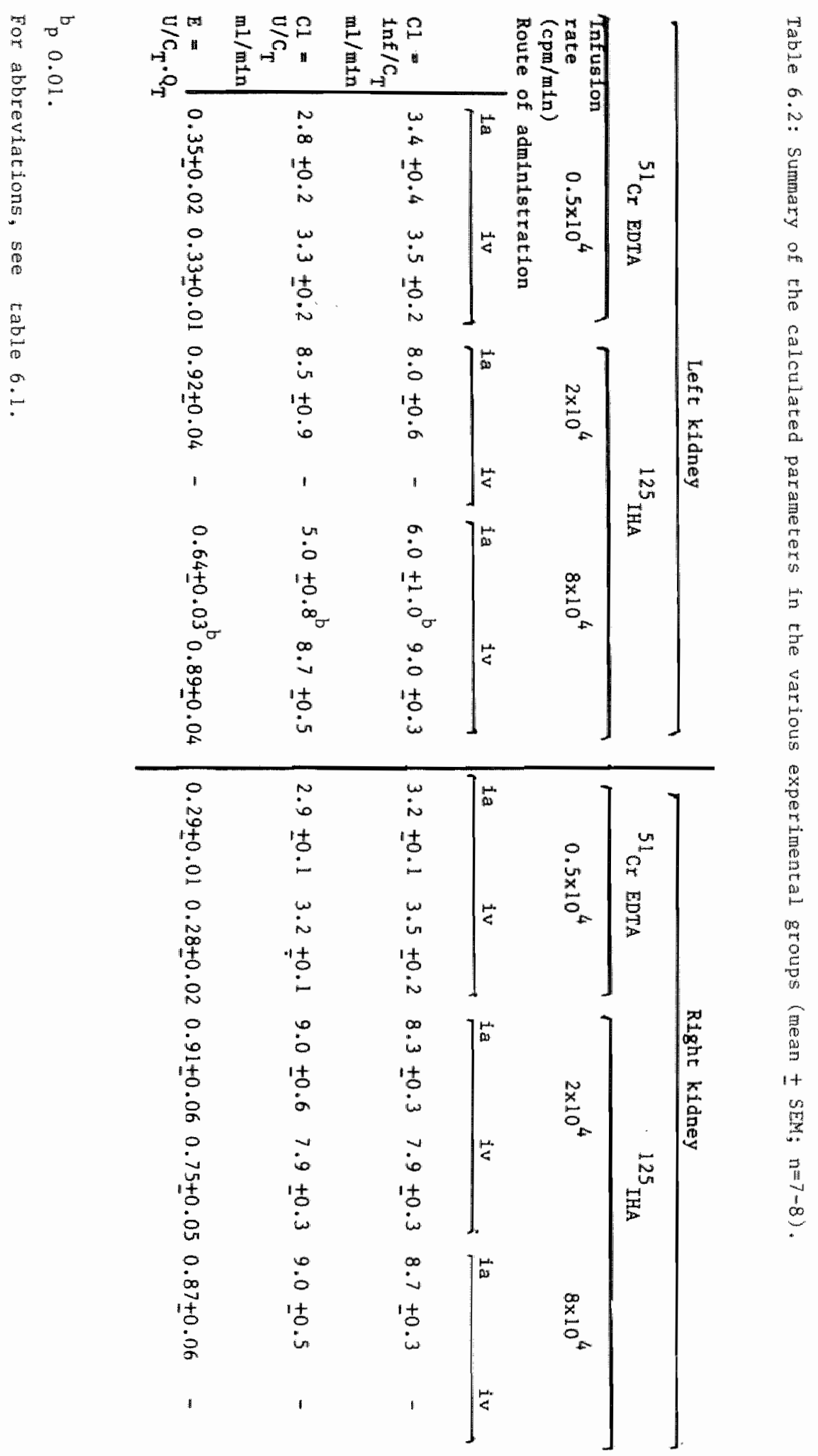
that experimental group, i.e. 7.8 mlinin (the other right kidney groups showed a renal blood flow of 8.9 and $9.8 \mathrm{ml} / \mathrm{min}$; table 6.1 ). Saturation of elimination processes could be a sultable explanation for this reduced extraction. This, however, would suggest that there was a difference in the capacity of extraction between the left and right kidney. The extraction ratlos of IHA in the left kidney during systemic infusion of $40 \mathrm{nCl} / \mathrm{min}$ and local infusion of $10 \mathrm{nCl} / \mathrm{min}$ were comparable with the extraction ratlos observed in the right kidney during systemic and local infusion of IHA. This indicates that the overall extraction capacity in both kidneys was almost similar.
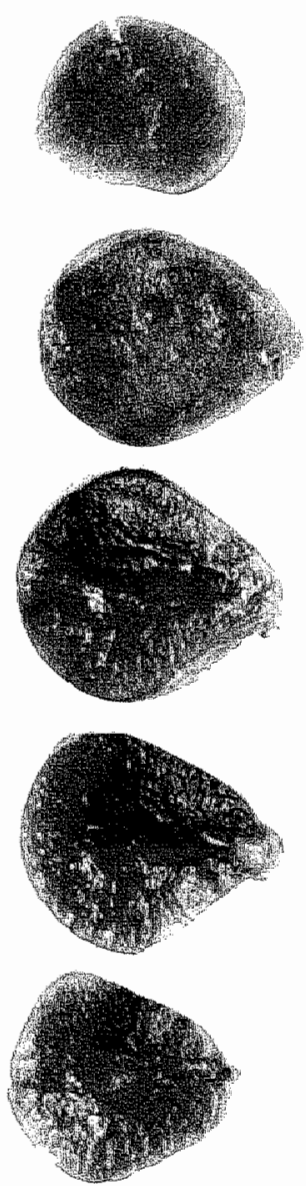

Fig. 6.2 Silces of the left kidney after injection of Evans blue via the suprarenal artery. 
Apparently, a local (dose-dependent) phenomenon present only in the left kidney attributes to the observed saturation during 1 .a. Infusion of IHA at the highest dose. We made a remarkable observation that might explain our findings; infusion of Evans blue via the suprarenal artery (i.e. the technique used throughout our experiments) into the left kidney showed that only parts of the kidney were colored (flg. 6.2). In contrast, right kidney preparations showed a homogenous distribution of the dye. The conbination of lamfinar flow patcerns and the short distance between the suprarenal entrance and the first branch of the renal artery, preventing a thorough mixing (E1g. 6.3), explains this inhomogenous distribution. As only a fraction of the renal blood flow receives the compound, the part of the kidney perfused by it recelves high concentrations and the tubular excretion process might become saturated locally. A lower extraction will be the result.

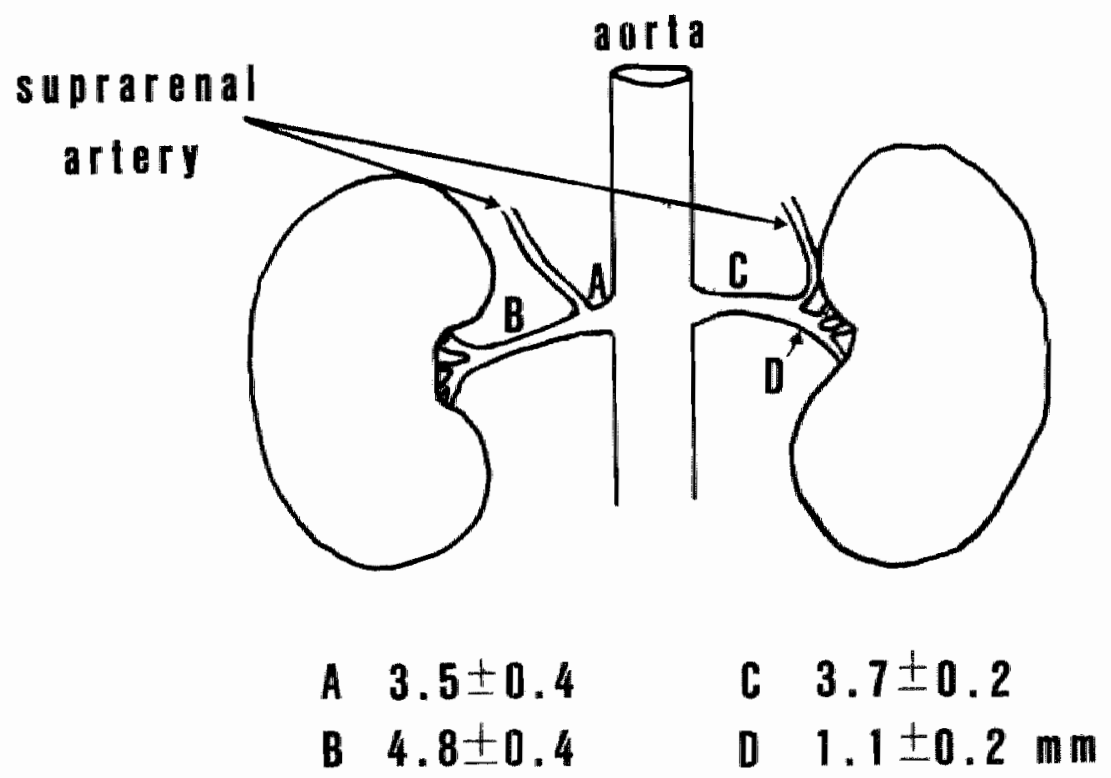

Fig. 6.3 The length (mm) of the renal artery between the aorta and the suprarienal artery at the right (a) and the left stde (c) and the length of the renal artery between the suprarenal artery and 1 ts first branch to the kidney at the left (b) and the rlght side (d) measured In 10 WKY rats (mean + SEM). 
Won-11near pharmacokinetics have been shown to 1 imit the advantages of 5-fluorouracll admintstration via the hepatic artery (Boublil et al, 1985). Other fmpllcations of saturation kinetics during local drug administration have been discussed recently (Smits and Thijssen, $1986)$.

As predicted by theory, chronic intrarenal drug Infusion has no advantage if it 1 intended to reach higher local drug concentrations: steady-state concentrations in the renal artery were independent of the route of administration (table 6.1) with the exception of the high IHA infusion in the left kidney.

In summary, our experiments affirm the theoretical considerationg about the pharmacokinetic advantages of local drug administration, 1.e. advantages are obtained if either the target organ has a high extraction ratio for the drug or the syatemic clearance of the drug is high with respect to the blood flow through the organ. Deviations from theoretical predictions can be expected because of saturation kinetics. This study shows that an inhomogeneous flow distribution can cause localized saturation kinetics in the target organ. Since renal size and vasculartsation could be a function of genetic lines (Mcurtry et al, 1981; Mulvany and Korsgaard, 1983) care has to be taken to extrapolate our findings to other rat strains or other species. 
7. LOCAL DRUG ADMINISTRATION: KINETIC BVALUATION OF LONG-TERM INTRARENAL AND SYSTEMIC INFUSION OF PROPRANOLOL IN CONSCIOUS WISTAR RATS

\subsection{INTRODUCTION}

In the previous chapter, it was shown that intrarenal administration of a drug cleared by the target organ reduces the systemic drug avallability following the first pass effect of the drug by the target organ. Increases in regional drug concentration shall not be achieved.

In this study the suitability of intrarenal drug administration to increase the drug concentration in the kidney as compared to systemic drug administration will be investigated. In experimental pharmacology, intrarenal drug administration is an often applied instrument to study the direct effects of drugs on the kidney (Smits et al, 1986; Kleinjans et al, 1983). In experimental surgery it is used to treat the $\mathbb{i}$ mmunoresponse after kidney transplantation (Ruers et al, 1986).

As may be obvious from the theoretical considerations on the advantages of local over systemic drug administration (chapter 1), the ratio of the systemic clearance and the blood flow through the target organ indicates the increase of the concentration in the target organ during local drug administration. Applying this in the model of intrarenal drug administration a minimal regional advantage is to be expected, because of the relatively high blood flow through the kidney. Propranolol was used as a model substance since this drug has a high hepatic clearance $(14-28 \mathrm{ml} / \mathrm{min})$ in the rat.

\subsection{EXPER IMENTAL SECTION}

d1-Propranolo1-HC1 (Sigma, St. Louis, MO, USA) solved in 1sotonic saline was used for intrarenal and subcutaneous infustion. 


\subsubsection{Animal experiments}

Male inbred Wistar-Kyoto rats, 250-300 g were used. The rats were on standard food and tap water. For intrarenal infusion, an elongated $\mathrm{PE}-1 \mathrm{O}$ catheter was introduced in a retrograde fashion in the rlght suprarenal artery as described in chapter 2. The other end was gulded subcutaneously to the neck and connected to an osmotic minipump, (Model 2001, Alzet, Palo Alto, Ca, USA). Subcutaneous delivery of propranolol was performed by subcutaneous placing of a PE-10 catheter, attached to an osmotic minipump. The contralateral kidney was removed. Propranolol concentration was determined in plasma and kidney homogenates following the procedure described in chapter 2.3 .

\subsubsection{Experimental protocol}

Propranolol was infused elther intrarenally (i.r.) or subcutaneously (s.c.) at a constant rate of $1 \mathrm{mg} / \mathrm{kg} / \mathrm{d}$ durfing 5 days. At day 5 the animals were euthanized and blood and kidney removed.

\subsubsection{Statistical analysis}

Data are presented as mean $+S E M$. Significances were calculated using Student"s t-tests. Differences were regarded to be statistically significant if $\mathrm{p}<0.05$.

\subsection{RESULTS}

The systemic plasma concentrations after intrarenal and subcucaneous administration of propranolol are shown in table 7.1 . At steady state the plasma concentrations were comparable: $28.2+3.4 \mathrm{ng} / \mathrm{ml}$ at $1 . \mathrm{r}$. and $20.0+3.0 \mathrm{ng} / \mathrm{m} 1$ at $\mathrm{s.c}$. Infusion. The concentration of propranolol in the kidney was $104+6.0 \mathrm{ug} / \mathrm{g}$ at $\mathrm{i} . \mathrm{r}$. and $53+5.4 \mathrm{ug} / \mathrm{g}$ at systemlc administration. There was no systemic advantage of intrarenal over systemic propranolol administration. The regional advantage $1 . e$. the ratio of the concentration of propranolol in the kidney during i.r. and s.c. Infusion was 2.0.

The systemic plasma clearance, calculated by the quotient of the 
infusion rate ( $\mathrm{ng} / \mathrm{min}$ ) and the systemic concentration (ng/mi) was $6.5+1.0$ and $9.3+1.5 \mathrm{ml} / \mathrm{min}$ at $1 . r$. and $\mathrm{s} . \mathrm{c}$. Infusion, respectively.

Table 7.1: Mean $\pm \operatorname{SEM}(n=4)$ of the measured and calculated parameters during long-term constant rate infusion of propranolol (1 $\mathrm{mg} / \mathrm{kg} / \mathrm{d}$ ) either intrarenally or subcutaneously in conscious male Wistar-Kyoto rats.

\section{Intrarenal Subcutaneous}

Systemic propranolol

concentration ( $\mathrm{ng} / \mathrm{ml})$

$28.2 \pm 3.4 \quad 20.0+3.0$

Propranolol concentration

in the kidney $(\mathrm{ng} / \mathrm{g})$

$$
104+6.0^{a} \quad 53.0+5.4
$$

Plasma clearance

$(\mathrm{m} 1 / \mathrm{m} 1 \mathrm{n})$

$6 \cdot 5+1.0$

$9 \cdot 3+1 \cdot 5$

a $\quad p<0.05$ as compared to subcutaneous infusion.

\subsection{DISCUSSION}

In this study, the model substance propranolol was infused intrarenally and subcutaneously at a constant rate of infusion during 5 days in conscious rats. It was found that intrarenal infusion of propranolol did not lower systemic concentrations as compared to systemic administration of propranolol. The drug concentration in the infused kidney, however, was two fold higher during intrarenal infusion as compared to systemic administration.

Long-term direct administration of propranolol into the kldney seems at first sight an obvious approach to investigate hemodynamics after specific long-term suppression of renal beta-adrenoceptors. The choice for target organ directed drug administration is then based upon the assumption that intrarenal delivery of the drug reduces the systemic drug concentrations and thus systemic effects and/or enhances the renal drug concentrations as compared to systemic administration (chapter 1). Kinetic analysis of this experiment, as presented in this study, indicates 1) that no systemic advantage is to be expected since propranolo1 is not cleared by the kidney (Iwamoto et 1, i9.85) and 2) 
that the regional advantage of intrarenal over systemic propranolol admintstration is limited because of the relative high blood flow of the kidney $(10 \mathrm{~m} / \mathrm{min})$. The reglonal advantage assuming a propranolol clearance of about $14 \mathrm{ml} /$ min after a single dose of $1 \mathrm{mg} / \mathrm{kg} \mathrm{s.c}$. (Smits et a1, 1979), would be about 2. 4. However, data presented here, show that the propranolol clearance after long term administration is decreased to 7-9 $\mathrm{m} / \mathrm{m} / \mathrm{n}$. This low clearance value decreases the regional advantage even more.

In sumary, this study clearly demonstrates that long-term infuston of propranolol into the renal artery increases the propranolol concentration in the kidney only slightly which is 1 in conformity with the theoretical predictions. It seriously questions the kinetic advantage of long-term intrarenal over systemic administration of propranolol. 
8. LOCAL DRUG ADMINISTRATION: RINETTC EVALUATION OF LOCAL AND SYSTEMTC INFUSION OF THE HIGH HEPATIC CLBARANCE SUBSTANCE PROPRANOLOL IN RAT CARDIAC GRAFTS

\subsection{INTRODUCTION}

The local treatment of the immuneresponse after a tissue transplantation is a new and promising application of local drug administration. Recently, Ruers et al (1986) reported a beneficlal effect of intrarenal over intravenous administration of prednisolone in the treatment of rat renal grafts. Intrarenally administered prednisolone ( $4 \mathrm{mg} / \mathrm{kg} / \mathrm{day}$ ) slgnificantly prolonged the graft survival time, whereas intravenous administration of the same dose was ineffective.

The cardiac graft is used also in experimental surgery, to study the immuneresponse after tissue transplantation. In this model the direction of the blood flow in the transplanted aorta is artifictally changed and the venous outflow of the transplanted heart drains entirely into the portal vein of the acceptor animal (fig. 8.1), putting the liver immediately downstreams from the transplanted heart. This experiment thus creates optimal kinetic conditions for high-advantage local administration of immunotherapeutic drugs that have a high hepatic clearance. The systemic concentration of such a drug when administered locally to the transplanted heart, should be very small. This because of the high first pass effect of elimination of the 11 ver (Pond and Tozer, 1984). Low systemic concentrations should reduce the systemic side-effects, which often are limiting factors in immunosuppressive therapy.

In the present study, the actual kinetic advantages of local over systemic drug administration in the cardlac graft are determined. Propranolol was chosen as the representative of the kinetlc class of substances with a high hepatic clearance (14-28 mi/min, chapter 4). The blood flow to the target organ was measured, because $1 t$ is inversely related to the regional advantage of local over systemlc drug administration. Flow was measured by means of an electromagnetic flowneter placed on the artery supplying the cardlac graft. 


\subsection{EXPER IMPNTAL SECTION}

\subsubsection{Materials}

d1-PropranoloI-HCl (Sigma, St. Louls, MO, USA) in isotonic saline $(0.16 \mathrm{mg} / \mathrm{m} 1)$ was used for direct infusion into the coronary arterles (1.c.) of the transplanted heart. Tritium-labeled 1-propranolol (specific activity $18.5 \mathrm{Cl} / \mathrm{mmol}, \mathrm{NEN}$, Boston, MA, USA) was used for Intravenous ( $1 . v^{*}$ ) infusion.

\subsubsection{Anima1 experiments}

Male inbred Brown Norway and Lewis rats were obtained from the Central Animal Facilitles of our University. Rats of 250-300 gr were used in all experiments. The rats were maintalned on standard lab food and tap water available ad libitum. For these experiments rats with cardiac grafts were kindly provided by the Department of Surgery. The heart of a Brown-Norway rat was heterotopically transplanted into a Lewis rat, whereas the heart of the recipient animal remained functionally in sltu (Ruers et al, 1987). Briefly, the aorta of the donor heart was anastomosed on the abdominal aorta of the acceptor and the donor heart's pulmonary artery was connected to the portal vein of the acceptor. The transplanted heart was placed in the right upper quadrant of the abdomen of the acceptor. All surgery was done under pentobarbital anesthesila.

A flow scheme of the status quo during the infusion of propranolol is shown fin fig. 8.1: a fraction of the blood in the abdominal aorta reaches the aorta of the donor heart. It flows in a retrograde fashion through the aortic arch of the donor. Blood entering the heart flows Into the coronary vessels in an orthograde fashion. The cavity of the left ventricle does not recelve blood as the aottic valves are closed due to retrograde blood flow. The venous blood of the donor heart flows via the coronary sinus, right atrium, right ventricle and pulmonary artery into the portal vein and enters the liver.

The carotid artery of the implanted aorta was cannulated with a PE-10 catheter (see also chapter 2) for local infusion of propranolol. Two days after the heart transplantation, the rats were used for the propranolol experiments. At this time, animals had recovered from 


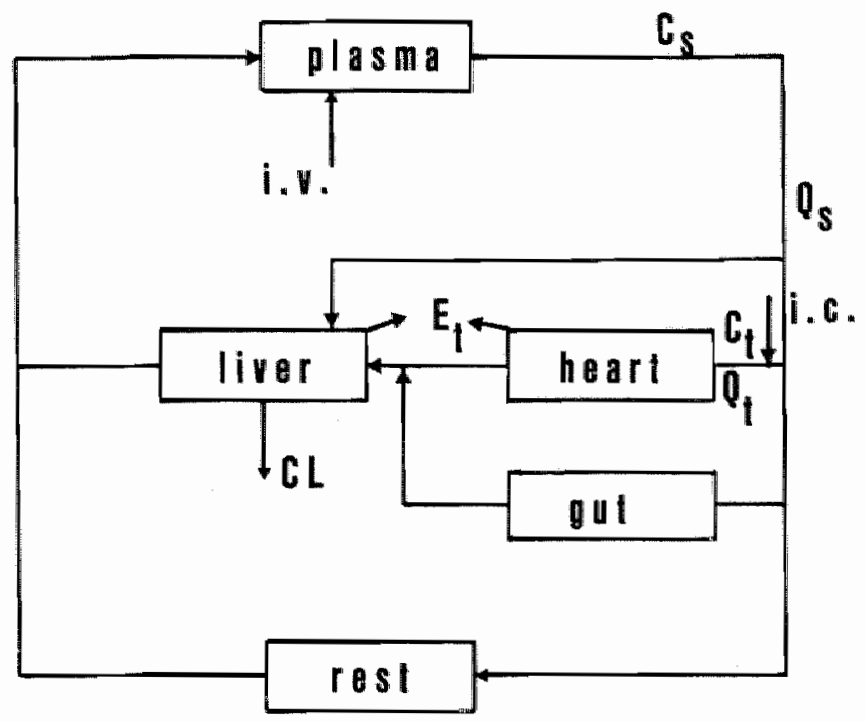

Fig. 8.1: Flow diagram of the rat cardiac graft. $\mathrm{Cl}=\mathrm{clearance} ; \mathrm{E}_{\mathrm{T}}=$ extraction ratio; $1 . \mathrm{V}$. intravenous

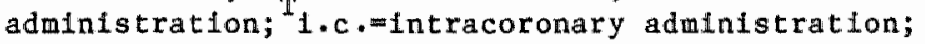
$\mathrm{C}_{\mathrm{S}}$ ssystemic arterlal concentration at steady state; $\mathrm{C}_{\mathrm{T}}=$ concentration in the artery supplying the target organ; $Q_{S}=$ cardiac output; $Q_{T}=b l o o d$ flow in the artery supplying the target organ.

operation and graft survival was optimal. In the experiments, a bolus injection of pentobarbital ( $30 \mathrm{mg} / \mathrm{kg}$ in isotonic saline) was given Intraperitoneally for anesthesia. Anesthesla was maintained by repeated 1.p. Injections of $6 \mathrm{mg} / \mathrm{kg}$ of the pentobarbltal solution every 60 min. The trachea was cannulated to provide a patent allway* PE-10 catheters were placed in the left femoral artery and vein for gystemic arterial blood sampling and systemic intravenous infusion respective1y. For measurements of the blood flow to the cardiac graft, an electromagnetic flow probe (Internal diameter $1.8 \mathrm{~mm}$, Skalar, Delft, The Netherlands) was placed around the transplanted aorta. The flow stgnals were measured with a sine-wave flowmeter (type MDL 400, Skalar, Delft, The Netherlands) and recorded on a Grass polygraph.

The body temperature was measured rectally and maintalned at $37.5^{\circ} \mathrm{C}$ by a thermostatica1ly controlled heat lamp. 


\subsubsection{Drug admintstration and sampling}

d1-Propranolol was administered locally via the carotid catheter by a constant rate infusion of $4 \mathrm{ug} / \mathrm{min}$. At the same time ${ }^{3} \mathrm{H}$-1-propranolol was infused systemlcally by constant rate infusion of 115.000 $\mathrm{dpm} / \mathrm{min}$ (1.e. $0.73 \mathrm{ng} / \mathrm{min}$ ). These infusion rates were chosen to mintmilze the use of labeled drug as well as to be able to detect any 10cally dellvered drug systemlcally, that had to be performed by an analytical procedure. To prevent dehydration the infusion volumes were 25 u1/min at both Infuston sites (Maddox et al, 1977). Blood samples ( 500 ul) were taken at $t=120,150,180 \mathrm{~min}$ via the femoral arterial catheter and collected in heparinized vessels. The lost blood volume was replaced by blood from litter mates. After centrifugation the plasma was stored at $-20^{\circ} \mathrm{C}$ unt 11 assayed. At the end of the experiment $(t=180$ min), the animal was euthanized with an overdose pentobarbital i.v. and the donor heart removed. After washing and weighing the hearts were also stored at $-20^{\circ} \mathrm{C}$.

\subsubsection{Pharmacokinetic analysis}

Comparisons between propranolol concentrations from local and intravenous delivery are made after correction for the difference in infusion rate. Preliminary experiments showed that steady state was reached after 120 min of infusion. The plasma and flow data of each individual animal were obtained as the mean of the 3 values at 120 , 150 , and $180 \mathrm{~min}$. The systemic plasma clearance $(\mathrm{Cl})$ of intravenously administered propranolol was calculated by $\mathrm{CI}_{\mathrm{S}}(\mathrm{ml} / \mathrm{min})=1 \mathrm{nf} / \mathrm{C}_{\mathrm{S}}$, where inf equals the Infusion rate (ng/min) and $\mathrm{C}_{S}$ the systemic arterial steady-state plasma concentration $(\mathrm{ng} / \mathrm{ml})$. The steady-state plasma concentration of propranolol in the artery supplying the target organ $\left(C_{\mathrm{T}} ; \mathrm{ng} / \mathrm{m} 1\right)$ was calculated by $C_{\mathrm{T}}=\mathrm{C}_{\mathrm{S}}+\operatorname{Inf} / \mathrm{Q}_{\mathrm{T}}$, where $Q_{\mathrm{T}}$ equals the plasma flow through the target organ $(\mathrm{ml} / \mathrm{m} \mathbb{1} \mathrm{n})$. Since the plasma concentration of propranolol equals its blood concentration (Bianchett1 et al, 1980) calculations were made using the values of the blood concentration and blood flow. The systemic plasma (blood) clearance was calculated by $\mathrm{Cl}_{\mathrm{S}}=\left(1-\mathrm{E}_{\mathrm{T}}\right) \cdot \mathrm{inf} / \mathrm{C}_{\mathrm{S}}$, where $\mathrm{E}_{\mathrm{T}}$ equals the extraction ratio of propranolol by the liver. $\left(1-\mathrm{E}_{\mathrm{T}}\right)$ represents the quotient of $\mathrm{C}_{S}$ derived from local and intravenous infusion, i.e. the systemic 
advantage of local over systemic drug delivery (chapter 1 ). The regional advantage of local over systemic propranolol delivery is expressed by the quotient of the concentration in the target artery from locally $\left(\mathrm{C}_{\mathrm{TiC}}\right)$ and intravenously $\left(\mathrm{C}_{\mathrm{Tiv}}\right)$ administered propranolol. This quatient equals $\left(1-E_{T}\right)+C 1_{S} / Q_{T}$ (Appendix 8.5).

\subsubsection{Statistical analysis}

A11 data are presented as mean $\pm S E M$. Differences between the routes of administration were compared using Student's t-test. The 0.05 level of probability was used as the level of significance.

\subsection{RESULTS}

Eight rats were prepared and all were technically suited and used for the experiments. The blood flow through the transplant was $7.2+0.5 \mathrm{ml} / \mathrm{min}$. All data are corrected for the difference in infusion rates between intracoronary and systemic administration. The systemic plasma concentrations after 1.v. and $1 . c$. administration of propranolol are shown in table 8.1. At steady state, the plasma concentrations of propranolol at intracoronary infusion were much lower than those at simultaneous i.v. administration: $20+3.3$ and $357+16 \mathrm{ng} / \mathrm{m} 1$ plasma respectively. This finding is concomitant with the first pass effect of elimination of propranolol by the liver. The plasial clearance of propranolol was about $11 \mathrm{ml} / \mathrm{min}$.

Higher propranolol concentrations in the transplanted hearts were observed after systemic administration : $791+46$ and $637+36 \mathrm{ng} / \mathrm{g}$ heart at $i \cdot v$ and $1 . c$. administration, respectively. The differences however, were not statistically significant. The blood concentration of propranolol in the artery supplying the transplant $\left(\mathrm{C}_{\mathrm{T}}=\mathrm{C}_{\mathrm{s}}+1 \mathrm{in} / \mathrm{Q}_{\mathrm{T}}\right)$ was $581+38 \mathrm{ng} / \mathrm{ml}$ at $1 . c$. infusion. $C_{\mathrm{T}}$ of the $1 . \mathrm{v}$. Infused propranolol. equaled $C_{s}$ hence 1 was $357 \pm 16 \mathrm{ng} / \mathrm{ml}$ blood.

The quotient of the systemic concentrations at $\mathbb{1} \cdot c$. and $1 . v$. administration was $0.05+0.01$. This quotient represents the reduction In systemic concentration during local as compared to systemic administration, the so called systemle advantage of local over systemic drug 
adminlstration and indicates the blo-avallability $\left(F=1-E_{T}\right)$ of propranolo1. The increase in drug concentration in the artery supplying the cardiac graft during local as compared to systemic drug administration, the so-called regional advantage of $10 \mathrm{cal}$ over systemic drug administration, expressed by the quotient of $C_{T i c}$ and $C_{T i v}$, was 1.60 \pm 0.4 . The reglonal advantage calculated by the formula $\left(1-E_{T}\right)+C 1_{S} / Q_{T}$ was $1.65+0.4$.

Table 8.1: Mean values $+S E M, n=8$ of the measured and calculated parameters during local and systemic infusion of propranolol. a. measured; b: calculated; *: corrected for the difference in infusion rate.

Route of

administration

Infuston rate $\mathrm{e}^{\mathrm{a}}$

(ng/min)

Blood flow ${ }^{2}$

(m1/miln)

Systemic plasma

(blood) concentration ${ }^{a}$

( $\mathrm{ng} / \mathrm{ml}$ )

Concentration in

the transplanted heart ${ }^{a}$

( $\mathrm{ng} / \mathrm{g}$ )

Blood concentration

In the artery sup-

plying the target organ

(ng/m1)

Systemic advantage ${ }^{a}$

$\left(\mathrm{C}_{\mathrm{Sic}} / \mathrm{C}_{\mathrm{SIV}}\right)$

Reglonal advantage $e^{b}$

$\left(\mathrm{C}_{\mathrm{TLV}} / \mathrm{C}_{\mathrm{TLV}}\right)$

Regiona1 advantage

$\left(\left[1-\mathrm{E}_{\mathrm{T}}\right]+\mathrm{c} 1_{\mathrm{S}} / \mathrm{Q}_{\mathrm{T}}\right)$

Plasma (blood) clearance

(m1/min)
Intracoronary

Intravenous

4000

0.73

$\left(=1.810^{-4} \times\right.$ IC $)$

$7.2+0.5$

$20.0+3.3$

$0.07+0.005$

$(357 \mp 16) *$

$581+38$

$791+46$ *

$581+38$

$357+16 *$
$0.054+0.01$

$1.50+0.4$

$1.65+0.4$ 


\section{4 DISCUSSION}

In this study, the kinetlcs of a high hepatic clearance substance, propranolol, were investigated in rats in which donor heart was transplanted, under controlled experimental conditions. The advantages of local over systemic admitnistration were determined, to provide a pharmacokinetic base for local immotherapy in this model.

The cardiac graft, used here, has a unique flow pattern which offers, in theory, ideal conditions for advantageous local drug delivery. In these rats the venous outflow of the transplanted hearts drains into the portal vein of the acceptor. Hence, before reaching the systemic circulation, all of the blood leaving the transplanted heart flows through the liver of the acceptor animal. This implies that drugs with a high cardiac extraction and/or high hepatic extraction will be cleared very efficiently before entering the systemic circulation.

The observed propranolol clearances of about $11 \mathrm{ml} / \mathrm{min}$ are $\mathrm{in}$ agreement with literature data on rat liver flow (see also chapter 4). These values therefore suggest that in spite of the changed blood supply to the liver, the clearance capacity of this organ is not affected significantly.

Propranolol was infused locally at a high dose (i.e. $4 \mathrm{ug} / \mathrm{min}$ ). Tracer amounts were glven systemically $(0.73 \mathrm{ng} / \mathrm{min})$. The ratio of the systemic concentrations of propranolol from local and systemlc infusion was 0.05 indicating the liver extraction to be $95 \%$ of the propranolol influx. This value is comparable with the value obtalned in normal rats (Iwamoto, 1985). Saturation of the extraction process in the 11 ver because of the local administration of high doses of propranolol apparently did not occur (Suzuki et al, 1981).

The ratio of the concentration of propranolol in the artery sup plying the transplanted heart during local and systemic administration shows that in this model only minor reglonal advantages can be achieved by administering the drug 1ocally $\left(\mathrm{C}_{\mathrm{TAC}} / \mathrm{C}_{\mathrm{Tiv}}=1.62+0.4\right)$. This is in agreement with a theoretical analysis of this experiment, whlch predicts a regional advantage of about 1.6 (Appendix 8.5). The concentrations of propranolol derived in the transplanted hearts, whether 
the drug was given $1 . c$. or $1 . v \cdot$, were not different. Thus intracoronary administration of propranolol did not enhance the local tissue concentration. The relatively high flow to the target organ $\left(Q_{b}=7.2\right.$ t0.5 milmin) limits any possible reglonal advantage. In general, a limited regional advantage of local over systemic drug administration can be expected to hold true for target organs with relatively high flows, such as the kidney and the 1iver. In low flow organs, however, as for example the testis, it can be shown that a great reglonal advantage can be achleved by local administration of the kinetically proper drug (chapter 10).

In this study, the target organ was artificially placed in serles with the liver. In nature, an organ like the 1 ung may act as a clearance organ situated in series with a target organ as was demonstrated by the advantages of intrarenal aver systemic administration of bradykinin (Wedlund et a1, 1983; Smits and Brody, 1984). In other words, not only the extraction of the locally infused drug by the target organ but also the extraction of any organ in series with the target organ w11 influence the systemic advantage.

To summarize, the clearance capacity of the liver in our cardiac grafts was not reduced. Hence, the first pass effect of elimination of the liver ylelded a brisk reduction of the systemic drug concentration during local as compared to systemic delivery. Thus, the systemlc advantage was very high. However, the regional advantage was limfted. These results provide an experimental pharmacokinetic basis for local fmmunotherapy: by local delivery of an tmmunosuppreslve agent with a high hepatic clearance it should be possible to reach therapeutic concentrations in the transplanted hearts but to reduce the systemic side-effects drastically, as compared to systemic delivery of the same drug at the same dose. Currently, experfments are being undertaken to extend these observations to the class of immunotherapeutic drugs. 
The concentration in a systemic artery at steady state during systemic drug administration $\left(\mathrm{C}_{\mathrm{S}}\right)$ is calculated by

$$
\mathrm{C}_{\mathrm{S}}=\operatorname{lnf} / \mathrm{Cl}
$$

where inf equals the infusion rate and $\mathrm{Cl}$ the clearance of the drug. Here, $C_{S}$ equals the concentration in the artery supplying the target organ $\left(\mathrm{C}_{\mathrm{T}}\right)$.

During local (i.c.) Infusion, $C_{S}$ is defined by

$$
\mathrm{C}_{\mathrm{S}}=\frac{\left(1-\mathrm{E}_{\mathrm{T}}\right) \cdot \inf }{\mathrm{CI}}
$$

where $E_{T}$ represents the extraction ratio of the drug by (the target organ and) the liver. Here, the concentration in the artery supplying the target organ $\left(C_{T}\right)$ is defined by

$$
\mathrm{C}_{\mathrm{T}}=\frac{1-\mathrm{E}_{\mathrm{T}} \cdot \operatorname{lnf}}{\mathrm{C} 1}+\frac{\ln E}{\mathrm{Q}_{\mathrm{T}}}
$$

where $\mathrm{Q}_{\mathrm{T}}$ equals the blood flow through the target organ.

The reglonal advantage of local over systemic drug delivery is expressed by the ratio of the concentration in the artery supplying the target organ at local $\left(\mathrm{C}_{\mathrm{TIC}}\right)$ and systemic $\left(\mathrm{C}_{\mathrm{T} 1 \mathrm{v}}\right)$ administration of the drug:

$$
\frac{\mathrm{C}_{\mathrm{T}}}{\mathrm{C}_{\mathrm{T}} \mathrm{T}_{\mathrm{iC}}}=\frac{\frac{\left(\mathbb{1}-\mathrm{E}_{\mathrm{T}}\right) \cdot \inf }{\mathrm{Cl}}+\frac{\inf }{\mathrm{Cl}}}{\frac{\mathrm{inf}}{\mathrm{Cl}}}=\left(1-\mathrm{E}_{\mathrm{T} T}\right)+\frac{\mathrm{Cl}}{\mathrm{Q}_{\mathrm{T}}}
$$

The systemic advantage of local over systemic drug delivery is expressed by the ratio of the systemic concentration at local ( $\left.\mathrm{C}_{\mathrm{Stc}}\right)$ and systemic $\left(\mathrm{C}_{\mathrm{Siv}}\right)$ administration of the drug:

$$
\frac{\mathrm{C}_{S_{i c}}}{C_{S_{i v}}}=\frac{\frac{\left(1-E_{T}\right) \cdot i n f}{C l}}{\frac{i n f}{C l}}=1-E_{T}
$$


9. LOCAL DRUG ADMINISTRATION: KINETIC EVALUATION OF INTRAHEPATIC AND INTRAVENOUS INFUSION OF S-ACENOCOUMAROL

\subsection{INTRODUCTION}

In a previlous study (chapter 2 and Daemen et al, 1986a), the hepatic clearance of S-acenocoumarol (AC) was found to be dose-dependent. The hepatic clearance of AC was high at infusion rates below 0.6 $\mathrm{ug} / \mathrm{min}$ and decreased at higher infusion rates. A saturable hepatic binding aite of low capactity but high affinity was observed, which could account for this dose dependency.

According to theoretical considerations a regional advantage of ditect intrahepatic administration of AC over its systemic administration is not to be expected, since the substance is eliminated by the target organ only. This latter characteristic also determines the systemic advantage. The extraction ratio of $\mathrm{AC}$ is small. Therefore, the systemic advantage will be limited. In a simulation study (Smits and Thifssen, 1986) on the advantages of local over systemic drug administration of a drug that is cleared by the target organ, it was shown that higher target organ concentrations can be achieved by the local administration of a drug as compared to its systemic administration, especially in the interval before steady-state conditions are achlleved. Using the liver as a target organ this would imply that hepatic binding sites of low capacity but high affinity can become saturated by the local but not by the systemic infuston of AC at an Infusion rate even below $0.6 \mathrm{ug} / \mathrm{min}$. Although no regional advantage w11 be obtained at ultimate steady state, in pre-steady-state conditions higher local concentrations will be achleved. A saturated binding site would decrease the clearance of AC (see a1so chapter 2).

To examine these latter hypotheses, $A C$ was administered via the systemic route and vila the hepatic arterial route at an infusion rate of $0.5 \mathrm{ug} / \mathrm{min}$ in anesthetized rats. Liver $\mathrm{AC}$ concentrations were determined at different tines in one animal with the biopsy technique (chepter 5). 
Male inbred Wistar Kyoto rats, weighing $250-300 \mathrm{~g}$, were used. Before the experiment, the animals were on standard lab food and tap water. All experiments were performed in anesthetized animals. For anesthesia, $60 \mathrm{mg} / \mathrm{kg}$ pentobarbital was given intraperitoneally. The body temperature was controlled rectally and maintained at $37.5^{\circ} \mathrm{C}$ by a thermostatically controlled heat lamp. A PE-10 catheter was introduced in a retrograde fashion into the gastroduodenal artery (chapter 2) for hepatic arterlal drug administration. Another PE-10 catheter was introduced into the femoral vein for intravenous drug admintstration as well as into the femoral artery for blood sampling. Liver biopsiles were taken as described earlier (chapter 5).

\subsubsection{Experimental protocol}

In the first series of animals, the distribution of AC in the liver during its administration via the two routes was investigated. $A C$, dissolved in phosphate buffer, $0.1 \mathrm{M}, \mathrm{pH} 8.0$, was given at a constant rate of infuston $(0.5 \mathrm{ug} / \mathrm{min})$ either via the femoral veln or the hepatic artery. Liver blopsies were taken at $30 \mathrm{~min}$ of infusion from the edge or the central part of each 1 iver 1 obe.

To another series of animals ( 3 groups of 6 anlmals), AC was delivered also at an infusion rate of $0.5 \mathrm{ug} / \mathrm{min}$ by either one of the two routes. Here, 11 ver blopsies from the edge and an artertal blood sample (100 ul) were taken at $t=15,30,60,90,120,150$ and $180 \mathrm{mln}$.

Samples were prepared for AC determination as described in chapter 2 .

\section{2 .2 Statistical analysis}

Al1 data are presented as mean I SEM (except for data in table 9.1). Data were evaluated by analysls of varlance. Signiffcant differences between the groups were determined by a modifled t-test. Signiflcance was defined at the $\mathrm{p}<0.05$ level. 
Table 9.1: Comparison between the concentration of $\mathrm{AC}$ (ug/g) in a blopsy taken from the centre (C) or from the edge of a liver (P) lobe, after 30 minutes of infusion, either systemically or intrahepatically.

Route of

administration

Systemlic

Intrahepatic

Rat number

1

2

3

4

Place of the

blopsy

p

c

c $\quad$ p $\quad$ c

Left latera 1 lobe 0.70

0.76

0.78

$0.87 \quad 0.35$

$0.33 \quad 0.34$

0.39

Right lateral lobe 0.60

0.70

$0.74 \quad 0.78$

$\begin{array}{lll}0.39 & 0.41 & 0.30\end{array}$

0.38

Medlan lobe left

central part

$0.60 \quad 0.69$

$0.78 \quad 0.73$

0.38

0.44

$0.43 \quad 0.40$

Caudate lobe

0.65

0.71

0.75

0.80

$\begin{array}{lll}0.38 & 0.39 & 0.37\end{array}$

0.43

\subsection{RESULTS}

\subsubsection{Distribution of $\mathrm{AC}$ in the liver}

In table 9.1 , the hepatic concentrations of $\mathrm{AC}$ at different sites in the liver are deplcted. Liver biopsies were taken from the periphery or the centre of the liver after 30 min of infusion (systemic or loca 1). It can be seen that $\mathrm{AC}$ was evenly distributed in the liver. It can also be seen that at this time point, the hepatic AC concentration was dependent on the route of adminlstration. At local administration the liver concentrations were about half of those at systemic administration.

\subsubsection{Influence of the route of administration}

The concentration time relations for $A C$ in plasma and in liver tissue are deplcted in fig. 9.1 and 9.2, respectively. As can be seen systemic plasma concentrations of $A C$ were dependent on the route of administration. Plasma concentrations of AC administered intrahepatically were $25 \%$ lower than plasma concentrations during systemic administration $(p<0.05)$. The ultimate plateau concentration of $A C$ in the 


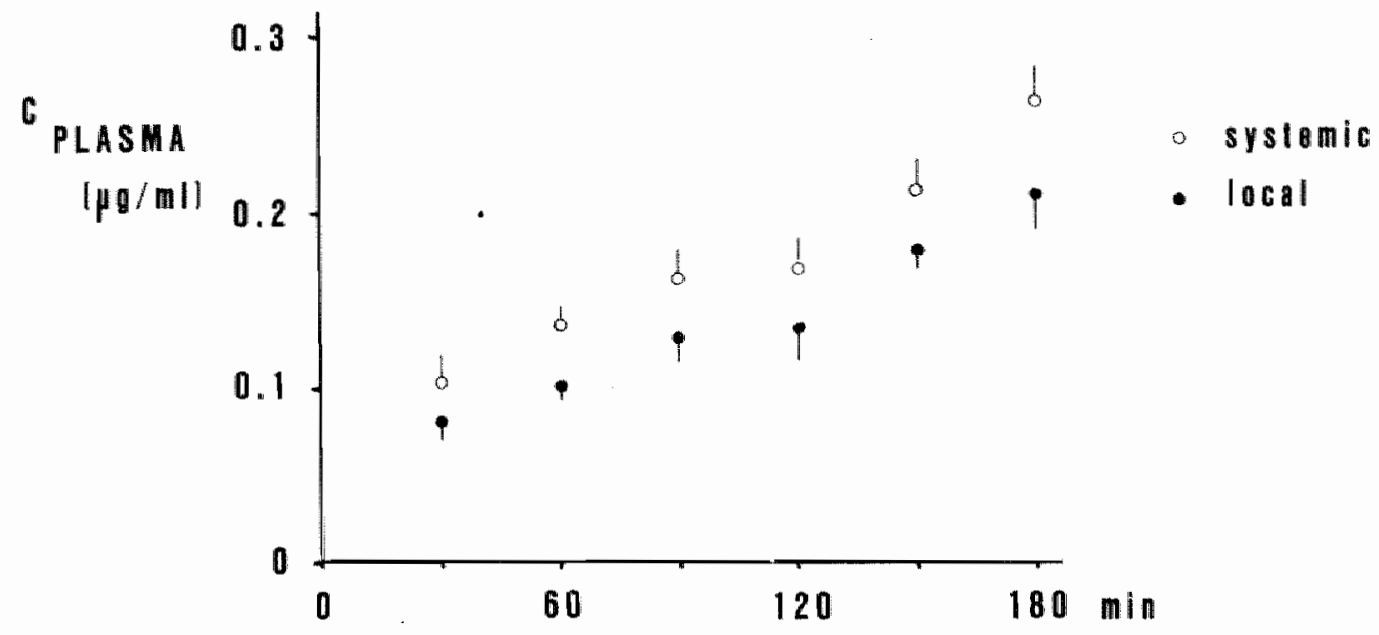

Fig. 9.1: Influence of the route of administration (systemic or intrahepatic) on the plasma concentration of AC (ug/mi) after a constant rate of infusion $(0.5 \mathrm{ug} / \mathrm{min}$ ) (mean $\pm \mathrm{SEM}$, $\mathrm{n}=6$ ).

* p<0.05 as compared to systemic infusion $(0-180 \mathrm{~min})$.

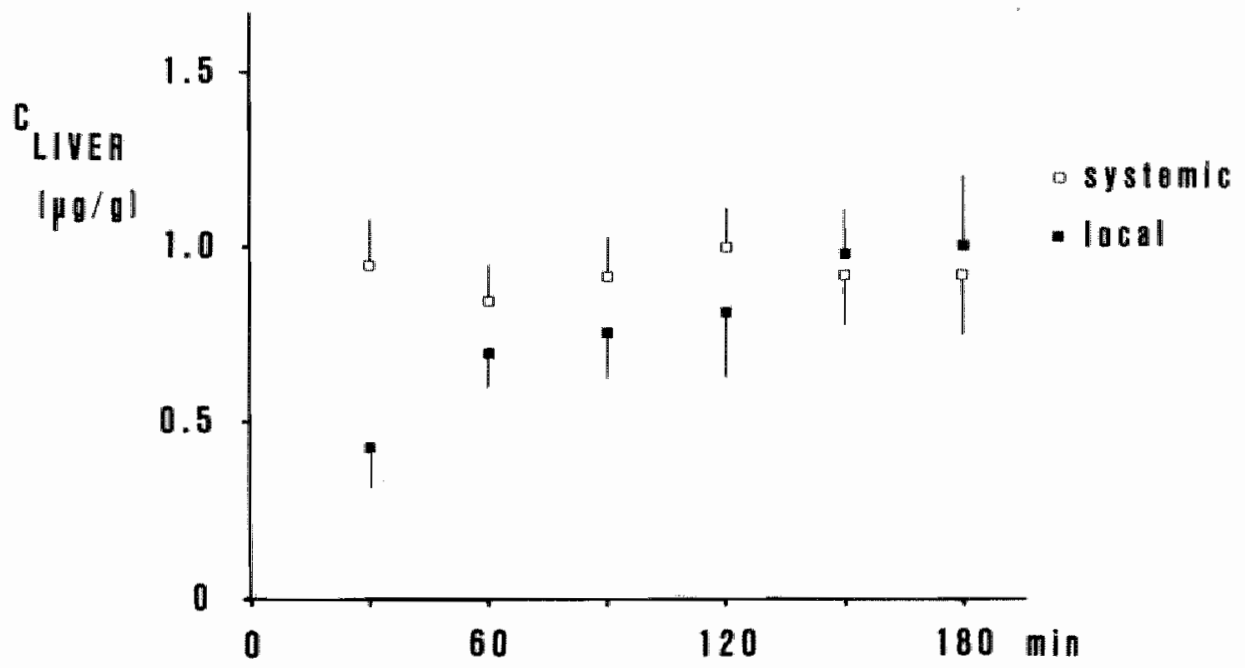

Fig. 9.2: Influence of the route of admintstration (systemic ot intrahepatic) on the liver concentration of $\mathrm{AC}(\mathrm{ug} / \mathrm{g})$ after a constant rate of infusion $(0.5 \mathrm{ug} / \mathrm{m} / \mathrm{n})$.

* p<0.05 as compared to systemic infusion $(0-120$ min). 
liver (approximately $1 \mathrm{ug} / \mathrm{g}$ ) was also dependent on the route of entry. Liver concentrations, however, were lower during local than during systemic $A C$ administration in the time period before steady state was achieved.

\subsection{DISCUSSION}

As may be expected, systemic plasma concentrations of acenocoumarol were found to be dependent of the route of administration (fig. 9.1). Following the first pass effect of extraction by the 11ver $A C$ plasma concentrations in the locally infused group were lower than in the systemically infused group. Concentrations of AC in liver biopsies taken at the same time from different sites in the liver indicate that AC is distributed homogeneously over the different liver lobes and that this distribution is independent of the route of administration (table 9.1). The outcome of preliminary experiments in which $A C$ was administered via the portal veln using the same infusion protocol as above indicates that the systemic and hepatic concentrations at portal venous admintstration are comparable with those achleved by hepatic artertal infusion. These findings are in accordance with literature reports. The route of hepatic administration is known to influence the avallability of high but not of low hepatic clearance substances (Shand et al, 1975; He and Huang, 1981; Ahmad et a1, 1984; Didolkar et al, 1984). AC can be classifled as a low hepatic clearance subtance.

According to theoretical considerations on the advantages of local drug admintstration (chapter 1), no reglonal advantage of intrahepatic over systemic AC administration may be expected at steadystate conditions. Indeed, as can be seen in fig. 9.2, no advantage was observed during hepatic arterial infusion of $\mathrm{AC}$ as compared to its systemic infusion. On the other hand, before steady-state conditions were achieved the drug concentration in the target organ should be higher durling local than during systemic administration of the same drug at the same dose (Smits and Thijssen, 1986). This, however, was not observed in our experiments. We found that although the ultimate 
steady-state levels were comparable, the liver did bind AC dellvered vila the systemic route faster than $A C$ admintstered via the local route. This result suggests that the locally delivered AC is not as available for hepatic binding nor for hepatic eltmination as systemically delivered $A C$. The preference of the hepatic binding site for systemically delivered $A C$ might be due to a difference in the distrtbution of AC in the several Intrahepatic spaces or to shunting of locally administered AC. Shunting is unlikely, since plasma concentrations of local administration were lower than those of AC during systemic administration. A third explanation might be that locally admintstered $A C$ is not available for binding but only for el imination* To sumarize intrahepatic infusion of AC lowers the systemic drug concentrations as compared to systemic infusion, a finding concomitant with theoretical predictions. A reglonal advantage of intrahepatic over systemic AC infusion can not be achleved. Initially intrahepatic infusion even lowers the hepatic concentration of $\mathrm{AC}$. 
10. LOCAL DRUG ADMINISTRATION: KINETIC EVALUATION OF LONG-TERM INTRARENAL AND INTRATESTICULAR INFUSION OF S-ACENOCOUMAROL IN CONSCIOUS RATS

\subsection{INTRODUCT TON}

This study was performed to substantiate the theoretical considerations on the advantages of local drug administration, by measuring the actual reglonal advantage during intratesticular infusion of S-acenocoumarol (AC) as compared to systemic administration and to provide a kinetlc basis for the effects of Intratesticularly administered $\mathrm{AC}$ on the vitamin $K$ dependent systems in the testis (chapter 11).

By direct Infusion of $\mathrm{AC}$, at the same dose, Into one kidney the effect of an increase of the blood flow of the target organ on the reglonal advantage was studied. In a physiological pharmacokinetic flow scherne the kidney and the testis differ in amount of flow by a factor 50 (about 10 and $0.2 \mathrm{ml} / \mathrm{min}$ respectively; Nishiyama et al, 1976).

The effect of an increase of the systemic clearance on the reglonal advantage was investigated by inducing the hepatic AC clearance with phenobarbital co-treatment.

\subsection{EXPERTMENTAL SECTION}

Wlstar rats were purchased from WInkelman (Borchen, West Germany). Before and throughout the whole experiment the rats were on stoandard food and tap water.

\subsubsection{Intratesticular administration}

Male rats, agling 14-16 weeks, were used. Under light ether anesthesia, a femoral artery and a testicular catheter were placed, for blood sampling and drug administration respectively. The testicular catheter was placed as described in chapter 2 . 


\section{Experimental protocol}

$A C$, solved in $0.1 \mathrm{M}$ phosphate buffer, $\mathrm{pH} 8.0$, was infused at a constant rate of $1 \mathrm{ug} / \mathrm{hr}$ via an osmotic minipump (Mode1 2001, Alzet, Palo Alto, Ca, USA) during five days. Preliminary experiments showed that AC administered at a rate of $1 \mathrm{ug} / \mathrm{hr}$ subcutaneously for several days caused no bleeding complications. Arterial blood samples ( $0.5 \mathrm{ml})$ were taken on the third, fourth and fifth day of infuston. On the fifth day the animals were euthanlzed. Blood, Hiver, both testes and kidneys were removed.

Another group of animals received phenobarbital ( $1 \mathrm{mg} / \mathrm{mi}$ ) in their drinking water, starting 3 days before the experiment, to increase the hepatic clearance of $A C$, and followed the protocol as above (intratesticular AC administration ( 1 ug/hr) during 5 days).

\subsubsection{Intrarenal administration}

AC $(n=8)$ was infused directly into the right kidney of male Wistar rats, aging 14-16 weeks. For this purpose, an elongated PE-10 catheter was introduced in a retrograde fashion in the right suprarenal artery under a 11 ght ether anesthesia following the procedure described in chapter 2 . The other end of the catheter was tunneled to the neck and attached to an osmotic minipump (Mode1 2001, Alzet, Palo Alto, $\mathrm{Ca}, \mathrm{USA})$, filled with $\mathrm{AC}$ ( 1 ug/u1). At the fifth day of Infusion the animals were sacrificed and kidneys, testes, 11 ver and blood removed.

\subsubsection{Analytical procedures}

After adding $0.1 \mathrm{M}$ trisodium citrate (citrate : blood volume = 1:9) the blood samples were centrifugated and the plasma stored at $-20^{\circ} \mathrm{C}$ until assayed. The removed organs were rinsed and homogenized in three volumes $(w / v)$ of lice-cold buffer, $0.02 \mathrm{M}$ tris HC1, $0.15 \mathrm{M} \mathrm{KCl}$, $\mathrm{pH} 7.4$, using the Potter technique.

AC concentrations were determined in plasma, 11ver, testis and kidney homogenate on HPLC according to the procedure described by Thijssen et al (1983b) and $\mathbb{1}$ ) chapter 2. Plasma coagulation activity was measured using the prothrombin time. 


\subsubsection{Statistical analysis}

Datá are presented as mean \pm SEM. Groups were composed of 7-9 anfmals. Significances were calculated using Student's t-tests. Differences were regarded to be statistically significant if $p<0.05$.

\section{OAC}

- AC - PHENOBARB I TAL

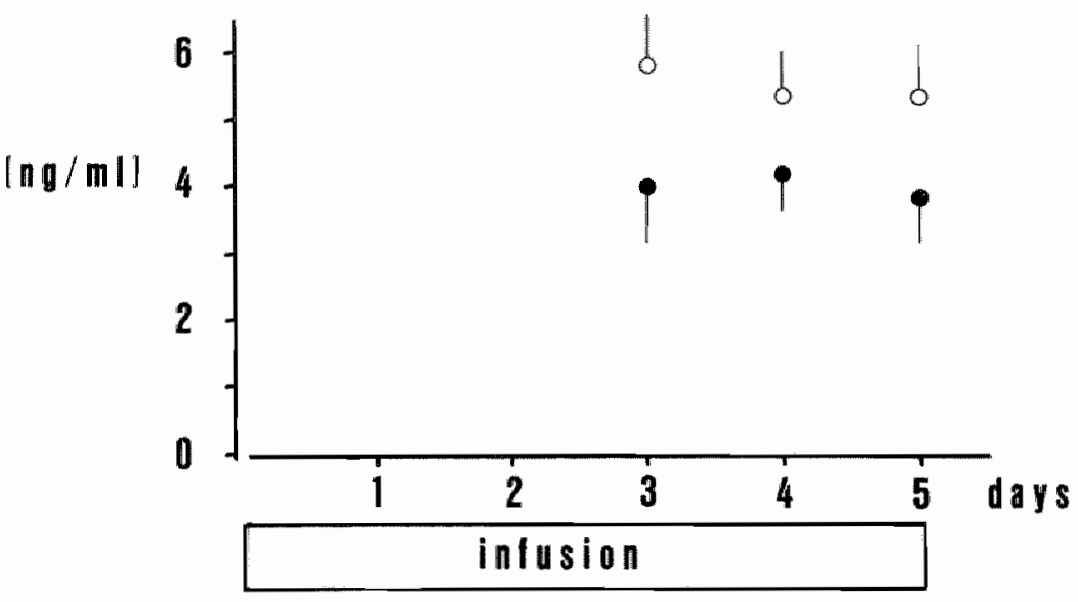

Fig. 10.1: Plasma concentrations of AC during its intratesticular infusion for 5 days with (•) or without (o) phenobarbital co-treatment (mean $\pm \mathrm{SEM}, \mathrm{n}=9$ ).

\subsection{RESULTS}

\subsubsection{Intratesticular administration}

The plasma concentrations of $A C$ on the third, fourth and fifth day of infusioa are depicted in fig. 10.1. AC concentrations were between 5 and $6 \mathrm{ng} / \mathrm{ml}$ in normal rats, while co-treatment with phenobarbital reduced the plasma concentration to $3-4 \mathrm{ng} / \mathrm{ml}$. As the half11fe time of elimination of AC in the rat is short (approximately 24 min) steady state conditions during constant rate infusions are achieved within the first day of infusion.

On the fifth day, the liver contalned $360+30 \mathrm{ng} / \mathrm{g}$, the kidneys $31+2 \mathrm{ng} / \mathrm{g}$ AC (table 10.1). In the left testis $771+90 \mathrm{ng} / \mathrm{g}$ AC was found, while the right testis contalned only $26 \pm 3 \mathrm{ng} / \mathrm{g}$. Plasma clear- 
Table 10.1: Mean + SEM of the values of all measured and calculated parameters during intratesticular (with or without phenobarbital co-treatment) and intrarenal infusion of AC for 5 days $(n=7-9)$. a: $p<0.05 ;$ b: $p<0.01$ (as compared to intratesticular infusion); c: Ratio of the concentration in the target organ and its contralateral organ; $d: Q_{m}$ (testis) $=0.2 \mathrm{ml} / \mathrm{min}$, (Nishiyama et a. 1976 ); N: nor mal; n.d.: not determined.

$\begin{array}{ll}\text { Intratesti- } & \text { Intratesti- Intrarenal } \\ \text { cular } & \text { cular }+ \text { pheno- } \\ & \text { barbltal }\end{array}$

Infusion rate (ug/hr)

1

1

1

AC concentration in

plasma ( $\mathrm{ng} / \mathrm{m} 1$ )

liver ( $\mathrm{ng} / \mathrm{g}$ )

left testis $(\mathrm{ng} / \mathrm{g})$

right testis (ng/g)

right kidney ( $\mathrm{ng} / \mathrm{g})$

left kidney $(\mathrm{ng} / \mathrm{g})$

$5.0+1$
$360+30$
$771+90$
$26 \pm 3$
$31 \pm 2$
$31 \pm 2$

$3.4+0.4$

Plasma clearance

(ml/min)

Liver to plasma

concentration ratio

Reglonal advantage ${ }^{c}$

(measured)

Reglonal advantage

(calculated

by $\left.1+C 1 / Q_{T}\right)^{d}$

18.0
N

$3.6+0.5^{a}$
$340+25$
$860+30$
$12+0.6^{a}$
n.d.
n.d.

$\mathbb{N}$

$4 \cdot 6+0 \cdot 3^{b}$

$72+8.0$

$22+2.0$

$98+5 \cdot 0^{\mathrm{a}}$

$29+2.0^{\mathrm{a}}$
$3.0+0.5$

$51+7.0$
$0.9+0.05$

$51 \pm 7.0$
$0.9+0.05$

$5.5+1$ $289 \overline{+17}$

$25 \overline{+4}$

$25 \overline{74}$

$30 \overline{+2}$

$34+3$

N

$-$

23

1. 3

ance was $3.4+0.4 \mathrm{ml} / \mathrm{min}$. Plasma coagulation activity was not affected.

Phenobarbital increased the hepatic clearance of AC to $4.6+0.3$ $\mathrm{ml} / \mathrm{min}$. It had no effect on the concentration in the left testis: $860 \pm 30 \mathrm{ng} / \mathrm{g}$. In the right testis $\mathrm{AC}$ concentration was reduced to $12+0.6 \mathrm{ng} / \mathrm{g}$. The hepatic AC content was comparable to the control experiment. Plasma coagulation activity was normal. 


\subsubsection{Intrarenal administration}

As can be seen in table 10.1, the plasma and 11ver concentratlons of $A C$ on the fifth day of infusion were $5.5+1 \mathrm{ng} / \mathrm{ml}$ and $289+1.7$ $\mathrm{ng} / \mathrm{g}$ respectively. In the right kidney $1 . e$. the target organ, $29.6+2$ $\mathrm{ng} / \mathrm{g}$ of $\mathrm{AC}$ was found and $1 \mathrm{n}$ the left $\mathrm{kldney} 33.6+3 \mathrm{ng} / \mathrm{g}$. The concentrations in the testes were $25+4 \mathrm{ng} / \mathrm{g}$. Plasma clearance was $3.0+0.5$ $\mathrm{ml} / \mathrm{min}$. Again plasma coagulation activity was not affected.

\subsubsection{DISCUSSION}

Direct infusion into the testis of S-acenocoumarol, a drug which is cleared only by hepatic blotransformation, increased the drug concentration in the infused testis about 20-fold as compared to the contralateral, systemically Infused testis. The infusion protocol used In this study was the same as that in the study on the effects of direct intratesticular infusions of $A C$ on vitamin $\mathbb{K}$ dependent systems In the testis of the rat (chapter 11). Therefore, the results of this study provide a kinetlc base for the effects observed in the latter study. The calculated values for the reglonal advantage during intratesticular and intrarenal infusion were comparable with the observed values (table 10.1). In this study, the reglonal advantage is defined by the ratio of the concentration in the directly infused organ and Its contralateral, systemically infused organ. We studied the effects of an enhanced drug clearance on the reglonal advantage during intratesticular infustion of $A C$ by adding phenobarbital ( $1 \mathrm{mg} / \mathrm{ml}$ ) to the drinking water. Phenobarbital co-treatment increased the hepatic clearance about $35 \%$ while the observed regional advantage increased about $32 \%$, as evidenced by a decreased concentration in the systemically infused testis.

A comparison of the regional advantages observed during Intratesticular and intrarenal infusion of AC clarifles the importance of a low blood flow of the target organ for achleving high reglonal advantages: a high reglonal advantage achieved with intratesticular infusion vs non with intrarenal infusion.

The high reglonal advantage observed during intratesticular in- 
fusion enabled us to reduce the infused dose in such a way that, on the one hand relatively high drug concentrations were achieved at the target site, while, on the other hand, the systemic concentrations were wery low. In other words, the reglonal advantage was used to lower the dose and thus the systemic bleeding complications.

In summary, the results of these experiments give experimental support to the theories on local drug administration. Only the combination of a drug which is not cleared in the target organ and a target organ with a relatively low blood flow results in high reglonal advantages. The confirmation of the kinetic theory provides the possibility to reduce the systemic side-effects observed during equally effective systemic infusion, by reducing the infused dose during local drug administration. 
11. SUPPRESSION OF VITAMIN $K$ DEPENDENT ENZYME SYSTEMS IN THE TESTIS OF THE RAT DOES NOT AFFECT FERTILITY

\subsection{INTRODUCTIOH}

Oral antlcoagulants of the coumarin type, as for lnstance acenocoumarol, warfarfin and phenprocoumon, interrupt the vitamin $K$ cycle In the liver by blocking the enzyme vitamin $\mathrm{K}$ epoxide reductase. This reduces the degree of carboxylation of several coagulation factors in the liver. Vitamin $K$ dependent enzyme systems are also shown to be present in several non-hepatic tissues (Vermeer et al, 1982; Thijssen et $a 1,1986)$, as for instance the testis. To date any function of the $v$ iltamin $K$ dependent systems in the testis is unknown. It is suggested that vitamin $K$ dependent systems may play a role in fertility (Vermeer et $a 1,1984 \mathrm{~b})$.

The purpose of this study was to elucldate more of the function of these systems in the testis. A frequently used method for investigating the function of enzymes is to study the function of a system that lacks the enzyme, or to study the function of a system in which the activity of the enzyme is depressed. Since 4-hydroxycoumarins are known to depress the activity of vitamin $K$ dependent systems in the testis of the rat (Thijssen et al, 1986), the second option is preferred here. Subsequently the route for the administration of the 4hydroxycoumarin had to be chosen. On systemic administration coumarin derivatives are known to distribute poorly to the testis of the rat and to accumulate in the 11ver (ThIfssen et al, 1985; Daemen et a1, 1986a and chapter 2). Assuming a relationship between the concentration of a drug at a target site and its effect, relatively high concentrations have to be administered to the testis to depress its vitamin $K$ dependent enzyme systems. Systemic administration of these high doses, however, would certainly depress the synthesis of coagulation factors in the 1lver and cause serious bleeding disorders. Direct administration of a coumarin derivative into the testis would on the one hand result in high concentrations in the testis and would on the other hand decline the drug concentration in the 11ver. Regarding the theoretical considerations of the advantages of local over systemic 
drug administration the direct administration of a hepatically cleared drug into a target organ with a low blood flow is an ideal combination for achieving high local concentrations (chapter 1). For this purpose, S-acenocoumarol is the drug of first cholice from the group of the 4hydroxycoumarins, because of its relatively high liver clearance in the rat. Hence in theory, the local infusion of a drug, which is cleared in the liver, into a target organ with a low blood flow provides ideal conditions to study the effects of depression of vitamin $k$ dependent enzyme systems on the function of the testis (1.e. on fertility). As was demonstrated in chapter 10, high testicular concentrations can indeed be achieved. In this study the effects of long-term administration of $S$-acenocoumarol on the vitamin $\mathbb{K}$ dependent systems in the testis are described.

\subsection{EXPERIMENTAL SECTION}

Wistar rats were purchased from Winkelman (Borchen, West Germany). Before and throughout the whole expertment the rats were on standard lab food and tap water.

\subsubsection{Intratesticular administration}

Male rats, aging 14-16 weeks, were used Under light ether anesthesia a testicular catheter was placed, for drug administraton (see chapter 2). AC solved in 0.1 M phosphate buffer, pH 8.0 was infused at a constant rate of $\mathrm{L}$ ug/hr via an osmotlc minipump (Model 2001, Alzet, Palo Alto, Ca, USA), connected to the other end of the catheter, during 5 days. Preliminary experiments showed that infuslon of $5 \mathrm{ug} / \mathrm{hr}$ resulted in bleeding complications. An infusion rate of 1 ug/hr for several weeks revealed no bleedings. On the fifth day the animals were euthanized and the 11 ver and both testes removed.

\subsubsection{Fert11ity experiments}

Male wistar rats aging 7 weeks at the start of the experiment were used. According to the above described procedure, one end of a small silastic catheter was placed into the left testis, while the 
other end was connected to an osmotic minlpump placed subcutaneously between the shoulder blades. The right testis was removed. A group of 30 female Wistar rats (aging 9 weeks) was sterilized one week before the experiment by 1igation of both uterine horns. A group consisting of 50 female animals underwent no surgery.

\subsubsection{Experimental protocol}

AC or saline $(N=5 / 5)$ was infused at a constant rate ( 1 ug/hr of $\mathrm{AC}, \mathrm{l}$ ul/hr of saline) for 8 weeks. New osmotic minipumps were placed every week. Each rat received elther AC or saline throughout the whole experimental perilod. The first 50 days of the infusion a male rat was housed with three sterlitzed female rats to stimulate spermatogenesis. On the 55th day of the experiment, the three sterilized female rats were replaced by flve nonsterilized female rats. On the 56 th day of the experiment, a 11 male animals were euthanized and plasma, liver and testis removed. From that day on, the female rats were housed separately and their offspring was counted.

\subsubsection{Analyt1cal procedures}

The removed testes were rinsed extensively in ice-cold saline to wash out drug in the extracellular fluld and homogenized in three volumes (w/v) of icecold buffer, $0.02 \mathrm{M} \mathrm{Tris} \mathrm{HCl}, 0.15 \mathrm{M} \mathrm{KC1}, \mathrm{pH} 7.4$, using the Potter technique.

Liver microsomes were made following the procedure of Thijssen et al (1986). The activity of the enzyme vitamin $K$ epoxide (Ko) reductase was measured separately in 11 ver and testis homogenates on HPLC, followling the procedure of Thljssen et al (1986). In short, 20 ul samples were incubated at $37^{\circ} \mathrm{C}$ for $3 \mathrm{~min}$ in 75 ul $0.02 \mathrm{M}$ Tris-HCL, pH 7.4. DTT ( $5 \mathrm{ul}, 0.1 \mathrm{M}$ was added and allowed to preincubate with the enzyme for 3 min at $37^{\circ} \mathrm{C}$. The vitamin $\mathrm{K}$ epoxide reductase was started by adding $4 \mathrm{ug}$ vitamin $\mathrm{K}$ epoxide in 2 ul isopropanol. The incubation lasted for $30 \mathrm{~min}$. The reaction was stopped by adding $0.9 \mathrm{ml}$ isopropanol contalining $5 \mathrm{ug}$ tocopherol acetate (Sigma, St. Louis, MO, USA) for internal standardization. Analysis of vitamin $K$ and vitamin $K$ epoxide was performed as follows. Substrate and product were extracted with $0.6 \mathrm{ml}$ hexane contalning $0.5 \mathrm{ml} \mathrm{AgNO}_{3}(0.01 \mathrm{M})$ for removing DTT from 
the organic phase. The hexane phase was washed with $0.5 \mathrm{ml}$ of $1 \% \mathrm{NaCl}$ in $\mathrm{H}_{2} \mathrm{O}$, where after it was evaporated at $37^{\circ} \mathrm{C}$ under a nitrogen gas stream. The residue sa dissolved in 50 ul isopropanol and analyzed by HPLC.

Vitamin $\mathrm{K}$ and $\mathrm{KH}_{2}$ dependent carboxylase activity was determined in testis microsomes, following the incorporation of ${ }^{14} \mathrm{CO}_{2}$ in a pentapeptide (FLEEL), following the procedure of Vermeer, 1984a. Plasma coagulation activity was determined using the prothrombin time. Protein content was determined following the method of Lowry et al (1951).

In the fertility experiment, the sperm cells in the cauda epididimys were counted in a counting chamber, inmediately after euthani$z$ ing the animals. The mobile fraction of the total amount of counted cells was determined. After removing and weighing, the testis was frozen quickly $\left(5 \mathrm{~min}\right.$ at $-70^{\circ} \mathrm{C}$ ) and a representative piece was cut with a knife, fixed in formalin ( $4 \%$ in phosphate buffer, $0.1 \mathrm{M}, \mathrm{pH}$ 7.4) and stained with haemato-oxyline eosine for morphological analysis. The remaining part was prepared for reductase and carboxylase assay, as described above.

\subsubsection{Statistical analysis}

Data are presented as mean $\pm S E M$. Differences were compared using Student's t-test. The 0.05 level of probability was used as the level of silgnificance.

\subsection{RESULTS}

\subsubsection{Five days expertments}

Following the administration of $\mathrm{AC}(1 \mathrm{ug} / \mathrm{hr})$ for 5 days into the left testis, vitamin $K$ epoxide reductase activity in liver microsomes was reduced by about $50 \%$. If the reductase activity in total liver homogenates was estimated a similar suppression was observed (fig. 11.1). We therefore decided to measure vitamin $\mathrm{K}$ epoxlde reductase activity in testis in homogenates and not in microsomes, whlch enabled us to measure the activity in each individual animal (for measurements of vitamin $k$ epoxide reductase and vitamin $k$ dependent 
carboxylase in testis microsomes, at least 3 testes have to be pooled). N.B.: Vitamin $K$ epoxide reductase activity in tissue homogenates 1lke microsomal reductase needs DTT to function and is equally susceptible to warfarin inhibition as microsomal activity. In the left testis, $26.4 \pm 5.0 \%$ and in the right testis, $64+8 \%$ of control testicular reductase activity was observed. Direct $A C$ administration did not change the $\mathrm{KH}_{2}$ dependent caxboxylase activity $\mathbb{L}$ the $\mathbb{1}$ fufused testis as compared to the non-infused testis. K dependent carboxylase activity, however, was reduced to $22 \%$ (table 11.1). Plasma coagulation activity was not affected.

Table 11.1: The effect of $\mathbb{1}$ ug/hr AC delivered directly to the left testis during 5 days on vitamin $\mathrm{K}$ and $\mathrm{KH}_{2}$ dependent carboxylase activity

Carboxylase activity ${ }^{a}$

$$
\mathrm{KH}_{2} \text { dependent } \mathrm{K} \text { dependent }
$$

Infused testis $\quad 1055 \quad 291$

$\begin{array}{lll}\text { Contralateral testis } & 1432 & 1298\end{array}$

$\mathrm{a}_{\mathrm{cpm} / \mathrm{mg}}$ protein microsomes in $\mathrm{AC}$ treated animals.

\subsubsection{Ferti11ty experiments}

Because of technical limitations, which lncluded infection and disconnection of pump and catheter, only three of five AC treated animals finished the infusion period of eight weeks. Four of five animals In the control group completed the experiment. The values of the determined parameters are presented in fig. 11.1, right panel. The activity of vitamin $K$ epoxide reductase in homogenates of the infused testis was $29.3+3.3 \%$ of control, which is comparable with the value of the infused testis in the 5 day infusion group. Hepatic vitamin $K$ epoxide reductase activity in AC treated animals was about half of the activity of the enzyme in the control group. Plasma coagulation acti- 
vity was unaffected again.

Mating behavior in the two groups was similar. The number and mobility of sperm cells of animals treated with $A C$ during a period of eight weeks were not different from control. The mating behavior in the two groups of animals was similar. Morphological analysts of fixed sperm cells and of testis tissue revealed no differences either. The litter size was $9.9+1.0$ in the $A C$ treated group and $11.0+0.6$ in the control group (statistically no significant difference) (table 11.2).

Tab1e 11.2: Effects of 1 ug/hr AC, dellvered directly to the left testis during 8 weeks on fertility parameters.

Control

Mobility (\% of 200 ce11s) $>75$

Litter size
11. $0+0 \cdot 6$

a Statistically not significant from control.

$\mathrm{AC}$

$>75^{\mathrm{a}}$

$9 \cdot 9+1 \cdot 0^{\mathrm{a}}$

\subsection{DISCUSSION}

Although the existence of speciflc vitamin $\mathrm{K}$ dependent proteins has been shown in various non-hepat1c tissues, their precise function is not known yet. The vitamin $K$ dependent bone protein osteocalcin probably prevents early calciflcation of the growing bone and regulates bone resorption (Lian et al, 1984). Any function of the vitamin $K$ dependent protein found in human sperm (Vermeer et a1, $198.4 \mathrm{~b}$ ) 18 not known.

The apparent selectivity of 4-hydroxycoumarins to distribute to the liver (Thijssen et a1, 1985; Daemen et a1, 1986a) does not facllitate the study of chronic suppression of non-hepatic vitamin $K$ dependent systems in the rat, since bleeding complications will terminate the experiment within a short time after start. The tool of target 


\section{VITAMIN KO-REQUCTASE ACTIVITY}

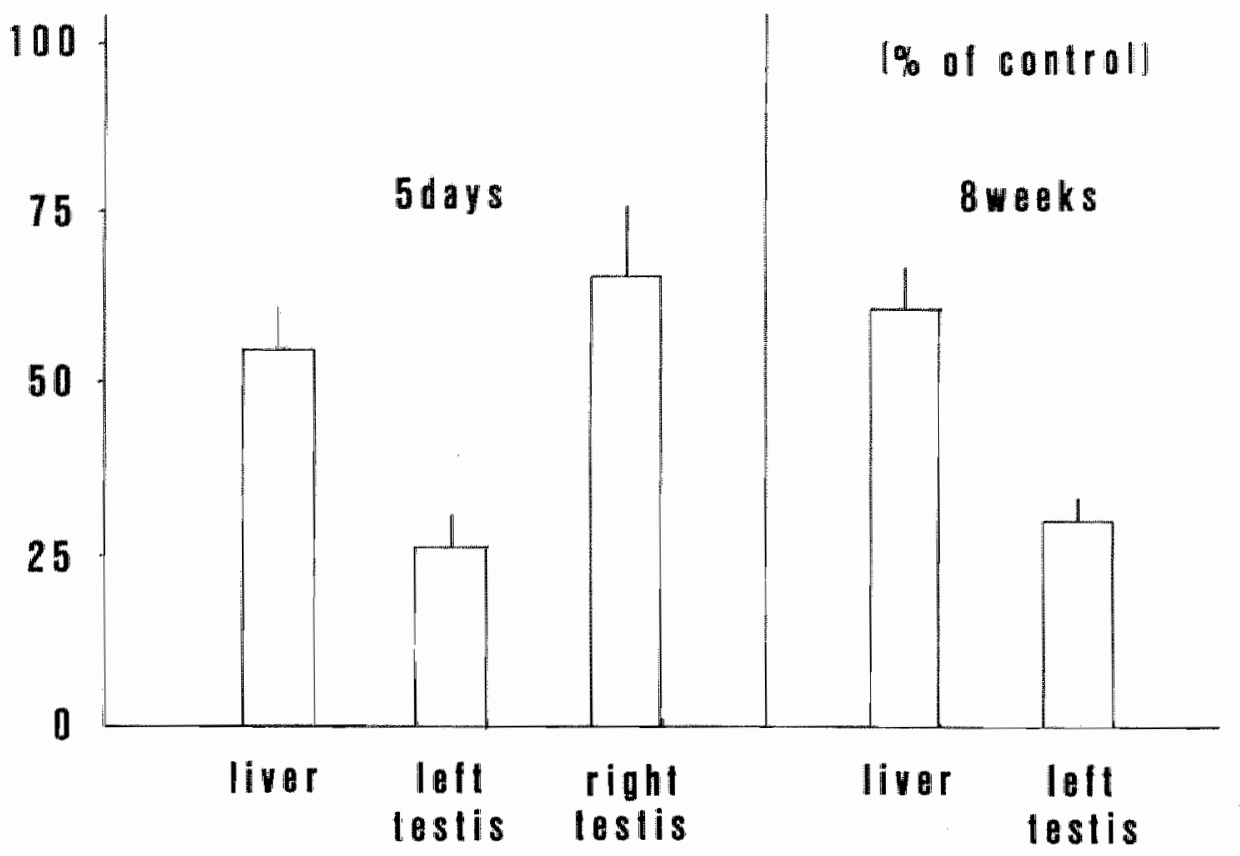

Fig. 11.1: The activity of the enzyme vitamin $K$ epoxide (Ko) reductase in the liver, infused left testis and in the contralateral, non-infused, right testis during constant rate infusion of S-acenocoumarol for 5 days (left pane1) and 8 weeks (right panel). Animals recelving an isotonic saline infusion served as control.

organ directed drug delivery was successfully applied here: on the one hand bleeding was prevented, while on the other hand high concentrations could be achleved in the testis (see chapter 10).

Durling the flve days of Infusion of $1 \mathrm{ug} / \mathrm{hr}$ AC KO reductase activity in the Infused testis was about $25 \%$ of control. Administrathon of the same drug at the same dase for elght weeks reduced $x 0$ reductase activity to an almost equal level. Adaptation of the enzyme systems apparently did not occur. Vitamin $K$ dependent carboxylase activity in the infused testis was reduced also to the about $25 \%$ of control. Notwlthstanding these pronounced blochemical effects of direct Intratesticular administration of $A C$, no effects on fertilty parameters could be detected: the quantity and quality of sperm cells derived from 8 weeks AC treated animals were comparable with those from control animals. Several arguments can be put forward to explain this discrepancy: (1) $80 \%$ reduction of vitamin ko reductase and vita- 
min $K$ dependent carboxylase in the testis is not suffictent to affect spermatogenesis or sperm function; (2) the vitamin $K$ cycle in the testis of the rat is different from that in the rat liver. Suppression of $K O$ and $K$ reductase might have been ineffective to interrupt the vitamin $K$ cycle since other reducing pathways preserve the cycle; (3) the infusion period of 8 weeks was too short to affect spermatogenesis, although it is known that spermatogenesis in the rat lasts about 40 days (Bennett and Vickery, 1970); (4) vitamin $\mathrm{K}$ dependent enzyme systems have no function in spermatogenesis nor in male fertlity.

In summary, suppression of the testis reductase by local administration of a coumarin derlvative was successful but did not provoke detectable deficiencies in testis function. Since high testicular concentrations of S-acenocoumarol, which could on $1 \mathrm{y}$ be reached by local administration of the drug, did not affect fertl11ty, these data indicate that orally administered S-acenocoumarol will not influence fertility parameters. Therefore, it is not surprising that during oral anticoagulant therapy in clinical practice deflciencies in testicular function have not been reported. 
In the previous chapters, experlmental data have been presented to examine the hypotheses on the kinetic advantages of local over systemic drug administration at steady-state conditions during constant rate Infuston. In all experiments, with the exception of the infusion of acenocoumarol in the testis, local drug administration was achleved by the adminlstration of drugs into the artery supplying the target organ. Technically, this admintstration was posible by cannulation of a side-branch of the artery supplying the given target organ. Several substances, e.g. Cr EDTA, lodohippurate, propranolol and acenocoumatol, with distinct pharmacokinetic properties were infused into the artery of several target organs: the kidney, the 1iver, the transplanted heart and the testis. At steady-state conditions, the actual systemic and reglonal advantages of local over systemic drug administration were determined (table 12.1). As described in chapter 1 , systemlic advantages of local over systemic drug adminlstration can be expected for drugs that are efficiently extracted by the target organ. Local infusion of todohippurate, a high renal clearance substance, Into the kidney reduces the systemic concentration by more than $80 \%$ as compared to systemic delivery. Local infusion of propranolol, a substance efflciently cleared by the liver, into the transplanted heart reduces the systemic drug concentration by more than $90 \%$. In this latter model the clearance organ is situated in series with the target organ. Any drug infused directly into the transplanted heart reaches the liver and is subsequently extracted, before it reaches the systemic circulation. Local infusion of $\mathrm{Cr}$ EDTA, a low renal clearance substance, reduces the systemlc drug concentration by approximately $30 \%$ ondy.

Saturation of elimination processes and/or inhomogeneous drug distribution in the target organ excepted, local infusion of drugs that are extracted by the target organ does not enhance the regional drug concentration as compared to systemic infusion.

If the infused drug is not cleared by the target, the ratio of the non-target organ clearance and the blood flow to the target organ 


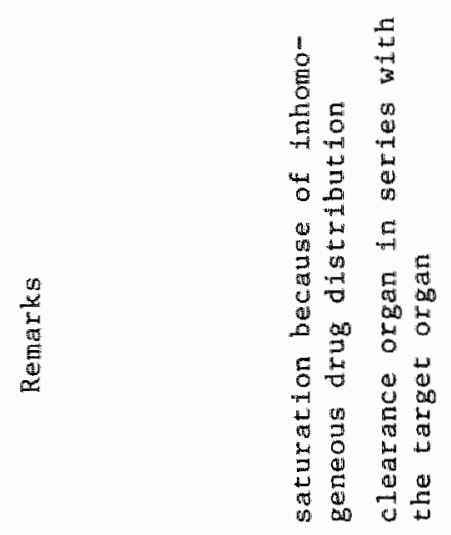

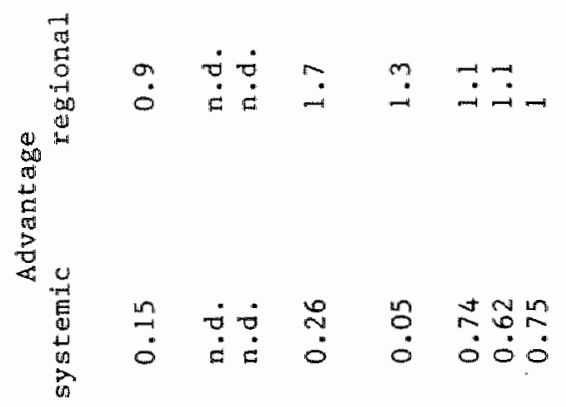

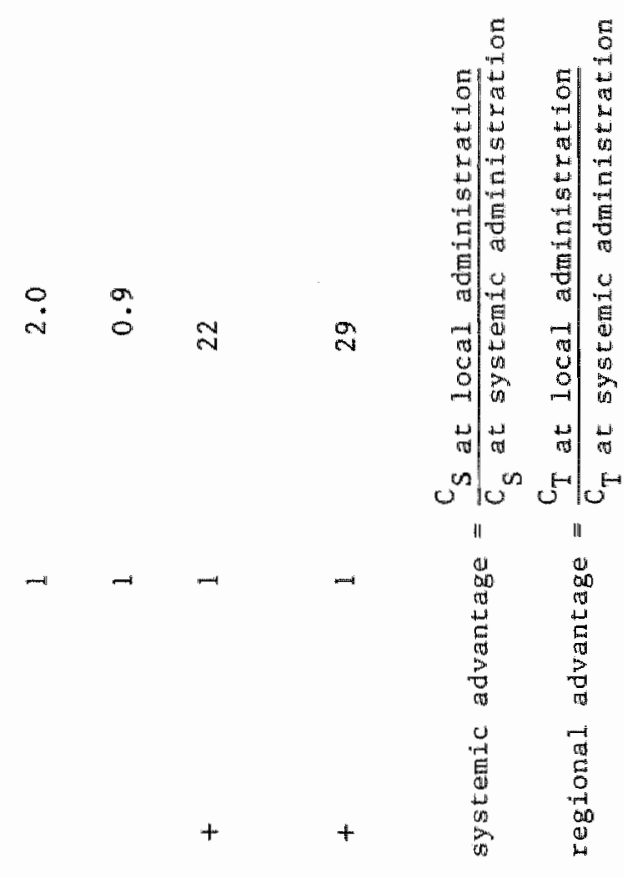

$\begin{array}{llll}0 & 0 & 0 & \text { 崩 } \\ 0 & 0 & 0 & 0 \\ 0 & 0 & 0 & 0 \\ 0 & 0 & 0 & 0 \\ 0 & 0 & 0 & 0\end{array}$

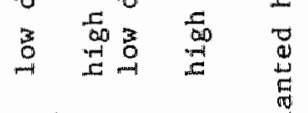

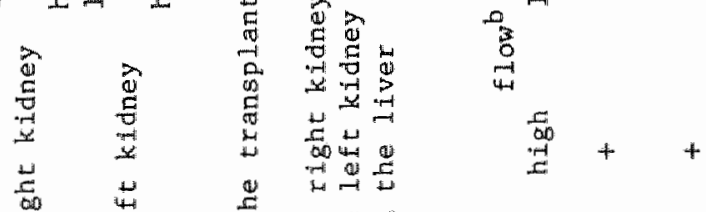

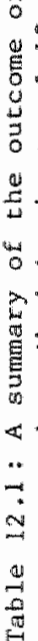

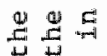

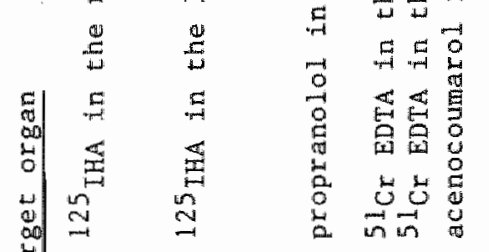

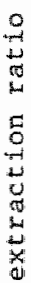

我 
(1.e. the systemic clearance) determines the advantage of local over systemic drug administration. This so-called reglonal advantage can be applied to lower the local infused dose, as compared to systemic drug Infusion, and thus to reduce the systemlc side-effects. This dose reduction is based on the assumption of a defined effective steadystate concentration in the arterial bed supplying the target organ that can be achieved by local as well as systemic administration.

Indeed, aur experiments indicate that infusion of a drug with a low systemic clearance into a target organ with a high blood flow does not increase the regional drug concentration (acenocoumarol in the kidney, table 12.1). Adminlstration of acenocoumarol into an organ with a low blood flow like the testis ylelded a high regional advantage, which could even be increased after induction of the hepatic clearance of acenocoumarol by phenobarbital ca-treatment.

In general, the experimental data confirmed the theoretical considerations. However, some pitfalls were observed.

\subsection{PITFALLS OF LOCAL DRUG ADMINISTRATION}

\subsubsection{Saturation}

The efficlency of the elimination processes in the target organ determines the reduction of the systemic concentration during local as compared to systemlc drug administration. From this relation, a first pitfall of local drug administration can be derived. During intra-arterial administration, deviations from linear pharmacokinetics may occur. Smits and Thijssen (1986) demonstrated the effects of deviation from non-1inear kinetics in a simulation study: in a physiologically based kinetic model comparable with $\mathrm{flg} .1 .3$, the effects of saturation of carrier-mediated transport and of intracellular elimination mechanisms on the regional and systemic advantages of local vs. systemic drug administration were Investigated. It was demonstrated that saturation of target organ transport mechanisms during local but not during systemic drug administration decreased the regional advantage of local drug administration. Saturation of elimination mechanisms in the target organ decreased the extraction ratio of the drug to almost 
zero, resulting in a decreased systemic advantage. On the other hand, the increased concentration in the target organ enhanced the regional advantage. An example of the effects of saturation is found in the report of Boub111 et al (1985) who described the effects of saturation of 5-FU elimination processes during its chronic intrahepatic delivery.

Non-linearity in plasma and/or tissue protein binding may also alter the expected advantages (Meijer et al, 1984; Mackichan, 1984; Rowland, 1984b; Harashima et al, 1985).

\subsubsection{Inhomogeneous drug distribution}

An inhomogeneous drug distribution over the target organ during local drug administration can be another pitfall. Laminar flow patterns in the artery supplying the target organ and/or a dual blood supply can cause this inhomogeneity. Inhomogeneous drug distribution may cause localized saturation of transport and/or elimination mechanisms which have the above-described effects on the reglonal and systemic advantage. An example of this pitfall is described in this thesis (chapter 6). Iodohippurate infused locally into the kidney was distributed inhomogeneously in the left, but not in the right kidney. This resulted in saturation of elimination processes in the infused part of the left kidney during the infusion of the highest dose. Subsequently the regional advantage increased but the systemic advantage decreased.

A remarkable phenomenon was observed in the experimental evaluation of intrahepatic delivery of acenocoumarol in the 1iver, a drug with a saturable hepatic binding site. Local drug administration did not increase but rather decreased the hepatic drug concentration.

A nice demonstration of the distinction between the study of drug effects (pharmacodynamics) and the study of drug concentrations (pharmacokinetics) (Powis, 1985) was shown in the experimental evaluation of local delivery of acenocoumarol in the tests. Notwithstanding the profound kinetic benefits of local drug dellvery in this model, the effects of this intervention were poor. 


\subsection{TARGETING OF DRUGS - A PROBLEM OF SELECTIVITY}

The experiments presented in this thesis indicate that pharmacokinetic research can provide a quantative perspective with regard to the potentlal benefits of local drug administration. Certain drugs can be attractive candidates, while others are unattractive. Similarly some target sites are more favorable than others (Collins, 1984). These experiments also indlcate that the probability of successful local drug administration can be substantially enhanced if the choices of drug and target are guided by pharmacokinetic principles (Schabel et a1, 1983; Colling et a1, 1986).

Recent pharmacochemical technologies glve new possibilities for drug deslgn. Speciflcally, drugs which are efflclently cleared by the target organ or which have a high systemic clearance can in some sttuations be favorable over drugs with a low clearance which are prefered in oral therapy.

Although the intra-arterial administration of drugs can lead to a more or less selective drug delivery, also some disadvantages are present. One important disadvantage is its invasiveness, that necessitates a surgical procedure. Surgery limits widespread use in human medicine since qualified persons and materlals are not avallable at any time at any place.

Almost all attention has been pald to the administration of drugs lnto the blood vessel supplying a target organ since this is in the scope of the experimental section of this thesis. The many other approaches of selective drug delivery such as liposomal drug delivery systems, antibody-drug carrier systems, cellular drug carriers or microspheres and macromolecules as drug carriers and pro-drug delivery systems are described briefly in the first chapter of this thesis.

All systems of selective drug delivery have to deal with and are actually destgned to cope with the so-called targeting problem (Poznansky and Jullano, 1984): a drug has to be delivered to that particular ce11, where desirable effects can be achieved, while a cell where toxic effects can be achleved has to be passed by. The administration of a drug into the blood vessel supplying the target offers a kinetic approach to the solution of this problem, but is a relatively 
non-selective cell targeting approach. The solution of the targeting problem presumes the existence of a molecular characteristic that differs between a target and a non-target cell. Subsequently reagents, i.e. drug carrier conjugates, have to be developed that bring the drug in or to the selected target cell (Chabner et al, 1984). Here, an additional problem may be that the target cell may not be a static but a dynamic entity, which can loose its specific receptors, can have a down regulation of receptors or can becone otherwise insensitive to the targeted drug.

The key to selectivity will be found in the design of agents intervening in the pathogenesis of diseases at a very fundamental level. In cancer research oncogenes or the products of oncogenes may be seen as selective agents that are not subject to any escape mechanism. Also the discrimination of unique receptor molecules offers the possibility to manipulate processes in specific cell populations by antireceptor antibodies. The design of drugs selective in this respect is a plan for the future. Until that time, drug targeting can be achleved by the lacal administration of less selective drugs. 
Appendix I: A PHYSTOLOGICALLY BASED COMPUTERIZED MODEL TO SIMULATE PHARMACOKINETICS - SIMULATIONS ON THE PHARMACORINETICS OF S-ACENOCOUMAROL IN THE RAT -

\section{1 INTRODUCTION}

In chapter 2, studies are described on the apparent dose-dependent hepatic clearance of $\mathrm{S}$-acenocoumarol (AC) in the rat. A saturable hepatic binding site $\left(\mathrm{K}_{\mathrm{D}}=2 \mathrm{ng} / \mathrm{m} 1 ; \mathrm{B}_{\max }=1.4 \mathrm{ug} / \mathrm{g}\right.$ of liver $)$ was found that could account for this dose-dependency. The results did not allow differentiation between a mere binding protein (for instance ligandIn or protein $Y$ ) or a transport system (Daemen et al, 1986a). A binder was suggested by the slower elimination from the liver than from the plasma (Th1jssen et al, 1983a; Daemen et al, 1986a). A transporter, however, should be more compatible with the dependency of the drug's blood clearance on its infusion rate. The simulations described below were performed to give more insight in the effects of a hepatic binding protein on the pharmacokinetics of S-acenocounarol.

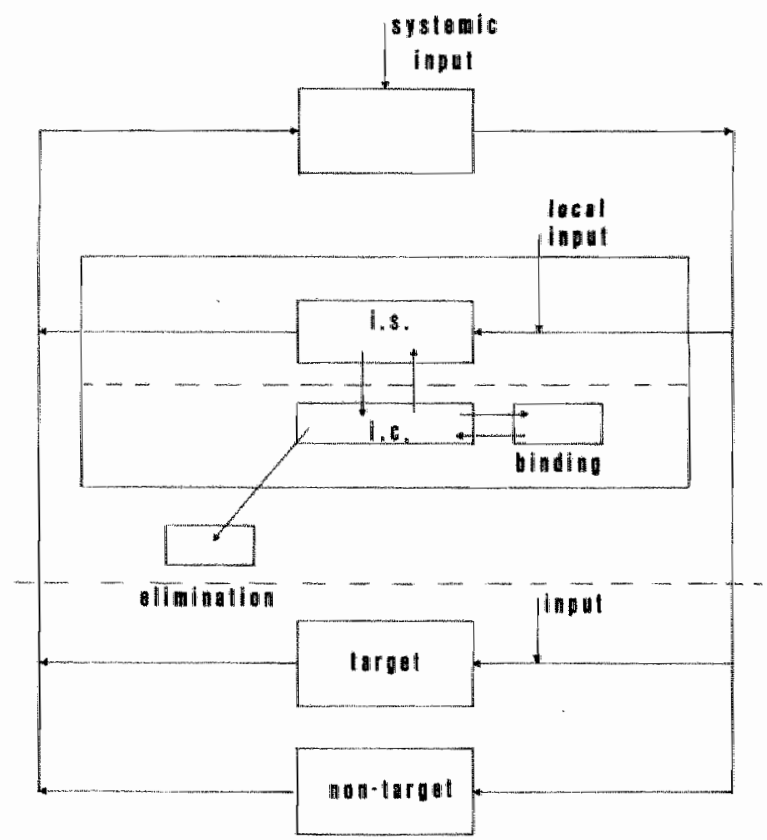

Fig. I.1: Scheme of a physiological model for the pharmacokinetics of S-acenocoumarol in the rat.

i.s. =interstitial space; i.c.= intracellular space. 
A physiologically based pharmacokinetic computerized model was created according to the scheme described in fig. I.1. A flow diagram of the model is given in fig. I.2. It includes a systemic compartment (fig. I.2.A) to which a drug can be delivered and from which a drug can be cleared. The vascular/interstitial space of the liver is represented by block $B$. Via this compartment the drug enters or leaves the liver. From the interstitial space drug is rapldly exchanged with the intracellular space, $C$. In the intracellular space the drug can be bound or cleared. The free concentration of the drug in the Intracellular space is calculated by the formula

$$
C_{f}=1 / 2\left[C_{t o t}-\left(K_{D}+B_{\max }\right)+\sqrt{\left.\left[\left(K_{D}+B_{\text {max }}\right)-C_{t o t}\right]^{2}+4 K_{D} \cdot C_{t o t}\right]}\right.
$$

where $C_{f}$ represents the free concentration of the drug in the intracellular space, $K_{D}$ the dissociation constant and $B_{\max }$ the total number of binding sites. This calculation is performed in block D.

In the simulations S-acenocoumarol was used as the example drug. Values of the different parameters were based on physlological and pharmacological data on the pharmacokinetics of AC in the rat. Drug could be delivered via the systemic route or via the local route ( 1 .e. intrahepatically). The blood flow to the 11 ver was $20 \mathrm{ml} / \mathrm{min}$, which $1 \mathrm{~s}$ comparable wh that 1 iver flow. The dissoctation constant was $2 \mathrm{ng} / \mathrm{ml}$, whlle the value of the total binding sites was $1.4 \mathrm{ug} / \mathrm{g}$ (Daemen et al, 1986a). The apparent intrinstc clearance was $3 \mathrm{ml} / \mathrm{mln}$, which $1 \mathrm{~s}$ comparable with the steady-state clearance of $A C$ during the Infusion of high doses, assuming all binding sites to be saturated.

Processes were simulated using THTSIM (Technische Hogeschool Twente, Enschede, The Netherlands) as simulation language. 


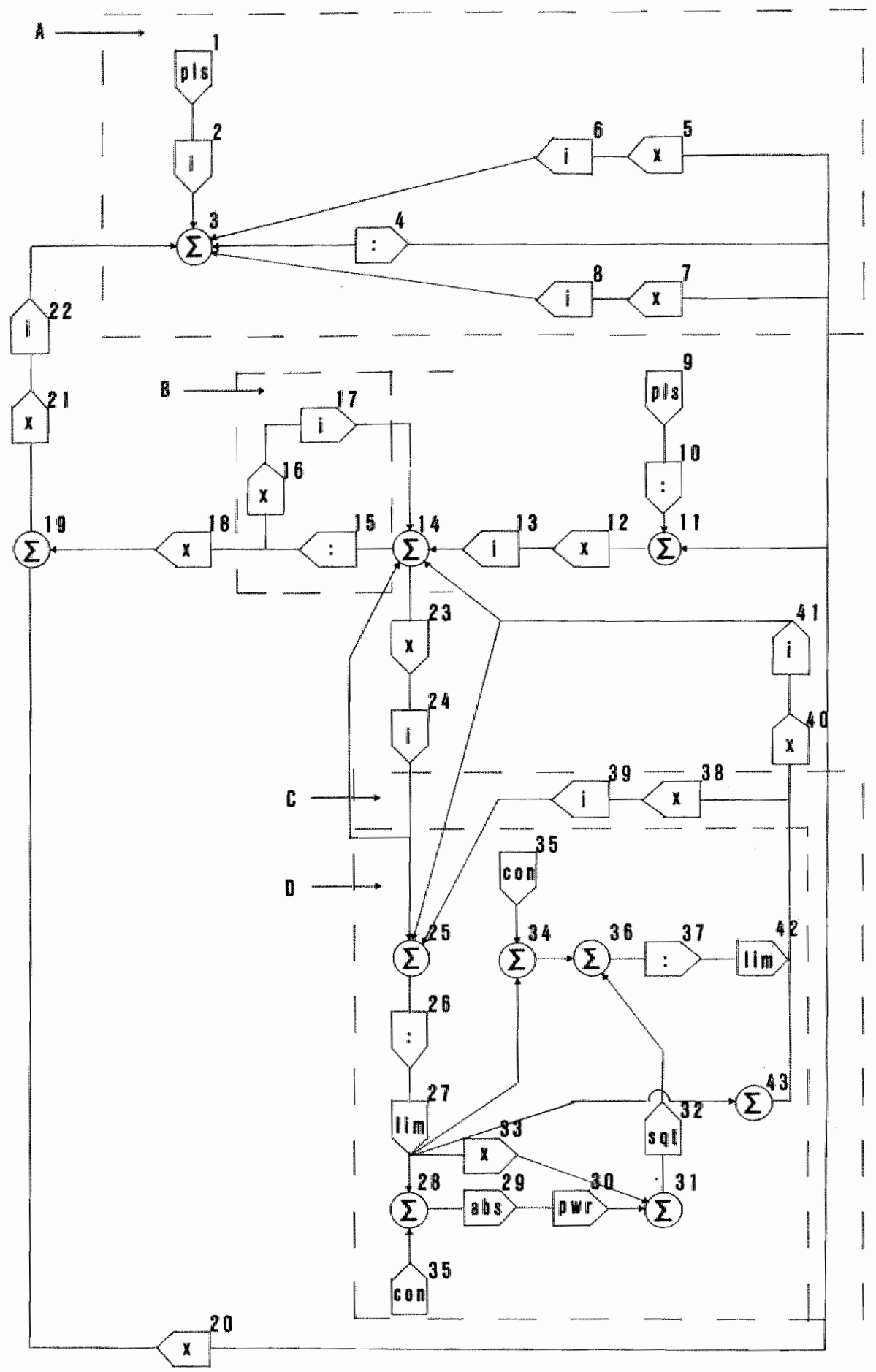

Fig. I.2: Flow diagram of the mode1 used in the first set of simulations. 
Table I.1: Listing of the simulation model described in Iig. I.2

\begin{tabular}{|c|c|}
\hline $1 \mathrm{p} 1 \mathrm{~s}$ & $23 \mathrm{gail} 15$ \\
\hline 2 int 1 & 24 int 23 \\
\hline 3 sum $2,22,-6,-8$ & 25 sum $24,-39,-41$ \\
\hline 4 att 3 & 26 att 25 \\
\hline 5 gai 4 & $27 \lim 26$ \\
\hline 6 int 5 & 28 sum $35,-27$ \\
\hline 7 gai 4 & 29 abs 28 \\
\hline $8 \operatorname{lnt} 7$ & 30 ptr 29 \\
\hline 9 pls. & 31 sum 33,30 \\
\hline 10 att 9 & $32 \mathrm{sqt} 31$ \\
\hline 11 sum 10,4 & 33 gai 27 \\
\hline 12 gai 11 & 34 sum $-35,27$ \\
\hline 13 int 12 & 35 con \\
\hline $14 \operatorname{sum} 13,41,-17,-24$ & 36 sum 32,34 \\
\hline 15 att 14 & 37 att 36 \\
\hline $16 \mathrm{ga} 15$ & 38 gai 42 \\
\hline 17 int 16 & 39 int 38 \\
\hline $18 \mathrm{ga1} 15$ & 40 gai 42 \\
\hline 19 sum 18,20 & 41 int 40 \\
\hline 20 gai 4 & $4211 \mathrm{~m} 37$ \\
\hline 21 gat 19 & 43 sum $27,-42$ \\
\hline 22 int 21 & \\
\hline
\end{tabular}

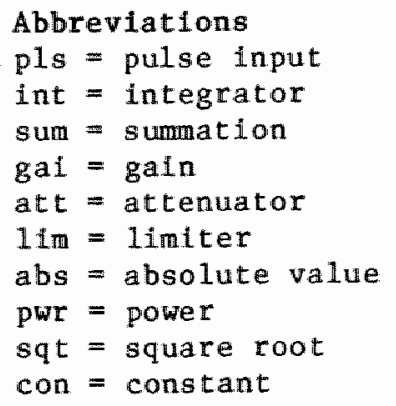


Table 1.2: Value of important parameters used in the simulation models $I$ and $I I$.

\begin{tabular}{|c|c|c|}
\hline Block no. & description & value \\
\hline 4 & blood volume & $10 \mathrm{~m} 1$ \\
\hline 5 & systemlc clearance & $0 \mathrm{ml} / \mathrm{m} \ln$ \\
\hline 10,12 & 1iver flow & $20 \mathrm{~m} 1 / \mathrm{min}$ \\
\hline 15 & interstitial volume & $25 \mathrm{~m} 1$ \\
\hline 21. & cardtac output & $100 \mathrm{~m} 1 / \mathrm{min}$ \\
\hline 23,43 & defusion constant & 100 \\
\hline 26 & intracellular volume & $10 \mathrm{~m} 1$ \\
\hline 33 & $4 \times K_{D}$ & $8 \mathrm{ng} / \mathrm{ml}$ \\
\hline 35 & $\mathrm{~K}_{\mathrm{D}}+\mathrm{B}_{\max }$ & $1.402 \mathrm{ug} / \mathrm{g}$ liver \\
\hline 38 & elimination rate & $3 \mathrm{ml} / \mathrm{min}$ \\
\hline
\end{tabular}

\section{I.2. SIMULATIONS}

\section{2.1 "Systemic and $\mathbb{1 n t r a h e p a t 1 c}$ administration of $\mathrm{AC}^{\text {"* }}$}

A constant rate of Infusion of $0.1,0.5$ or $1.0 \mathrm{ug} / \mathrm{min}$ via the systemic route was simulated. The infusion lasted from time 0 unt1 the $180 \mathrm{~min}$. The values of $\mathrm{C}_{\mathrm{s}}$ (the systemic arterlal concentration ( $u g /$ ow 1$)$ ) and $C_{b}$ (the concentration at the binding site in the liver ( $u g / g)$ ) In time are described $\ln f \mathbb{L}$. 1.3 (upper part). The clearance, calculated by $1 \mathrm{nf} / \mathrm{C}_{\mathrm{S}}$, at steady state, was about $8 \mathrm{~m} 1 / \mathrm{min}$ during the infusion of $0.1 \mathrm{ug} / \mathrm{min}$. The clearance decreased to $2.6 \mathrm{~m} 1 / \mathrm{min}$ during the constant rate infusion of 0.5 and $1.0 \mathrm{ug} / \mathrm{min}$. Infusion of 0.5 and 1.0 ug/min saturated the binding site completely. The ratio of the concentration of drug bound in the liver and the systemic plasma concentration was high (about 80 ) at the lowest infusion rate and decreased to about 3 at the highest infusion rate ( $1 \mathrm{ug} / \mathrm{min})$. Note that the liver concentration almost equalled the plasma concentration durlag the infusion of $12.5 \mathrm{ug} / \mathrm{min}$ (fig. I.4). Both these phenomena, the dose-dependent clearance and the inverse relation between the 

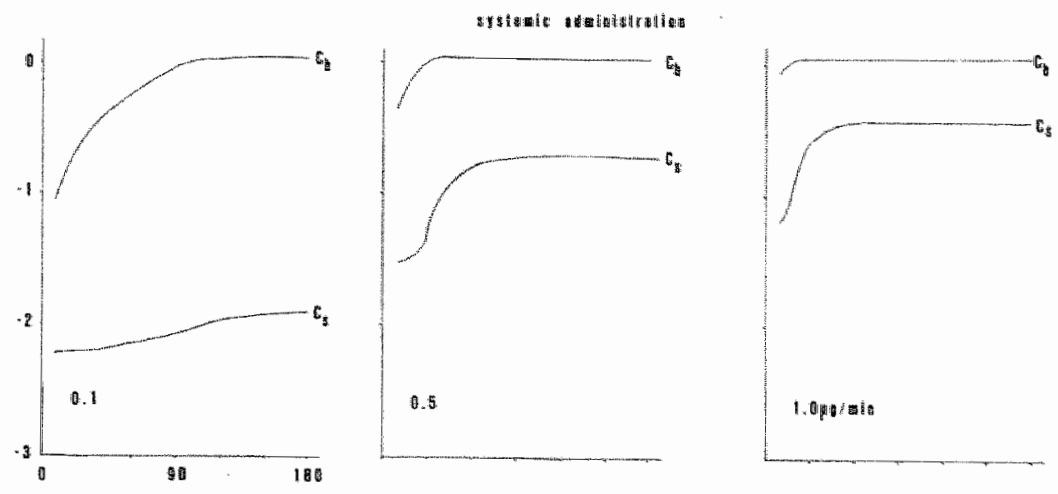

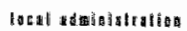
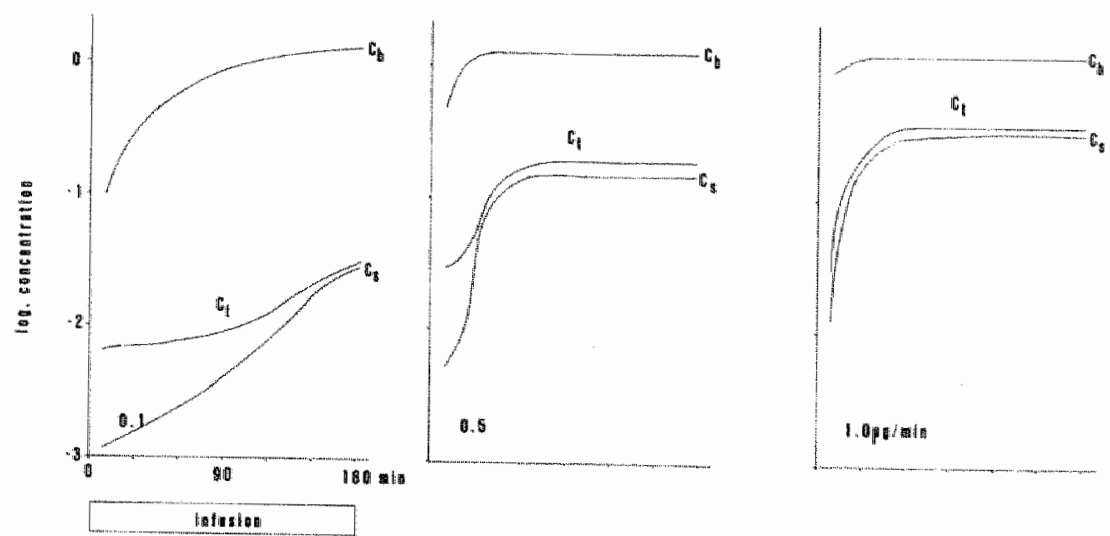

Fig. I.3: Outcome of simulations of systemic $\left(C_{S} ; u g / m \mathbb{l}\right)$ and hepatically bound $\left(\mathrm{C}_{\mathrm{b}} ; \mathrm{ug} / \mathrm{g}\right)$ concentrations of acenocoumarol after constant rate infusion of $0.1,0.5$ and $1 \mathrm{ug} / \mathrm{m} / \mathrm{n}, \mathrm{via}$ the systemic route (upper part) or via the local route (lower part; $C_{T}$ represents the concentration in the artery supplying the target organ).

1iver/plasma ratio and the infuston rate, state the results of experimental data on the kinetics of AC in the rat (Daemen et al, 1986a and chapter 2 ).

In fig. I.4, short-term constant rate infusion of $12.5 \mathrm{ug} / \mathrm{mIn}$ via the systemic route was simulated. $C_{b}, C_{11}$ and $C_{s}$ were followed during $450 \mathrm{~min}$. At $t=100$ (the end of the infusion), the total drug concentration in the liver was approximately $5.5 \mathrm{ug} / \mathrm{g}$ liver, the concentration in plasma $4.8 \mathrm{ug} / \mathrm{ml}$ and the concentration bound in the liver $1.4 \mathrm{ug} / \mathrm{g}$. Plasma clearance was $3 \mathrm{ml} / \mathrm{min}$. Initially, the decrease of the $A C$ concentration in the plasma was rapld ( $1 / 2$ approximately 


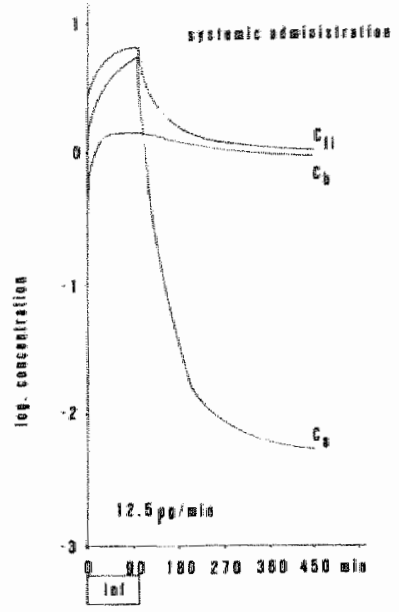

Fig. I.4: Outcome of simulations of $C_{S}$ and $C_{b}$ levels of acenocoumarol after a constant rate infusion of 0.5 ug/min wa the systemic route for $100 \mathrm{~min}$.
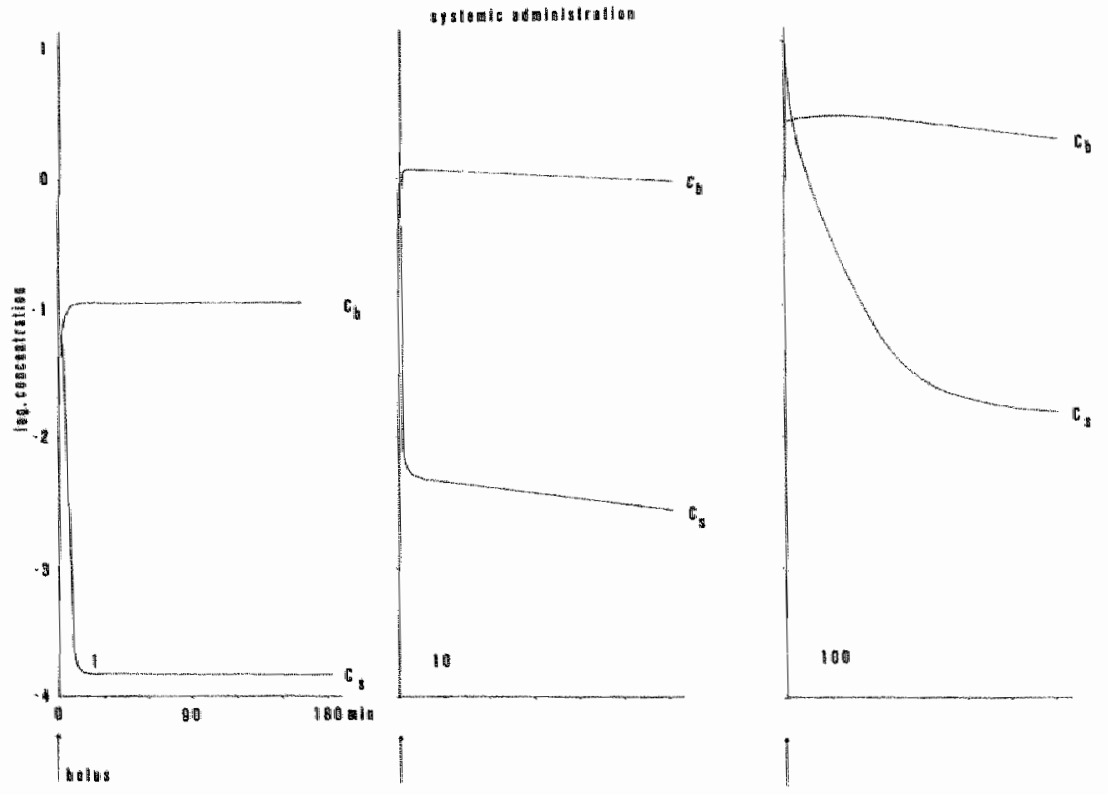

F1g. I.5: Outcome of simulations of $C_{S}$ and $C_{b}$ levels of acenocoumarol after a bolus injection of 1,10 , and 100 ug via the systemic route. 
$15 \mathrm{~min}$ ). From about $t=180, t 1 / 2$ increased. The disappearance of $A C$ from the liver was slower than from the circulation.

Local infusion of the drug was simulated also (fig. I.3, lower part). At the lowest infusion rate, steady-state conditions were not achieved after 180 min of infusion nor was the binding site saturated. The systemic concentrations during the local infusion of 0.5 and 1.0 ug/min were somewhat lower than during their systemic infusion $(0.17$ and 0.34 at local and 0.19 and $0.38 \mathrm{ug} / \mathrm{ml}$ at systemic infuston of 0.5 and $1.0 \mathrm{ug} / \mathrm{min}$, respectively). The concentration in the artery supplying the target organ almost equalled the systemic concentration. Hence, the reglonal advantage was minimal. The small systemic and regional advantage at steady state are in accordance with the predictions. The saturation of the binding site decreases the clearance, decreasing the systemic advantage. On the other hand, the high blood flow to the target organ $\left(Q_{T}=20 \mathrm{ml} / \mathrm{min}\right)$ in combination with no systemic clearance of the drug limits any reglonal advantage. Note that before saturation is achieved the concentration in the artery supplying the target organ was higher than the systemic drug concentration.

In $\mathrm{fig}$. I.5, the kinetic processes after systemic bolus injections of 1,10 and 100 ug $\mathrm{AC}$ are described. Here, one sees a biphasic dose dependent disappearance of the drug from the circulation. There is an initial fast disappearance of the drug from the circulation, especially to the binding site. Subsequently, this binding site with a high affinity 1 s a limiting factor for elimination of the drug (so called deep compartment).

The inttially fast disappearance of the drug from the circulatilon, followed by a very slow rate of disappearance after smal1 bolus injections, is also observed after injection of tracer amounts of warfarin in rats. (Thijssen, personal communication). 


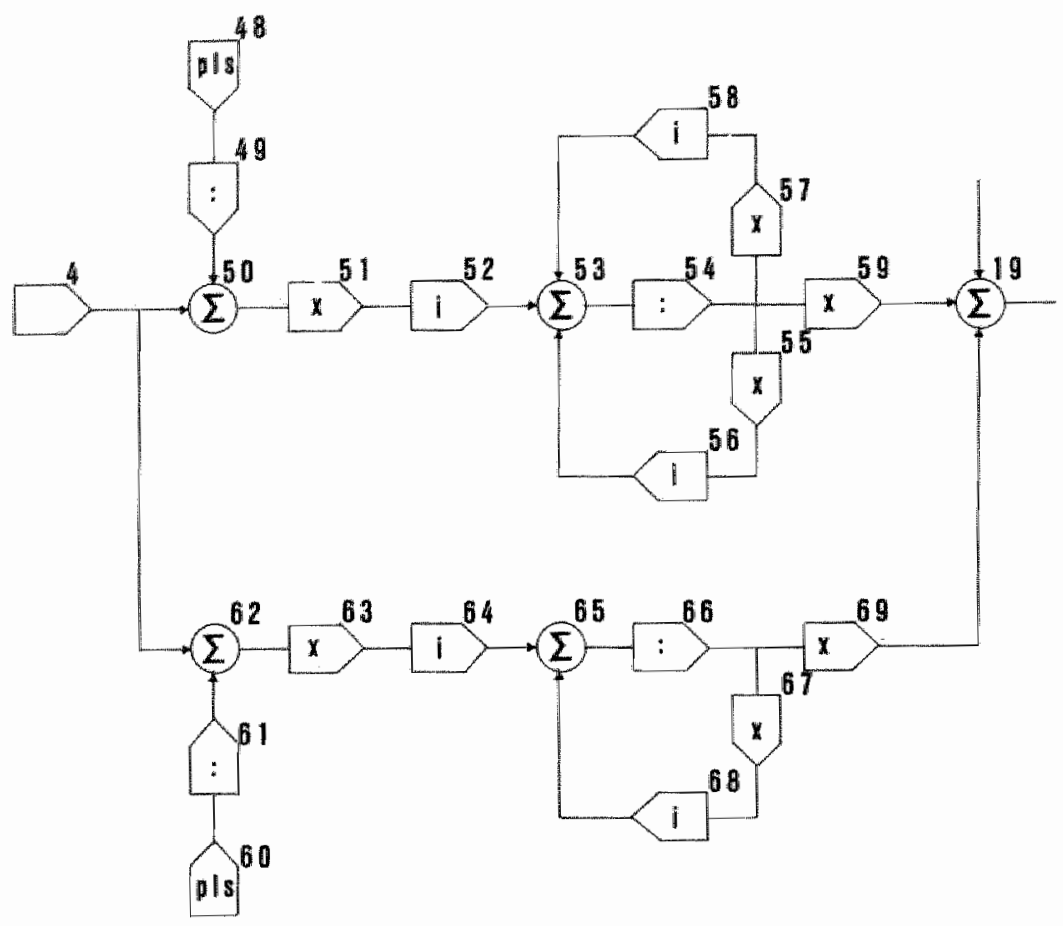

F1g. I.6: Flow diagram of the extension of the model described in IIg. I. 2, used to simulate the effects of changes in target flow $\left(Q_{T}\right)$ and systemlc clearance $\left(C 1_{S}\right)$ on the advantages of local over systemic drug delivery.

\subsection{2 "Intrarenal and intratesticular administration of AC"}

The flow diagram (fIg. I.2) is extended with two organs 1 inked in parallel as in $\mathrm{flg}$. I.6. This extension is necessary to describe the processes during the Infusion of a drug in other target organs than the 1iver, for Instance the kidney and the testis (chapter 10 and 11). The new target organ (blocks 50-59) has a volume of 5 mil and a blood flow of $4 \mathrm{ml} / \mathrm{min}$. It does not clear the infused substance. Local Infuston into the new target organ is possible. A paralle1-11nked identical organ 18 described by the blocks 60-69, representing the non-infused kidney or testis. The value of the parameters of the parallel-linked organs are identical. S-acenocoumarol is used as the example substance. The hepatic clearance is $3 \mathrm{ml} / \mathrm{min}$. All other parameters are identical to those described in the first set of simula- 
tions. The infusion rate was set at $0.5 \mathrm{ug} / \mathrm{min}$ during $180 \mathrm{~min}$.

The concentration in the artery supplying the target organ $\left(C_{\mathrm{m}}\right)$, the concentration in a systemic artery $\left(C_{S}\right)$ as well as the concentration in the artery supplying the parallel-1inked $\left(C_{\mathrm{NT}}\right)$ were followed in time. Their respective values are deplcted in fig. I. TA. The concentration in the artery suppyling the non-infused organ equals the systemic concentration. The concentration in the artery supplying the infused target organ is slightly higher than the concentration in the artery supplying the non-infused organ. Hence, there is only a small reglonal advantage (approxlmately 1.6 ).

The effects of an increased hepatic clearance (cf. phenobarbital co-treatment; chapter 10) was simulated (fig. I.7B). Both $\mathrm{C}_{\mathrm{T}}$ and $\mathrm{C}_{\mathrm{NT}}$ decreased. The regional advantage $\left(=\mathrm{C}_{\mathrm{T}} / \mathrm{C}_{\mathrm{NT}}\right)$, however, increased: $\mathrm{C}_{\mathrm{T}} / \mathrm{C}_{\mathrm{NT}}=2.5$.

In $f . g . ~ I .7 C$, the outcome of simulations of local infusion into a target organ with a low blood flow are described. The flow to the

Table I.3: Listing of the simulation model described in fig.I.6
48. $\mathrm{pls}$
49 att 48
50 sum 49,4
51 int 51
52 int 51
53 sum $52,-58,-56$
54 ate 53
55 gai 54
56 int 55
57 gai 54
58 int 57
59 gat 5

19 sum $59,18,20,69$

$60 \mathrm{p} 1 \mathrm{~s}$

61. att 60

62 sum 4,61

$63 \mathrm{gal} 62$

64 int 63

65 sum $-68,64$

66 att 65

67 gai 66

68 lnt 67

69 gai 66 


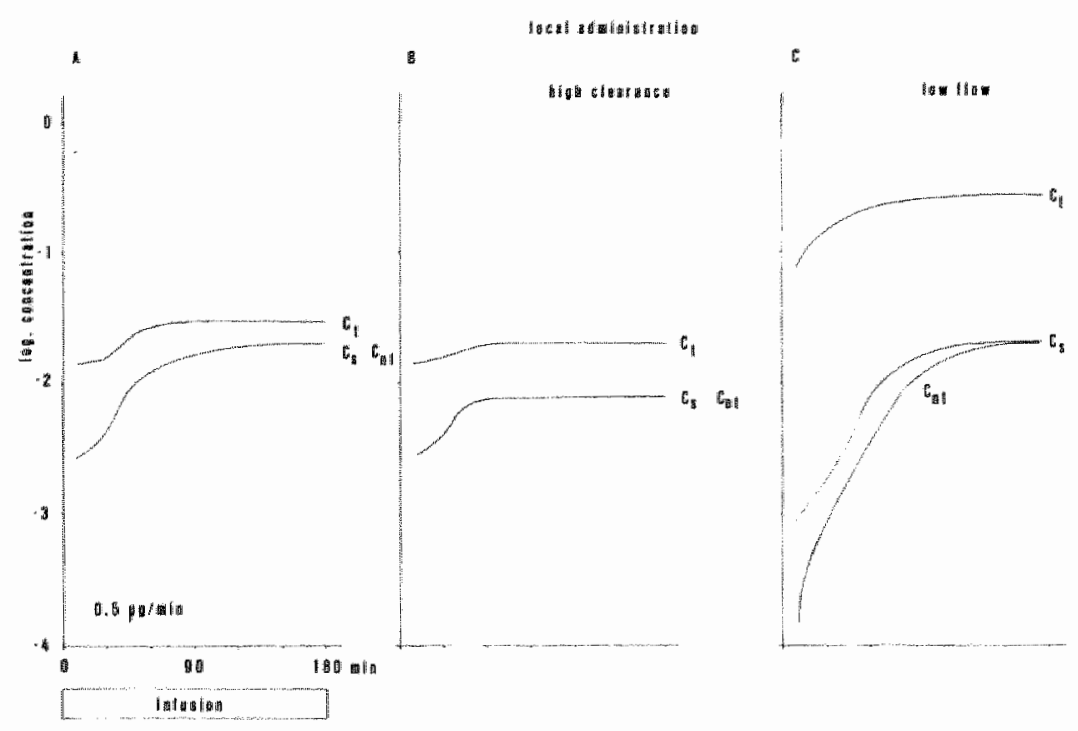

Fig. I.7: Outcome of simulations on the systemic concentrations $\left(C_{S}\right.$; $\mathrm{ug} / \mathrm{ml}$ ), the concentrations in the target organ (kidney or testis; $\left.C_{T} ; u g / g\right)$ and the identical, parallel-linked, non-target organ (non-1nfused kidney or testis; $\mathrm{C}_{\mathrm{NT}}$; $\mathrm{ug} / \mathrm{g}$ ). The infusion rate was set at $0.5 \mathrm{ug} / \mathrm{min}$.
A. $Q_{T}=4 \mathrm{ml} / \mathrm{min}$;
B. $Q_{\mathrm{T}}^{\mathrm{T}}=4 \mathrm{~m} \mathrm{~m} / \mathrm{m} \mathrm{In}$;
$\mathrm{C} 1_{\mathrm{S}}=3 \mathrm{ml} / \mathrm{min}$
C. $Q_{T}^{T}=0.2 \mathrm{ml} / \mathrm{min} ;$
$\mathrm{Cl}_{\mathrm{S}}=10 \mathrm{ml} / \mathrm{min}$
$\mathrm{Cl}_{\mathrm{S}}^{\mathrm{S}}=3 \mathrm{ml} / \mathrm{mln}$.

target organ is $0.2 \mathrm{ml} / \mathrm{min}$. The hepatic clearance is $3 \mathrm{ml} / \mathrm{min}$ again. Al1 other parameters are as above. One can see that $C_{T}$ is increased: $2.7 \mathrm{ug} / \mathrm{ml}$ at steady state during a blood flow of $0.2 \mathrm{ml} / \mathrm{min}$ and 0.31 ug/ml during a blood flow of $4 \mathrm{ml} / \mathrm{min}$. The ultimate level of $\mathrm{C}_{\mathrm{S}}$ and $\mathrm{C}_{\mathrm{NT}}$ are comparable with the values decribed in flg. I. 6A. The time course, however, is different. The ratio of $\mathrm{C}_{\mathrm{T}}$ and $\mathrm{C}_{\mathrm{NT}}$ is very large before steady state is achieved (at $t=50 \mathrm{~min}$, this ratio equals almost 100). At steady-state conditions, the ratio is still large: 13.5. 
I. 3 CONCLUSIONS

1. In the first set of simulations (fIg. I.3, I.4 and I.5), It was described that a hepatic binding site with a low capacity but a high affinity could indeed account for a dose-dependent clearance of a systemlcally infused drug. A binding site for acenocoumarol is consistent with the outcome of these simulations.

2. Local Infusion of the model substance yielded minimal regional and systemic advantages. At high infusions rates, steady state was achieved sooner than at lower infusion rates. These latter findings are in comparison with the experimental data described in chapter 9. The decreased concentration in the liver during local as compared to systemic infusion, however, cannot be explained by this model.

3. In the second set of simulations (fig. I.7), the effects of changes in the systemic clearance and the blood flow through the target organ were described. A target organ with a relatively high flow as compared to the systemic clearance of the locally infused drug is unsuited for achieving high reglonal advantages (chapter 10; fig. I.7A). By increasing the systemic clearance, the regional advantage is increased. Lowering of the blood flow to the target organ increased the regional advantage, especially in the time period before steady state is achieved (chapter 10; $\mathrm{fig} \cdot \mathrm{I} .7 \mathrm{~B}, \mathrm{C})$. 
SUMMARY

This thesis reports on an experimental pharmacokinetic study in the rat on the posslbtlities and limitations of local drug administration. Local drug administration means the administration of a substance directly in the artery supplying a target organ. This special way of drug delivery is widely applied, often based upon the assumption that local administration of a drug increases the local and decreases the systemic drug availability. The theoretical pharmacokinetic princtples, however, the basis of this way of drug administration, are not as known as the widespread use of local drug administration suggests.

Pharmacokinetic research on the possibilities and limitations of local drug administration is rare. It might, however, be a guide for advantageous local, i.e. Intra-arterial, drug administration.

In chapter 1, an overview is given of the many applications of local drug administration in clinical practice, like cancer chemotherapy and thrombolytic therapy, and in experimental research. The theoretical principles of local drug administration are described in the second part of the chapter. An advantage of 1 ocal over systemic drug administration can elther mean an increase of the local drug concentration and/or a decrease of the systemic drug concentration. The Increase of the local drug concentration is proportional to the systemic clearance of the drug and inversely related to the blood flow of the target organ. The decline of the systemic concentration is related to the extraction ratio of the drug by the target organ.

Chapter 2 describes the methods that are used in our experiments for the administration of substances into the artery supplying a target. Access to the artery supplying the target organ is galned by cannulating a side-branch of this artery. The different infused substances, which were chosen because of their distinct pharmacokinetic properties, are described.

In literature the clearance of Indocyanine green is seen as an indicator of hepatic blood flow. Experiments, described in chapter 3 , indicate that pentobarbital anesthesla and hypotherala during the 
anesthesia reduce the clearance of indocyanine green. Experiments in anesthetized rats, in which hepatic blood flow is measured simultaneously by electromagnetic flowmeters and the indocyanine green clearance method (chapter 4), serlously question the suitability of indocyanine green to indicate hepatic blood flow.

In chapter 5, a method of following the hepatic drug concentration in time in one experimental animal by taking small liver biopsies is evaluated.

In chapter 6 to 10 , local infusions of several substances are compared with their respective systemic infusions at the same dose. The results of experiments described in chapter 6 indicate that local, i.e. intrarenal, administration of hippuric acid, a substance with a high renal extraction ratio, reduces its systemic concentration (as compared to systemic infusion). During intrarenal infusion of chromium EDTA, a substance with a low renal extraction ratio, the reduction of the systemic concentration is much smaller. Inhomogeneous drug distribution during local but not during systemic infusion may decrease the extraction of the drug by the target organ, resulting in higher systemic concentrations. Intrarenal infusion of propranolol, a substance with a high hepatic clearance, hardly reduces its systemic concentration (chapter 7). Intracardial or in fact intrahepatic administration of the same substance (chapter 8), minimizes its systemic concentration, following the effect of extraction of propranolol by the liver. The experiments described in chapter 8 provide a pharmacokinetic base for the local administration of immunosuppressfve drugs wh a h $1 \mathrm{gh}$ hepatic clearance in the described graft. As is demonstrated in chapter 9, loca1, 1.e. intrahepatic, administration of acenocoumarol, a hepatically cleared oral antlcoagulant, decreases its systemic concentration. The local, hepatic, concentration does not increase but even decreases. In accordance with theoretical predictions, intrarenal administration of acenocoumarol does not decrease tis systemic concentration nor increases its local concentration (chapter 10). Local, intratesticular, administration ylelds relatively high testicular concentrations, which, because of serlous systemic alde-efects, cannot be achieved by systemic adminlstration of acenocoumarol.

In chapter 11 , experiments are described in which the local, 1.n- 
tratesticular infusion of acenocoumaroll was applied to investigate the function of vitamin $K$ dependent systems in the testis. The relatively high testiculat concentrations of acenocoumarol declined the activity of several biochemical parameters of the function of vitamin $k$ dependent systems, but did not affect fertility.

In chapter 12, the possibilities and limitations of local drug administration, now based on experimental evidence, are described. A discrete outlook in future indicates that as long as a really selective drug $1 \mathrm{~s}$ not yet avallable, local drug administration of more or less selective substances can provide a useful alternative. 


\section{SAMENVATTING}

In dit proefschrift word verslag gedaan van een experimenteel farmakokinetisch onderzoek in de rat nar de mogelijkheden en beperkingen van lokale toediening van geneesmiddelen. Lokale toediening wil zeggen: toediening van een middel direkt in het aanvoerend bloedvat van een bepaald doelorgaan. Deze speciale toedieningsvorm wordt op vrif uitgebreide schaal toegepast. De achterliggende aanneming is dan dat als een geneesmiddel lokaal wordt toegediend, dit ter plekke leidt tot hoge koncentraties van dit middel, terwijl er in de rest van het lichaam maar zeer weinig van het middel terecht komt. Ondanks de wijdverbreide toepassingen van lokale toedlening zijn de farmakokinetische principes, die de theoretische basis vormen van deze toedieningsvorm, aan velen onbekend. Er is slechts weinig farmakokinetisch onderzoek gedaan naar de mogelijkheden en beperkingen van lokale toediening. Dit onderzoek echter zou een leidraad kunnen zijn bij het lokal toedienen van geneesmiddelen.

In hoofdstuk 1 wordt een overzicht gegeven van de vele toepassingen van lokale toediening in de klinische praktijk, zoals kankerchemotheraple, thrombolytische theraple en in experimenteel onderzoek. In het tweede deel van dit hoofdstuk worden de theoretische princlpes van lokale toediening beschreven. Voordeel van lokale toedlenting ten opzichte van systemische toediening kan of een verhoging van de lokale koncentratie en/of een verlaging van de systemische koncentratie betekenen. De verhoging van de lokale koncentratie is evenredig met de systemische klaring van de stof en omgekeerd evenredig met de bloeddoorstroming in het doelorgaan. De verlaging van de systemische koncentratie is evenredig met de extraktieratio van de stof in het doe - $^{-}$ orgaan.

Hoofdstuk 2 beschrijft de methoden die gebruikt worden om stoffen toe te dienen in het aanvoerend bloedvat van een doelorgaan. Toegang tot dit aanvoerend bloedvat wordt verkregen door het kanuleren van een zijtak van het bloedvat. De verschillende stoffen, gebrulkt in onze studies en gekozen om hun verschillende farmakokinetische eigenschappen, worden eveneens beschreven. 
In de literatuur wordt de klaring van indocyanine groen wel gezten als een goede Indikator wan de leverdoorbloeding. Uit de resultaten van experimenten beschreven in hoofdstuk 3 blijkt dat pentobarbltalverdoving en een lagere lichaamstemperatuur tijdens die narkose de klaring vall het indocyanine groen verlaagt. De resultaten van experimenten in verdoofde ratten, warin met behulp van elektromagnetische floweters en met behulp van de indocyanine groen klaringsmethode de leverdoorbloeding wordt gemeten (hoofdstuk 4), doen ernstlge twiffel ontstaan aan de waarde van de klaringsmethode als indikator voor de leverdoorbloeding.

In hoofdstuk 5 wordt aangetoond dat het met behulp van kleine leverblopten mogelijk is on blj én proefdier de leverkoncentratie van een stof in de tijd te volgen.

In hoofdstuk 6 tot en met 10 wordt de lakale infusie van een aantal stoffen in een aantal doelorganen vergeleken met systemische infuste in dezelfde dosering van dezelfde stof. Uit de uitkomsten van de experimenten in hoofdstuk 6 blifkt dat lokale, dat wil zeggen intracenale, toedlening van para-aminohippuurzuur, een stof met een hoge extraktie in de nier, de systemische koncentratie vermindert vergeleken met systemische toedfening. B1j intrarenale toediening van chroom EDTA, een stof met een lage extraktie 1 n de nier, daalt de systemische koncentratie veel minder. Inhomogene verdeling van de lokaal toegediende stof over het doelorgaan kan de extraktle van de stof verminderen en leiden tot hogere systemische koncentraties. Intrarenale toedienlng van propranolol, een stof met een hoge leverextraktle, vermindert de systemische koncentratie niet of naurelijks (hoofdstuk 7). Wordt dezelfde stof intracardiaal of in feite direct an de lever aangeboden, dan dalt de systemische koncentratie evenredig aan de extraktleratio van propranolol in de lever (hoofdstuk 8). De exper1menten in dit hoofdstuk bieden een farmakokinetische basis voor lokale toedtening van immunsuppressiva met een hoge leverklaring in het beschreven harttransplantaat. Zoalls blljkt in hoofdstuk 9 vermindert intrahepatische toediening van acenocoumarol, een oraal antistollingsmiddel, dat door de lever geklaard wordt, de systemische koncentratie. De koncentratie van de stof in de lever neemt echter niet toe, zij neemt zelfs af. Geheel in overeenstemming met theoretische voorspel- 
lingen leidt intrarenale toediening van acenocoumarol noch tot lagere systemische noch tot hogere lokale koncentratles (hoofdstuk 10). Direkte toediening van acenocoumarol in de testis leidt tot relatief hoge lokale koncentratles die niet bereikt kunnen worden door de stof systemisch toe te dienen.

In hoofdstuk 11 wordt beschreven hoe met behulp van direkte chronische toediening van acenocoumarol in de testis onderzoek gedaan kan worden naar de funktie van vitamine $K$ afhankelijke systemen in de testis. De relatief hoge koncentraties van acenocoumarol in de testis verminderen wel de aktiviteit van een aantal biochemische parameters van vitamine $K$ afhankelijke systemen, waar leiden niet tot een vermindering van de fertiliteit.

In hoofdstuk 12 worden de, nu experimenteel onderbouwde, mogelijkheden en grenzen van lokale toediening beschreven. Een voorzichtige blik in de toekomst geeft aan dat zo lang een echt selektlef werkend geneesmiddel nog niet beschlkbaar 1s, de lokale toedtening van min of meer selektieve middelen een bruikbaar alternatief kan $z i j n$. 
RETERENCES

Ackerman NB, Llen WM, Kond1 ES, Silverman NA. Surgery 66, 1067-1072, 1969.

Ahmad $A B$, Bennet PN, Rowland M. J Pharmacol Exp Ther 230, 718-725, 1984.

Al-Jurf AS, Jochlmsen PR, Shirazi SS, Zike WL, Urdaneta LF. I Surg onco1 $27,119-123,1984$.

Anderson JH, Anderson RC, Hen LS. J Pharmacol Exp Ther 206, 172-180, 1978.

Anderson $\mathrm{L}$, Marsha11 HW, Bray BE, Lutz JR, Frederlck PR, Yanow1tz FG, Datz FL, Klausner SC, Hagan AD. New Eng $1 \mathrm{~J}$ Med 308, 1312-1318, 1983.

Arends BG, Böhm ROB, Van Kemenade JE, Rahn KH, Van Baak MA. Eur I CIIn Pharmaco1 $31,375-377,1986$.

Balch CM, Urist M, McGregor M. Ann Surg 198, 567-573, 1983.

Bengtsson $G$, Carlsson G, Haifström L, Jônsson PE. Am J Surg 141, 586589,1981 .

Bennett JP, Vickery BK. In: Reproduction and breeding techniques for laboratory animals. (eds: ESE Hafer). Lea and Febiger, Philadelphia, 1970, pp 299-316.

Berger M. Proc Am Soc Clin Oncol 22, 456, 1981.

Blanchett G, E1ghoz1 JL, Gomeni R, Meyer P, Morse111 PL. J Pharmacol Exp Ther $214,682-687,1980$.

Birnte JH, Grayson J. I Physiol 116, 189-201, 1952.

Blschoff KB, Dedrlek RL. J Pharm Se1 57, 1346-1351, 1968.

Blackshear PJ, Dorman FD, Blackshear PL, Varco RL, Buchwald H. Surg Gynecal Obstet $134,51-56,1972$.

Bock JU, Van Zwieten PA. Eur J Pharmacol 16, 303-310, 1971.

Bodor $N$. In: Optlmization of drug delivery (eds: B Bundgaard, $A B$ Hansen, H Kofod). Munksgaard, Copenhagen, 1982.

Bodor N, Simpkins JW. Science 221, 65-67, 1983.

Boelsterli $U$, Zbinden $G$ (ed: Zbinden $G$ ) In: Fine needle aspiration blopsy of the rat Ilver. Pergamon Press, Oxford, 1980, pp 17-31. 
Boubli1 $J \mathbb{L}$, Milano $G$, Khater R, Bourry J, Thyss A, Bruneton IN, René N, Philip C, Namer M. Br J Cancer 52, 15-20, 1985

Bradley SE, Ingelfinger FJ, Bradley GP, Curry JJ. J Clin Invest 24, $890-897,1945$.

Branch RA, Shand D, Wilkinson GR, Niles AS. J Pharaacol Exp Ther 184, 515-519, 1973.

Brandjes DPM, Deventer SJH, Meulenbelt J, Agenant DMA. Med TIjdschr Geneeskd 129, 1481-1483, 1985 .

Breedls C, Young G. Am J Pathol 30, 969-985, 1954.

Brenner BM, Troy JL, Daugharty TM, Deen WM. Am J Physiol 223, 1184$1190,1972$.

Burger PC, Kamenar E, Schold SC, Fay JW, Phillips GL, Herzig GP. Cancer $48,1318-1327,1981$.

Caesar J, Shaddon S, Chiandussi L, Guevara L, Sherlock S. C11n Sc1 21, $43-57,1961$.

Carlsson G, Ekelund L, Hafström L, Jonsson N, Stigsson L. J Surg OncoI 17, $249-261,1981$.

Cascino TL, Byrne PTN, Deck MDF, Posner JB. J Neurol Oncol 1, 211-218, 1983.

Chabner BA, Fine RL, Allegra CJ, Yeh GC, Curt GA. Cancer 54, 25992608,1984 .

Chang TMS. Science $8,62-67,1967$.

Charbon GA, VanderMark F. In: Measurement of blood flow (ed : N Granger, GR Bulkley). Williams and Wilkins, Baltimore, 1981, pp 122-155.

Chauvaud S, Grange D, Franco D, Bismuth H. Eur Surg Res 458-464, 1973. Chen H-SG, Gross JF. Cancer Chemother Pharmacol 2, 85-94, 1979.

Chen H-SG, Gross JF. Cancer Treat Rep 64, 31-40, 1980.

Cherrick GR, Stein SW, Leevy CM, Davidson CS. J Cllin Invest 39, 592600,1960 .

Chiou G. Biochem Pharmacol 30, 103-106, 1981.

Cho KC, Cafruny EJ. J Pharmacol Exp Ther 173, 1-12, 1970.

Civalleri D, Scopinaro G, Simond G, Claudiani Fepetto $M$, De Cian F. Tunori 71, 375-377, 1985 .

Cohen AM, Schaeffer N, Hïggins J. Cancer 57, 1115-1117, 1986. 
Collen D. Drugs $31,1-5,1986$.

Collins J. J Clin Oncol 2, 498-504, 1984.

Co1lins JM, Zaharko DS, Dedrick RL, Chabner BA. Cancer Treat Rep 70, $73-80,1986$.

Cotino HH, Zwaveling A. Eur J Cancer 12, 177-180, 1976.

Cox RH, Bagshaw FJ. Am J Physiol 237, H424-H432, 1979.

Cronan JJ, Dorfman GS. J Uro1 $130,757-758,1983$.

Cutler DJ. J Pharmacoktnet Btopharm 7, 101-116, 1979.

Daemen MJAP, Vervoort-Peters HTM, Thijssen HHW. J Pharm Sci 75, 238$240,1986 \mathrm{a}$.

Daemen MJAP, Thijssen HHW, Vervoort-Peters HTM, Smits JFM, Struyker Boudier HAJ. J Pharm Pharmacol 38, 122-125, $1986 \mathrm{~b}$.

Dakh11 S, Ensminger $W$, Cho K, Niederhuber J, Doan $K$, Wheeler $R$. Cancer $50,631-635,1982$.

Dean MF, Mulr H, Benson PF, Button LR. Pediatr Res 15, 959-963, 1981 .

DeWood MA, Ansterdan EA. Cardiology 72, 255-279, 1985.

Didolkar MS, Covell DG, Jackson AJ, Walker AP, Kalidindi SR. Cancer Res 44, 5105-5109, 1984 .

Dy C, Gil A, Algarra SM, Aparicio LA, Calvo F, Herranz P. Cancer Treat Rep 70, 465-468, 1986.

Eckman WW, patlak CS, Fenstermacher JD. J Pharmacokin Biopharm 2, $257-285,1974$.

Egorln MJ, Bellis EH, Salcman M, Collins JM, Splegel JF, Bachur NR. J Neurosurg $60,1005-1013,1984$.

Ensminger W, Rosowsky A, Raso V, Lewin DC, Glode M, Come S, Steele G, Fre. III E. Cancer Res $38,3784-3792,1978$.

Ensminger WD, Gyves JW. Pharmacol Ther $21,277-293,1983$.

Ensminger WD, Gyves JW. Cancer Treat Rep 68, 101-115, 1984.

Ensminger WD, Gyves JW, Stetson P, Walker-Andrews S. Cancer Res 45, $4464-4467$, 1985 .

Erichsen $C$, Bolmsjö $M$, Hugander A, Jönsson PE. J Cancer Res C1 in Oncol $109,38-41,1985$. 
European Cooperative Study Group for streptokinase treatment in acute myocardial infarction. New Engl J Med 301, 797-802, 1979.

Evans GH, Wilkinson GR, Shand DG. J Pharmacol Exp Ther 186, 447-453, 1973.

Feun LG, Wallace S, Stewart DJ, Chuang WP, Yung WKA, Leavens ME, Burgess A, Savaraj N, Benjamin RS, Young SE, Tang RA, Hande1 S, Mavligit G, Fields WS. Cancer 54, 794-799, 1984.

Fischer CP, Konnak JW, Cho KJ, Eckhauser FE, Stanley JC. J Uro1 125 , $402-404,1981$.

Fox IJ, Brooker LGS, Hesseltine DW, Essex H, Wood EH. Proc Mayo Clin $32,478,1957$.

Foster JH. Sem Liver Dis 4, 170-179, 1984.

Fujimoto S, Miyazaki M, Endoh F, Takahisha o, Okui K, Mor imoto Y. Cancer $56,2404-2410,1985$.

Fiume L, Bassi B, Busi C, Mathioli A, Spinosa G. Biochem Pharmacol 35, $967-972,1986$.

Gerlowsk1 LE, Jain RK. J Pharm Sci 72, 1103-1127, 1983.

Gibaldi M, Nagashima, Levy G. J Pharm Sci 58, 193-197, 1969.

Godbillon J, Richard J, Gerardin H, Meinertz T, Kasper W, Jähnchen E. Br J Clin Pharmacol 12, 621-629, 1981.

Grage TB, Vassilopoulos PP, Shingleton. WW, Jubert AV, Ellas EG, Aust MD, Moss SE. Surgery $86,550-555,1979$.

Greenberg HS, Ensminger WD, Chandler WF, Layton PB, Junck L, Knake J, Vine AK. I Neurosurg $61,423-429,1984$.

Greenberg HS, Ensminger WD, Layton PB, Gebarski S, Meyer M, Chaffee B, Bender JF, Gri11o-Lopez AJ. Cancer Treat Rep 70, 353-357, 1986.

Greenblatt DJ, Kach-Weser J. New Eng1 J Med 294, 702-705, 1975.

Greenway CV, Lawson AE, Mellander S. J Phys101 192, 21-41, 1967.

Greenway CV, Stark RD. Physiol Rev 51, 23-65, 1971.

Gregoriadis G, Kirby C, Large P, Meehan A, Senior J. In: Targeting of drugs (ed: G Gregoriadis, J Senior, A Trouet). Plenum Publishing Comp, New York, 1982a, pp 155-184.

Gregoriadis G, Allison AC. Drugs 24: 261-266, 1982b.

Groszmann RJ. Hepatology 3, 1039-1040, 1983. 
GISSI. The Lancet $387,1,397-405,1986$.

Gyves JW, Ensminger WD, Vantarken D, Niederhuber $J$, Stetson P, Walker S. Clin Pharmacol Thex $34,259-265,1983$.

Haq MM, Valdes LG, Peterson DF, Gourley WK. Cancer 57, 1281-1283, 1986.

Hafström L, Mobin A, Persson $\mathbb{B}$, Sundquist $K$. Cancer Res $40,481-485$, 1980.

Hafatrom L, Carlsson $G$, Gustavsson B, Holmberg S. Ann Chir Gynaecol $72,239-245,1983$.

Harashima H, Sawada $Y$, Sugfyama $Y$, Iga $T$, Hanano M. J Pharmacokin Blopharm 13, 425-440, 1985.

Hegarty JE, W1111ams R. Br Med J 288, 1254-1256, 1984.

Helntz R, Svensson CK, Stoeckel K, Powers GJ, Lalka D. I Pharmacol Sci $4,398-402,1986$.

Henning M, Van Zwieten PA. J Pharm Pharmacol 20, 409-417, 1968.

Hess H, Ingrisch H, Mietaschk A, Rath H. New Eng1 J Med 307, 16271630,1982 .

Hobbs JR. In: Advanced medicine (eds: MS Losowsky, RP Bolton). Pltman, Bath, 1983, pp 48-56.

Hodgson WJB, Friedland M, Ahmed $T$, Mittelman A, Berman H, Katz S, Morgan J, Byrne D. Ann Surg 203, 420-425, 1986.

Hohn D, Melnick J, Stagg $\mathbb{R}$, Altman D, Frledman M, Ignoffo R, Ferre11 L. Lewis B. J Clin Oncol 3, 98-102, 1985.

Huberman MS. Sem Onco1 10, 238-247, 1983.

Humphreys JD, Ihler G. In: Optimization of drug delivery (ed H Bundgaard, $A B$ Hansen, $H$ Kofod). Munksgaard, Copenhagen, 1982, pp 270-28.4.

Iwak1 A, Nagasue N, Kobayosk1 M. Cancer Treat Rep 62, 145-146, 1978.

Iwamoto $k$, Watanabe J, Arakd $K$, Deguchi $N$, Sugiyama H. J Pharm Phar$\operatorname{macol} 37,466-470,1985$.

Jaffe BM, Donegan WL, Watson F, Spratt JS. Surg Gynecol Obstet 127, $1-11,1968$.

Jansen A. J Pharmacokin Biopharm 9, 15-25, 1981.

Jenkins SA, Mooney B, Devitt P, Taylor I, Shields R. Clin Exp Pharmacol Physiol 11, 521-526, 1984. 
Jenkins SA, Baxter JN, Johnson JN, Devitt P, Shieldo R. Brit J Surg $72,354-358,1985$.

Jorl G, Reddi E, Cozzani J, Tomio L. Br J Cancer 53, 615-625, 1986 .

Jullano RL, Layton D. In: Drug delivery systems (ed: RL Jullano). University press, oxford, 1980, pp 189-236.

Kato T, Nemoto R, Mori H, Kumagai J. Cancer 46, 14-21, 1980.

Kato T, Nemoto R, Mori H, Takahashi M. Cancer 48, 674-678, 1981.

Kaye SB. Cancer Treat Rev 8, 27-50, 1981.

Kemeny N. Sem Onco1 10, 148-150 1983a.

Kemeny M, Daly JM, Oderman P, Shike M. Proc Am Soc Clin Oncol 2, 123, $1983 \mathrm{~b}$.

Kemeny M, Goldberg. DA, Browning S, Metter G, Miner P, Terz J. Cancer $55,1265-1270,1985 \mathrm{a}$.

Kemeny MM, Battifora H, Blayney DW, Cecchi $G$, Goldberg DA, Leong LA, Margolin KA, Terz JJ. Ann Surg 202, 176-181, 1985 b.

Kemeny MM, Goldberg D, Beatty D, Blayney D, Browning S, Doroshow J, Ganteaume L, Hill RL, Kokal WA, Rihimak1 DU, Terz JJ. Cancer 57, $492-498,1986$.

Kennedy JW, Ritchie $\pi$, Davis KB, Fritz JK. New Engl J Med 309, 1477$1482,1983$.

Khaja $\mathbb{F}$, Walton JA, Brymer JF, Lo E, Osterberger L, O'Ne111 WW, Colfer HT, Weiss $R$, Lee $T$, Kurlan $T$, Goldberg $D$, Pitt B, Goldsteln $S$. New Eng1 J Med 308: 1305-1311, 1983.

King FG, Dedrick RL, Farris FF. J Pharmacokin Biopharm 14, 131-155, 1986.

Kleinjans JCS, Smits JFM, Kasbergen CM, Vervoort-Peters HTM, Struyker Boudier HAJ. C1in Sc1 65, 111-116, 1983.

Klelnschmidt-De Masters BK. Cancer 57, 1276-1280, 1986.

Klopp CT, Alford TC, Bateman J, Berry GN, Winship T. Ann Surg 132 , $811-832,1950$.

Kosman KE. J Am Med Associat 241, 2301-2308, 1979.

Krarup N, Larson J. C11n Lab Invest 36, 1813-1818, 1976.

Krementz ET. Cancer 57, 416-432, 1986. 
Lee SS, Girod C, Brallion A, Hadengue A, Lebrec D. Am J Physiol 251, G1.76-G180, 1986 .

Leevy CM, Mendenhal1 CH, Lesko $W$, Howard MJ. I Clin Invest 41, 1169$1179,1962$.

Levin VA, Kabra PM, Freeman-Dove MA. J Neurosurg 48, 587-593, 1978.

Levin VA, Landah1 HD. J Pharmacokin Biopharm 13, 387-403, 1985.

Levy R, M11ler RA. Fed Proc 42, 2650-2656, 1983.

Lian JB, Tassinari M, Glowacki J. J Clin Invest 73, 1223-1226, 1984 .

Lindel1 B, Aronsen $\mathrm{K}-\mathrm{F}$, Noss1in B, Rothman U. Ann Surg 187, 95-99, 1978.

Lowry OH, Rosebough NV, Farr AL, Randal1 RS. J Blol Chem 193, 265-268, 1951 .

Madajewicz S, West CR, Park HC, Ghoorah J, Avellanosa AM, Takita H, Karakousis $C$, Vincent $R$, Caracandas $J$, Jennings E. Cancer 47, 653-657, 1981 .

McAl11ster RG, Tan TG, Tod EP. C1in Pharmacol Ther 23, 121, 1978.

McAllister RG, Bourne DW, Tiong G, Tan TG, Erickson JL, Wachte1 CC, Todd EP. Clin Pharmacol Ther 25, 1-7, 1979.

Maddox DA, Price DC, Reitor FC. Am J Physiol 233, F600-F606, 1977.

Mackichan JJ. C1In Pharmacokin 9 (supp1 1), 32-41, 1984.

Mardet VJ, Francis CW. Prog Hemost Thromb 17, 325-356, 1984.

McDevitt DG, Nies AS, Wilk1nson GR. Blochem Pharmaco1 26, 1247-1250, 1977.

McMurty JP, Wright GL, Wexler BC. Sctence 211, 1173-1175, 1981 .

Meljer DKF, Blom A, Weltering JG, Hornsveld R. J Pharmacokin Blopharm $12,43-65,1984$.

Muchmore JH, Carter RD, Krementz ET. Cancer Invest 3, 129-143, 1985.

Mulvany MM, Korsgaard N. J Hypertension I, 235-244, 1983.

Nitederhuber JE, Ensminger W, Gyves J, Thrall J, Walker S, Cozz1 E. Cancer 53, $1336-1343,1984$.

Nishiyama K, Nishyama A, Frohlich ED. Am J Physiol 230, 691-698, 1976.

Notar1 R. Pharmacol Ther 14, 25-53, 1981. 
Nxumalo JL, Terenaka M, Schenck WG. Ann Surg 187, 299-302, 1978.

Oberfield RA. Cancer Res 86, 15-25, 1983.

Ohnhaus EE. Br J Clin Pharmaco1 7, 223-229, 1979.

Die S; Huang JD. J Pharm Sci 70, 1344-1347, 1981.

Okamoto $Y$, Konno A, Togawa $K$, Kato $T$, Tamakawa $Y$, Amano $Y$. Br J Cancer $53,369-375,1986$.

Oldendorf WH. Trans Am Neurol Assoc 100, 225-226, 1975.

Pagano RE, Weinstein JN. Ann Rev Blophys Bioeng 7, 435-468, 1978.

Pettave1 J, Morgenthaler F. Prog C1in Cancer 7, 217-233, 1978.

Petrelli NJ, Barcewicz, Evans JT, Ledesma EJ, Lawrence DD, Mittelman A. Cancer $53,1347-1353,1984$.

Pond SM, Tozer TN. Clin Pharmacokin 9, 1-25, 1984.

Powis G. Cancer Chemother Pharmacol 14, 177-183, 1985 .

Poznansky M.J, Shandling M, Salkie MA, Elllott J, Lau E. Cancer Res 42, $1020-1025,1982$.

Poznansky MJ, Juliano RL. Pharmacol Rev 36, 278-336, 1984.

Rahn KH, Hawlina A, Kersting F, Planz G. Naunyn Schriedeberg's Arch Pharmacol 286, 319-323, 1974.

Ranney DF. Biochem Pharmaco1 35, 1063-1069, 1986.

Rappaport PL, Thiessen JJ. J Pharmacol Se1 71, 157-161, 1982.

Reed ML, Valtkeviclus KK, Al-Sarraf FM, Vaughn CB, Singhakowlnta A, Sexon-Porte M, Izblcki R, Baker L, Shatoma GW. Cancer 47, 402-409, 1981 .

Reneman RS, Wellens DLF, Jageneau AHN, Stijnen L. Cardlovasc Res 8, $65-72,1974$.

Rlchardson PD, Withrington PDG. Br J Pharmacol 60, 239-249, 1977a.

Richardson PD, Withrington PDG. Br J Pharmacol 60, 283-284, 1977b.

Richardson PD, Withrington PDG. Gastroenterology 81, 159-173, 1981

Roberts MS, Rowland M* J Pharmaco1 Sc1 74, 585-586, 1985.

Rogers WJ, Baxley WA, Hood WP, Mantle JA. J Am Coll Card1al I, 629, 1983. 
Rowel1 LB, Blackmon JR, Bruce RA. J Cl1n Invest 43, 1677-1690, 1964.

Rowland $M$, Tozer TH. In: Clinical pharmacokinetics. (eds: $M$ Rowland, TN Tozer). Lea and Febiger, Philadelphia, 1980, pp 9-78.

Rowland M. Drug Metab Rev 15, 55-74, 1984 a.

Rowland M. C11n Pharmacokin 9 (suppl 1), 10-17, $1984 \mathrm{~b}$.

Rowland M. Pharmacol Ther 29, 49-68, 1985.

Ruers TJM, Buurman WA, Smlts JFM, Van Dongen J, Struyker Boudler HAJ, Kootstra G. Transplantation, 41, 156-161, 1986.

Ruers TJM, Buurman WA, Van der Linden CJ, Kootstra G. Transplant Proc 1987 (in press).

Russo R, Bartosek J, Plazza E. Cancer Treat Rep 555-562, 1981.

Sandouk P, Scherrmann JM, Chauvin M. Eur J C11n Pharmaco1 30, 575-579, 1986.

Schabel FM, Gieswald DP, Corbett TH, Laster WR. Pharmac Ther 20, $283-305,1983$.

Schenk WG, McDonald JC, McDonald K. Ann Surg 156, 463-471, 1962.

Schneck DW, Pritchard JF, Hayes AH. J Pharmacol Exp Ther 203, 621-629, 1977.

Scholtholt J, Lochner W, Renn W, Shiraishi T. Arch Ges Physiol 293, $129-154,1967$.

Schroder R. J Am Coll Cardtol 5, 1254-1261, 1983.

Schulz V, Wlegand H, Ferlinz R. Prax Klin Pneumol 38, 357-365, 1984.

Schwartz SJ, Jones LS, Mcune CS. Ann Surg 201, 560-567, 1985.

Serruys PW, Simoons ML, Suryapranata $H$, Vermeer $F$, Wifns $W$, Van den Brand $M$, Bär $F$, De Zwaan $C$, Kralss $H$, Remme $W J$, Res $J$, Verbeugt FWA, Van Domburg $\mathbb{R}$, Lubsen J, Hugenholtz PG. J Am Cardio1 7, 729-742, 1986 .

Seyde WC, McGowan L, Lund N, Duling B, Longnecker DE. Am. J. Physiol $249,1164-H 173,1985$.

Shand DG, Rangno RE, Evans GH. Pharmacology 8, 344-352, 1972.

Shand DG, Kornhauser DM, WLlkinson GR. J Pharmacol Exp Ther 195, $424-432,1975$.

Sharma GVRK, Cella G, Parisi AF, Sasahara AA. New Eng1 J Med 306, $1268-1276,1982$. 
Shepard KV, Levin B, Karl RC, Faintuch J, Dubrow RA, Hagle M, Cooper RM, Beschorner RM, Stablein D. J Clin Ancol 3, 161-169, 1985.

Shepherd AN, Hayes PC, Jacyna M, Morrtson L, Bouchier IAD. Br J Clin Pharmacol 19, 393-397, 1985.

Sikuler ES, Groszmann RJ. Am J Physiol 250, G205-G212, 1986.

Simoons ML, Van den Brand $M_{*}$ De Zwaan $C$, Verbeugt FWA, Remme WJ, Serruys PW, Bär F, Res J, Krauss XH, Vermeer F. Lancet I, 578-582, 1985.

Simoons ML, Serruys PW, Van den Brand $M$, Res $J$, Verbeugt FWA, Krauss $H$, Remme WJ, Bär F, De Zwaan $C$, Van den Laarse A, Vermeer $F$, Lubsen $J$. J Am Coll Cardiol 7, 717-728, 1986.

Smart R, Trew P, Burke J, Lyons N. Eur J Nacl Med 6, 249-253, 1981 .

Smits JFM, Struyker Boudier HAJ. Naunyn Schmiedeberg"s Arch Pharmacol $309,19-24,1979$.

Smits JFM, Kasbergen CM, Van Essen H, Kleinjans JC, Struyker BoudLer HAJ. Am J Physiol 244, H304-H307, 1983.

Smits JFM, Brody MJ. Am J Physio1 84, R1003-R1008, 1984.

Smits JFM, Struyker Boudier HAJ. J Pharmacol Exp Ther 232, 845-849, 1985.

Smits JFM, Thijssen HHW. In: Rate-controlled drug administration and action (ed: HAJ Struyker Boudier). CRC Press, Boca Raton, USA, 1986, pp $83-115$.

Smits JFM, Van Essen H, Struyker Boudier HAJ, Lappe RW. Life Sci 38, $81-87,1986$.

Spurr GB, Dwyer NJ. J App1 Physiol 32, 362-368, 1972.

Stagg RJ, Lewis BJ, Friedman MA, Ignoffo RJ, Hohn DC. Ann Int Med 100, $736-743,1984$.

Stella VJ, Mikkelson TJ, Pipkin JD. In: Drug delivery systems (ed: RJ Julfano). Oxford University Press, New York, 1980, pp 112-176.

Stenf1o $J$, Fernlund P, Egan W, Roepstaff P. Proc Nat Acad Sc1 71 , $2730-2733,1974$.

Struyker Boudier HAJ. Rate controlled drug administration and action. (ed: HAJ Struyker Boudfer). CRC Press, Boca Raton, USA, 1986.

Stoeckel K, MCNamara PJ, Mclean AJ, Du Souich P, Lalka D, Gibald1 M. J Pharmacokin Blopharm 8, 483-496, 1980.

Sullivan RD, Norcross JW, Watkins E. New Eng1 J Med 270, 321-327, 1964. 
Suttle JW, Grant GA, Estuon CT, Shah DW. Mayo C11n Proc 49, 933-940, 1974.

Suzuk1 T, Kuma OH, Isozaki S. J Pharm Dyn 131-141, 1981.

Svensson CK, Edwards DJ, Lalka D, Mauricello PM, Middleton E. J Pharm Se1. $71,1305-1306,1982$.

Swlste1 AJ, Badling JR, Raaf JH. Cancer 53, 1397-1404, 1984.

Szabo G. Oncology 42, 217-223, 1985.

Takeuch1 T, Terada N, Koyama S. Jpn J Phys1o1 36, 65-76, 1986.

Terasak1. T, Suglyama $Y$, Iga $T$, Sawada $Y$, Hanano M. J Pharmacokin Blopharm 13, 265-287, 1985.

Teore11. T. Arch Int Pharmacodyn 57, 205-240, 1937.

Thiessen JJ, Rappaport PL, Eppe1 JG. Can J Physiol Pharmacol 62, $1078-1085,1984$.

Thijssen HHW, Baars LG, Reljnders MJ. J Pharm Pharmacol 35, 793-798, $1983 \mathrm{a}$ *

Thijsgen HHW, Baars LG, Refjnders MJ. J Chromatogr 274, 231-238, $1983 b$.

Th1jssen HHW, Baars LGM, Drittij-Re1jnders MJ. Drug Metab Dispos 13 , $593-597,1985$.

Thijssen HHW, Janssen CAT, Drittij-Reifnders MJ. Biochem Pharmaco1 35, $3277-3282$, 1986 .

T111et WS, Gauner RL. I Exp Med 58, 485-502, 1933.

Towbridge IS, Domingo D1. Cancer Surv 1, 543-556, 1983.

Trouet A, Baurain R, Deprez-De Campeneere D, Masqueller M, Pirson P. In: Targeting of drugs (eds: G Gregoriadis, $J$ Senior, A Trouet). Plenum Press, New York, 1982, pp 19-30.

Tsuj1 A, Nishide K, Minami $H$, Nakashima E, Terasaki T, Yamana T. Drug Metab Dispos $13,729-739,1985$.

Tvete ST, Hope A, Gadeholt G, Clausen G. Eur J Cancer Clin Oncol 20, 1433-1439, 1984.

Urquhart J, Fara JW, Willis KL. Ann Rev Pharmacol Toxico1 24, 199-236, 1984.

Uyama T, Morlwaki S, Yonezawa M, Fujita J. Cancer Chemother Pharmacol 11 (supp1) $559-563,1983$. 
Van Rossum JM, Van Lingen $G$, Maes RA. In: Quantitation modelling and control in anesthesla (ed: H Stoecke1). Georg Thieme Verlag, Stuttgart, 1985, pp 72-99.

Van Rossum JM, Snoeck HJM, Stefjger OM, Teeuwen HWA, Tissen JTWM, Van Wem TJF. In: Rate controlled drug administration and action (ed: HAJ Struyker Boudier). CRC Press, Boca Raton, 1986, pp 49-82.

Van Zwieten PA. Prog Pharmacol 1, 1-63, 1975.

Verbeek PCM. Thesis, Leiden, 1983.

Verheugt FWA, Eenige MJ, Rés JCJ, Simoons ML, Serruys PW, Vermeer F, Van Hoogenhuize DCA, Remme $P J$, De Zwaan C, Băr F. Br Heart J 54, $455-459,1985$.

Vermeer $C$, Hendrix $H$, Daemen M. FEBS Letters, 148, 317-320, 1982.

Vermeer C. Mol Cell Blochem 61, 17-35, 1984 a.

Vermeer $C$, Soute BAM, U1rich M, Hamulyak $k$, De Boer-Van den Berg MAG. Blochem Soc Trans 12, 922-924, $1984 b$.

Vermeer F, Simoons ML, Bär F, Tljssen JGP, Van Domburg RT, Serruys PW, Verheugt FWA, Res JCJ, De Zwaan $C$, Van der Laarse A, Krauss $H$, Lubsen $J$, Hulgenholtz PG. Circulation, 1986 (in press).

Vermeulen NPE, Danhof $M$, Steilawan $J$, Thio $T H$, Breimer DD. J Pharm Exp Ther 225, 201-205, 1983 .

Wagner JS, Adson MA, Van Heerden JA, Adson MH, I1strup DM. Ann Surg $199,502-508,1984$.

Wagner JG. Drug Metab Dispos 13, 119-1.20, 1985.

Walker MD, Green SB, Byar DP. New Engl I Med 303, 1323-1329, 1980.

Wanner M, Ziv G, Nicolet J, Noelpp UP, Roester H. Res Vet Scl 38 , $239-240,1981$.

Watkins $E$, Hering AC, Luna R. Surg Gynaecol Obstet $111,464-480,1960$. Wediund PJ, Chang SL, Levy RH. J Pharm ScL 72, 860-862, 1983.

Weiss GR, Garnick MB, Osteen RT, Steele GD, Wilson RE, Schade D, Kaplan WD, Boxt LM, Kandarpa K, Mayer RJ, FreI ET III. J CIIn Oncol 1 , $337-344,1983$.

Weiss M, Förster W. Eur J Clin Pharmaco1 16, 287-293, 1979.

Weliss M. Biopharm Drug Dispos 6, 57-66, 1985.

We1lens DL, Wouter LJMR, Reesse RJJ, Beirnaert p, Reneman RS. Brain Res $86,429-438,1975$. 
WIdder KJ, Senyel AE. Pharmacol Ther 20, 377-396, 1983.

Wegand BD, Ketterer SG, Rappaport E. Am J Digest Dis 5, 427-436, 1960.

W11kinson GR, Shand DG. C1in Pharmacol Ther 18, 377-390, 1975.

Yates MS, Emmerson J, Bowmer CJ, J Pharm Pharmacol 35, 335-338, 1983.

Yokota M, Awazu S, Hanano M. J App1 Phys1o1 41, 439-441, 1976.

Zalcberg JR. Pharmacol Ther 28, 273-285, 1985. 
CURRICULUM VITAE

The author of this thesis was born in Heerlen on April 20, 1959. From 1971 until 1977 he spent his school years at the Corlovallum College (gymnasium). Afterwards, he studied mediclne at the University of Limburg in Mastricht. In the 4 th year of the medical study, he was a student research-assistent at the Department of Blochemistry (dr. K. Hamulyák and $\mathrm{dr}$. C. Vermeer). He graduated in June 1983.

In the second half of 1983, he was a research-fellow at the Department of Pathology. The studies described in this thesis were performed at the Department of Pharmacology (head: prof. dr. H.A.J. Struyker Boudier) where the author started working in December 1983.

From Apr 111987 on, he w11 be a member of the Department of Pathology (head: prof. dr. F.T. Bosman) at the University of Limburg in Maastricht.

\section{LIST OF PUBLICATIONS}

\section{Full papers (published)}

Vermeer $\mathrm{C}$, Hendrix $\mathrm{H}$, Daemen $M$. Vitamin $\mathrm{K}$ dependent carboxylases From non-hepatic tissues. FEBS Letters $148,317-320,1982$.

De Koning RW, Daemen $M$, Schutte B, Geertzen HGM, B1Hjham GH, Bosman FT. Immunofluorescence detection of liver cell membrane autoantibodies. Eur J Cin Invest 15, 64-68, 1985.

Daemen $M$, Thijssen $H$, Verwoort-Peters $H$, Smits $J$, Struyker Boudier $H$. The effect of pentobarbitone anasthesla and hypothermia on the hepatic clearance of indocyanine green and $S(-)$-acenocoumarol. J Pharm Pharmaco1 38, 122-125, 1986. 
Daemen $M$, Vervoort-Peters $H$, Thijssen $H$. The dose dependent apparent clearance and hepatic uptake of s-acenocoumarol: a study using open 1lver blopsles in the rat. I Pharm Sc1 75, 238$249,1986$.

Daemen M, Th1jssen H, Van Essen H, Smits J, Struyker Boudier H. Local drug delivery: evaluation of direct infusion of ${ }^{51} \mathrm{Cr}$ EDTA and 125 IHA into the left and right kidney of the Wistar kyoto rat. J Pharm Sci, 1987, in press.

\section{Ful1 papers (submitted)}

Daemen $M$, Smits $J$, Ruers $T$, van Dongen J, Thijssen H. Experimental evaluation of local and systemic delivery of propranolol in rat cardlac grafts.

Daemen M, Smits J, Thijssen H, Struyker Boudfer H. Target organ directed drug delivery: possiblities and Imitations.

Daemen M, Thijssen H, Van Essen H, Vervoort-Peters H, Struyker Boudier $H$, Smits J. Liver blood flow measurement in the rat: the electromagnetic vs the clearance method.

Daemen M, Debets J, Hornsveld R, Struyker Boudier H, Smits J. Rena1 effects of infusions of atrlopeptin II in conscious unrestrained SHR.

Daeinen M, Vervoort-Peters H, Thijssen H. Local drug delivery: kinetic evaluation of long-term Intrarenal and testicular delivery of $S$-acenocoumarol in conscious Wistar rats.

Daemen $M$, Vervoort-Peters $H$, Vermeer $C$, Thijssen H. Suppression of vitamin $K$ dependent enzyme systems in the rat does not affect rat male fertility.

\section{Abstracts}

De Koning R, Daemen M. Autoantibodies to liver cell membranes, a new Immunofluorescence assay using PLC/PRE/5 cells. Fed Proc 
A222, 1984.

Daemen $M$, Thijssen $H$, Smits $J$, Vervoort-Peters L, Struyker Boudier H. The effect of pentobarbital anesthesia and temperature on the disposition of low and high clearance drugs. Pharm Wkb1 Sc1 Ed 6, 223, 1984.

Daemen $M$, Vervoort-Peters $H$. The dose-dependent clearance and hepat lc uptake of $\mathrm{S}(-)$-acenocoumarol. Naunyn Schmiedeberg's Arch Pharmaco1 29, A29, R7, 1985.

Daemen M, Van Essen $H$, Smits J, Thijssen H. The effect of renal bood flow reduction on the clearance of ${ }^{125}$ IHA and ${ }^{5 L}$ Cr EDTA in the rat. Naunyn Schmiedeberg's Arch Pharmacol 330, A120, 1985.

Daemen M, Van Essen H, Smits $J$, Thijssen H. Pharmacokinetics of intrarenal vs. Intravenous administration of ${ }^{51} \mathrm{Cr}$ EDTA and 125 Iodohippurate. Pharm Wkb1 Sci Ed 7, A229, 1985.

Smits J, Debets J, Struyker Boudier H, Daemen M. Renal effects of atriopeptin II in consclous SHR. Fed Proc A3480, 1986.

Daemen $M$, Debets J, Struyker Boudier H, Smits J. Renal function in consclous, unrestrained rats: effects of atriopeptin II. Naunyn Schmiedeberg"s Arch Pharmacol 332, A164, R41, 1986.

Daemen $M$, Thijssen $H$, Vervoort-Peters $H$. Local and systemic eftects of direct infusion of S-acenocoumarol into the testis of the conscious rat. Br J Pharmacol 89, A669, 1986.

Daemen M, Vervoort-Peters H, Thijssen H. Long-term suppresslon of vitamin $K$ dependent enzyme systems in the rat: blochemical and biological effects. Pharm Whi Sci Ed 8, A271, 1986.

Daemen M, Van Essen H, Vervoort-Peters HTM. Liver blood flow in the rat; electromagnetic flow measurements vs. the ICG clearance method. Naunyn Schmiedeberg's Arch Pharmacol, 1987, in press* 


\section{DAMKOOOD}

Allereerst wil ik prof. dr. Harry Struyker Boudier bedanken voor de stimulerende begeleiding niet alleen tijdens de uitvoering van de experimenten, waar ook tijdens het schrijven van dit proefschrift. Ik hoop dat in de toekomst nog veel kunnen samenwerken.

De co-promotor, dr. Henk Thijssen, heeft mij vanaf mijn eerste schreden in de farmakologie, in het bifzonder in het veld van lokale toedlening, tot aan deze laatste penstreken met een niet aflatend enthousiasme begeleid.

De referenten, prof. dr. J.M. van Rossum, prof.dr. D.K.F. Meyer en prof. dr. F.T. Bosman, dank $1 \mathrm{k}$ voor hun belangstelling voor mijn werk en de manter warop zij het manuskript gelezen hebben.

Dr. Jos Smits, hoewel offlcleel niet betrokken bij mijn onderzoek, heeft een grote blifdrage geleverd aan de totstandkoming van dit proefschrift. Zijn betrokkenheld, die niet alleen wetenschappelijk was, is voor mij van grote waarde geweest.

Dr. John Urquhart made useful and critical suggestions for improvements of this manuscript.

Lily Vervoort-Peters heeft met grote naukeurlgheid talloze analyses ultgevoerd. Helma van Essen, Jaques Debets, Caroline Tyssen en Maurlce Schaefer ondersteunden mij tijdens het uitvoeren van de experimenten.

Theo Ruers, Johan van Dongen, Berry Soute, Magda U1rich en Cees Vermeer dank ik voor hun medewerking bij de ultwoering van een aantal experimenten evenals de medewerkers van de dienst Proefdiervoorzieningen, met name Frans Weekers en Ton van den Bogaard. Magda Franken (RIVM, Bilthoven) beoordeelde de coupes van de testispreparaten.

Els Geurts en Mia Hogenboom hebben een manuskript vol doorhalingen en verbeteringen weten om te vormen tot datgene wat nu voor u 1igt. 